Prepared for the U.S. Department of Energy

under Contract DE-AC05-76RL01830

\title{
Technical Challenges of Plug-In Hybrid Electric Vehicles and Impacts to the US Power System: Distribution System Analysis
}

\section{Gerkensmeyer MCW Kintner-Meyer \\ JG DeSteese}

January 2010

Pacific Northwest

NATIONAL LABORATORY

Proudly Operated by Battelle Since 1965 


\section{DISCLAIMER}

This report was prepared as an account of work sponsored by an agency of the United States Government. Neither the United States Government nor any agency thereof, nor Battelle Memorial Institute, nor any of their employees, makes any warranty, express or implied, or assumes any legal liability or responsibility for the accuracy, completeness, or usefulness of any information, apparatus, product, or process disclosed, or represents that its use would not infringe privately owned rights. Reference herein to any specific commercial product, process, or service by trade name, trademark, manufacturer, or otherwise does not necessarily constitute or imply its endorsement, recommendation, or favoring by the United States Government or any agency thereof, or Battelle Memorial Institute. The views and opinions of authors expressed herein do not necessarily state or reflect those of the United States Government or any agency thereof.

\section{PACIFIC NORTHWEST NATIONAL LABORATORY \\ operated by \\ BATTELLE \\ for the \\ UNITED STATES DEPARTMENT OF ENERGY}

under Contract DE-AC05-76RL01830

Printed in the United States of America

Available to DOE and DOE contractors from the Office of Scientific and Technical Information, P.O. Box 62, Oak Ridge, TN 37831-0062; ph: (865) 576-8401, fax: (865) 576-5728 email: reports@adonis.osti.gov

Available to the public from the National Technical Information Service, U.S. Department of Commerce, 5285 Port Royal Rd., Springfield, VA 22161 ph: (800) 553-6847, fax: (703) 605-6900

email: orders@ntis.fedworld.gov

online ordering: http://www.ntis.gov/ordering.htm 
PNNL-19165

\section{Technical Challenges of Plug-In Hybrid Electric Vehicles and Impacts to the US Power System: Distribution System Analysis}

C Gerkensmeyer ${ }^{1}$

MCW Kintner-Meyer, Pacific Northwest National Laboratory

JG DeSteese, Pacific Northwest National Laboratory

January 2010

Prepared for

the U.S. Department of Energy

under Contract DE-AC05-76RL01830

Pacific Northwest National Laboratory

Richland, Washington 99352

${ }^{1}$ Consulting Engineer 


\section{Summary}

Replacing a significant portion of the nation's light vehicle fleet with plug-in hybrid electric vehicles (PHEVs) offers the potential of reducing our dependence on petroleum fuels together with important economic and environmental benefits. The electric power grid is built to support peak loads and, as a consequence, suffers from low asset utilization rates in off-peak periods. In principle, this under-utilized capacity could effectively power a national fleet of PHEVs with little need to increase the energy delivery capacity of the existing grid infrastructure. In practice, this ideal opportunity may be compromised by several factors including the size and distribution of the PHEV fleet, and the timing of vehicle charging activity.

This report documents work conducted by Pacific Northwest National Laboratory (PNNL) for the Department of Energy (DOE) to address three basic questions concerning how typical existing electrical distribution systems would be impacted by the addition of PHEVs to residential loads. These questions are:

- How many vehicles could the existing power delivery system support in the near future?

- What time of day would PHEVs be charged?

- Where would the vehicles be charged?

The present study complements other research being performed for the DOE by the University of Michigan (UM) in collaboration with PNNL on various issues relating PHEV adoption and marketability.

The primary focus of this study was to estimate impacts of PHEV charging on the components of residential feeders. The first part of the analysis was designed to study PHEV charging impacts on the distribution system as a whole. A load flow study was performed for various PHEV penetrations to observe whether any principal components of main feeders exceed their capacity because of PHEV charging.

The second part of the analysis focused on the potential impact of the additional load on the distribution transformers serving each individual residence. In both parts of the study computerized modeling of feeder-level load flow compared the existing loading profile and component-specific loads with those created by the superimposition of a hypothetical PHEV load distribution. Three electric utilities: Franklin PUD, Snohomish PUD and Puget Sound Energy (PSE) collaborated with this study by providing information that allowed system-specific feeder modeling.

A principal conclusion drawn from this study is that the addition of PHEV load at an individual residence may or may not have noticeable impacts on the existing distribution system depending on the overall penetration level and charging strategy used. The distribution utility's system planning philosophy used to size distribution transformers and the backbone feeder system also plays a large part in determining whether or not, or when in the future, additional PHEV load would impact the system. 
This study developed a methodology that can be used directly or extrapolated by utilities to establish new tools for calculating the diversity factors used to size transformers for new and existing services. Further work to increase the accuracy of such tools for assessing the potential impacts of new types of electrical load, such as PHEVs, is justified as an aid to distribution system planning. The results of this study also provide a basis for considering how the future integration of smart grid technologies, such as energy storage or demand response techniques, may provide efficient strategies for minimizing the impact of additional PHEV load on the distribution system. 


\section{Acknowledgements}

We would like to thank the employees of Franklin PUD, Puget Sound Energy, and

Snohomish PUD for their cooperation in supplying the feeder models and providing other data as needed. 


\section{Acronyms}

EV

PHEV

LDV

UM

PUD

PSE

V

A

W

$\mathrm{kVA}$

HEV

PNNL

DOE

SOC

DOT

SAE electric vehicle

plug-in hybrid electric vehicle

light-duty vehicles

University of Michigan

Public Utility District

Puget Sound Energy

volt

ampere

watt

kilovolt-ampere, rating of transformer capacity

hybrid electric vehicle

Pacific Northwest National Laboratory

Department of Energy

state of charge

Department of Transportation

SAE International, formerly Society of Automotive Engineers, a developer of organization standards 


\section{Table of Contents}

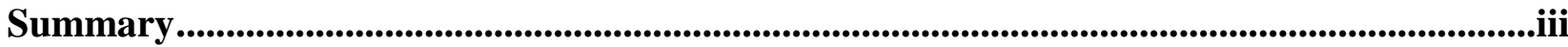

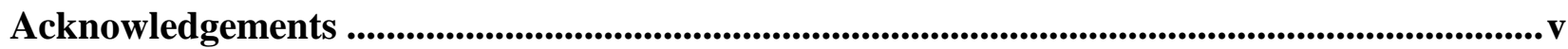

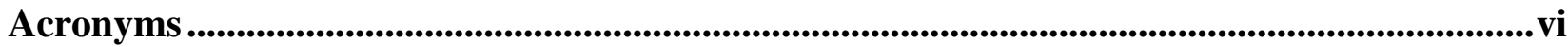

1 Introduction ...................................................................................................................................... 1

1.1 Related Studies on PHEV Adoption and Integration..........................................................

1.1.1 Technological Barriers for Acceptable PHEV Performance and Cost (Task 1

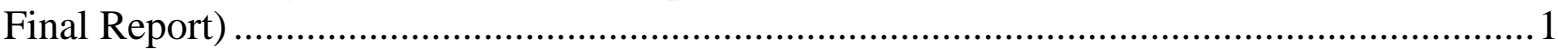

1.1.2 Plug-in Hybrid Electric Vehicles (Task 2a Final Report) ………..................................2

1.1.3 PHEV Marketplace Penetration (Task 2b Final Report).................................................2

1.1.4 Market Models for Predicting PHEV Adoption and Diffusion (Task 2c Final

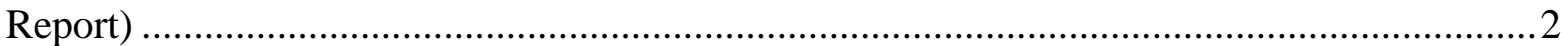

1.1.5 Impact of PHEVs on the Reliability of the Electric Grid (Task 3 Final Report) ........................................................................................................................

1.2 Focus of the Present Study .............................................................................................

2 Key Assumptions ..................................................................................................................................

2.1 PHEV Market Penetration ..........................................................................................

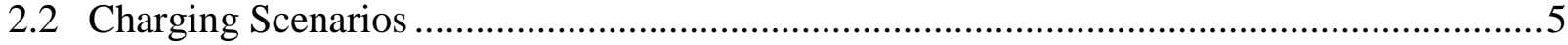

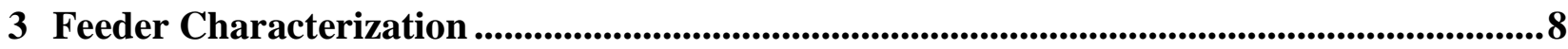

3.1 Feeder Load Composition ..........................................................................................

3.2 PUD Load Shapes .............................................................................................. 10

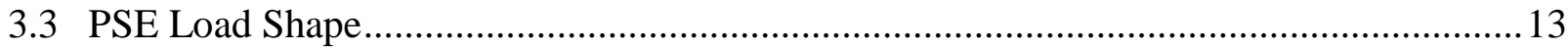

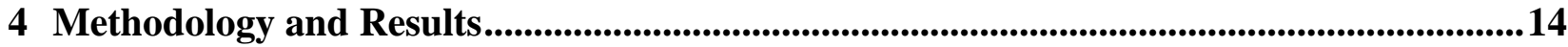

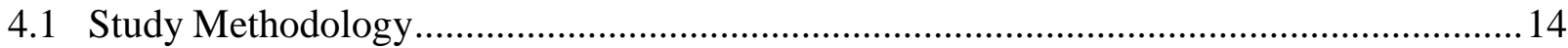

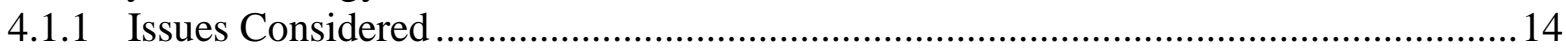

4.1.2 Analytical Approach and Results Presentation ..........................................................15

4.2 PHEV Impacts on Infrastructure Loading ………........................................................ 15

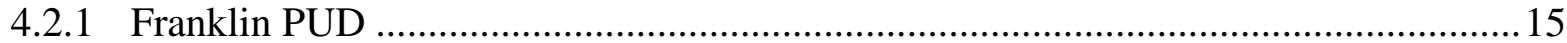

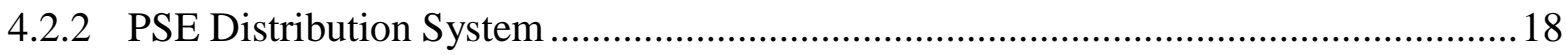

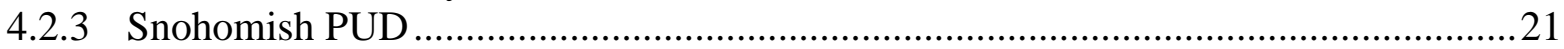

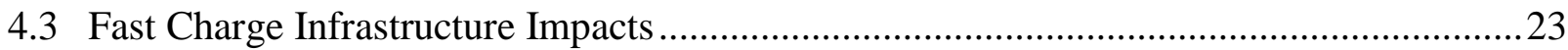

4.3.1 Franklin PUD Results for Quick Charging ……….................................................2. 24

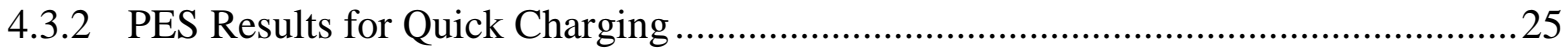

4.3.3 Snohomish PUD Results for Quick Charging ........................................................2

4.4 Impacts on Secondary Distribution System Transformers ..................................................2

4.4.1 Franklin PUD Results for Transformers Analysis ....................................................2 28

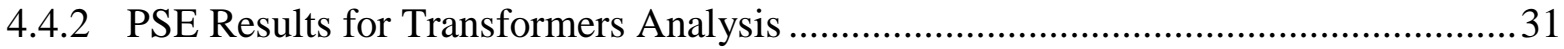

4.4.3 Snohomish PUD Results for Transformers Analysis ......................................................34

5 Key Findings and Conclusions .................................................................................................38

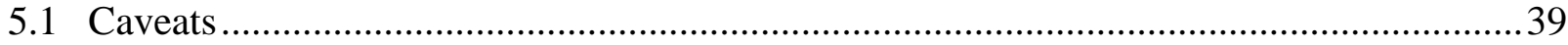

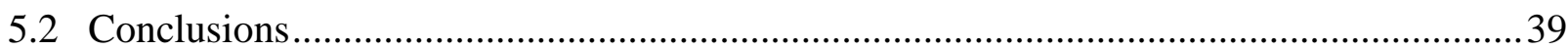

6 References ……......................................................................................................................................4 


\section{List of Figures}

Figure 2-1: PHEV Charging Profiles derived from the DOT Household Travel Survey

Data Set (DOT, 2001). Load profiles represent a diversified load............................................6

Figure 2-2: Modified Case 2 Charging Curve ............................................................................

Figure 2-3: Modified Case 5 Charging Curve ..............................................................................

Figure 3-1: Feeder Load Composition for Franklin PUD ...........................................................

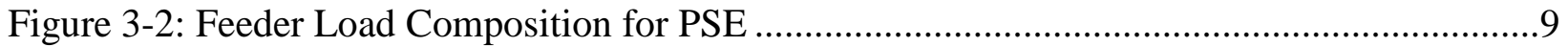

Figure 3-3: Feeder Load Composition for Snohomish PUD .............................................................

Figure 3-4: Franklin and Snohomish PUD Load Shape for Apartment Loads...............................10

Figure 3-5: Franklin and Snohomish PUD Load Shape for Residential Electric Heating

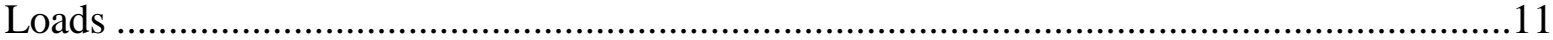

Figure 3-6: Franklin and Snohomish PUD Load Shape for Residential Gas Heating Loads ........11

Figure 3-7: Franklin and Snohomish PUD Load Shape for Commercial Loads ............................12

Figure 3-8: Franklin and Snohomish PUD Load Shape for Industrial Loads.................................12

Figure 3-9: Load Shape for PSE Residential Loads ..................................................................13

Figure 4-1: Number of Franklin PUD Feeders with Equipment Failures by Type for 50\%

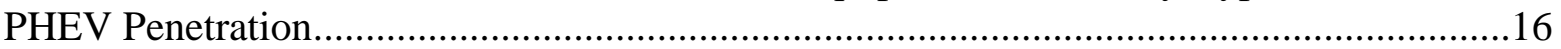

Figure 4-2: Number of Franklin PUD Feeders with Equipment Failures by Type for

100\% PHEV Penetration ..................................................................................................

Figure 4-3:Number of Franklin PUD Feeders Supporting PHEV Penetrations With No

Equipment Failures..........................................................................................................17

Figure 4-4: Franklin PUD Representative Feeder Load Curve for 50\% PHEV Penetration..........18

Figure 4-5: Franklin PUD Representative Feeder Load Curve for 100\% PHEV

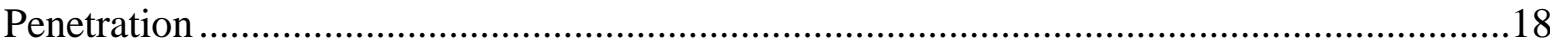

Figure 4-6: Number of PSE Feeders with Equipment Failures by Type for 50\% PHEV

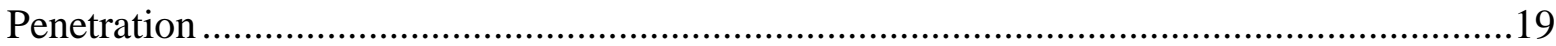

Figure 4-7: Number of PSE Feeders with Equipment Failures by Type for 100\% PHEV

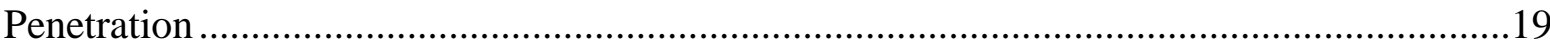

Figure 4-8: Number of PSE Feeders Supporting PHEV Penetrations With No Equipment

Failures (note, total number of feeders is 8) ....................................................................20

Figure 4-9: PSE Representative Feeder Load Curve for 50\% PHEV Penetration ..........................20

Figure 4-10: PSE Representative Feeder Load Curve for 100\% PHEV Penetration .......................21

Figure 4-11: Number of Snohomish PUD Feeders with Equipment Failures by Type for

100\% PHEV Penetration ..................................................................................................21

Figure 4-12: Number of Snohomish PUD Feeders Supporting PHEV Penetrations with

No Equipment Failures (note, total number of feeders is 8) .................................................22

Figure 4-13: Snohomish PUD Representative Feeder Load Curve for 50\% PHEV

Penetration .................................................................................................................22

Figure 4-14: Snohomish PUD Representative Feeder Load Curve for 100\% PHEV

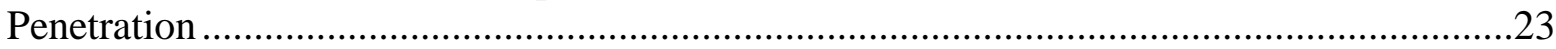

Figure 4-15: Quick Charge Scenario Charging Profile..................................................................23

Figure 4-16: Number of Franklin PUD Feeders with Equipment Failures by Type in

Quick Charge Scenario .....................................................................................................24

Figure 4-17: Number of Franklin PUD Feeders Supporting PHEV Penetrations With No

Equipment Failures in Quick Charge Scenario ....................................................................24 
Figure 4-18: Franklin PUD Representative Feeder Load Curve in Quick Charge Scenario .........25

Figure 4-19: Number of PSE Feeders Supporting PHEV Penetrations With Equipment

Failures by Type in Quick Charge Scenario...................................................................25

Figure 4-20: Number of PSE Feeders with No Equipment Failures in Quick Charge

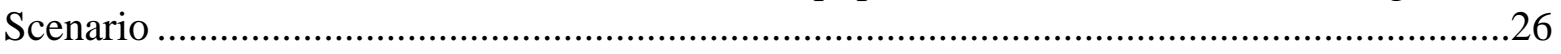

Figure 4-21: PSE Representative Feeder Load Curve for Quick Charge Scenario ......................26

Figure 4-22: Number of Snohomish PUD Feeders Supporting PHEV Penetrations With

Equipment Failures by Type in Quick Charge Scenario ................................................27

Figure 4-23: Number of Snohomish PUD Feeders with No Equipment Failures in Quick

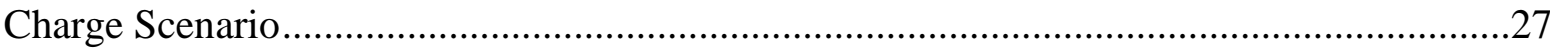

Figure 4-24: Snohomish PUD Representative Feeder Load Curve for Quick Charge

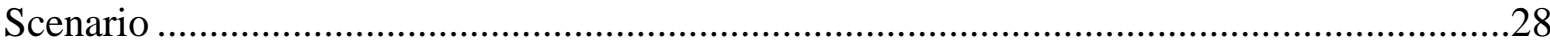

Figure 4-25: Franklin PUD Transformer Loading for Case 1 ..............................................29

Figure 4-26: Franklin PUD Transformer Loading for Case 2 .................................................29

Figure 4-27: Franklin PUD Transformer Loading for Case 3 .................................................30

Figure 4-28: Franklin PUD Transformer Loading for Case 4 ...............................................30

Figure 4-29: Franklin PUD Transformer Loading for Case 5 .............................................31

Figure 4-30: Franklin PUD Transformer Loading for Case 6 ...............................................31

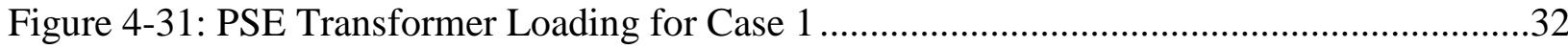

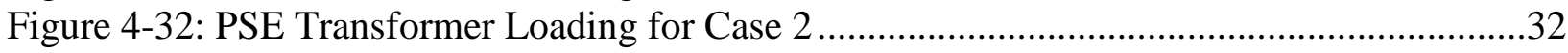

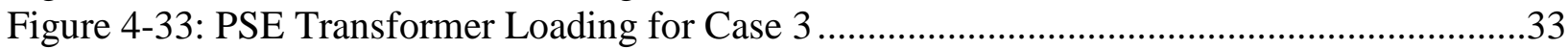

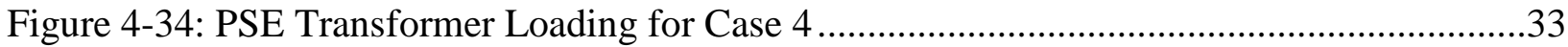

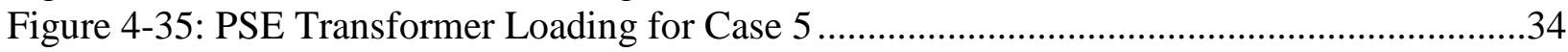

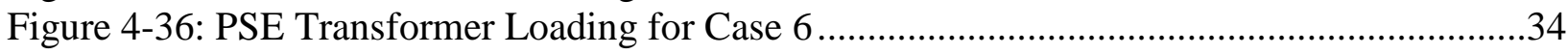

Figure 4-37: Snohomish PUD Transformer Loading for Case 1 .............................................35

Figure 4-38: Snohomish PUD Transformer Loading for Case 2 .........................................35

Figure 4-39: Snohomish PUD Transformer Loading for Case 3 ..............................................36

Figure 4-40: Snohomish PUD Transformer Loading for Case 4 ...............................................36

Figure 4-41: Snohomish PUD Transformer Loading for Case 5 .............................................37

Figure 4-42: Snohomish PUD Transformer Loading for Case 6 .............................................37 


\section{Introduction}

The prospect of replacing a significant portion of the nation's future light vehicle fleet with plug-in hybrid electric vehicles (PHEVs) appears to offer a pathway to realize national energy policy goals that may be difficult to achieve by other means. Probably of most importance, a significant penetration of PHEVs would reduce the overall dependence of the transportation sector on petroleum fuels and ease the presently high cost of importing these fuels.

Charging PHEVs from residential electrical outlets is both practical and convenient from the owner's perspective. In this regard, the existing electric power delivery system offers a natural advantage in being already built with the capacity to serve peak loads. As a consequence, it tends to be under-utilized during off-peak periods. If charging strategies can be planned and coordinated to match the availability of this off-peak capacity, a national fleet of PHEVs could be accommodated with little need to increase the energy delivery capacity of the existing grid infrastructure. In practice, this ideal opportunity may be compromised by several factors including the size and distribution of the PHEV fleet, and the timing of vehicle charging activity.

This report presents work conducted by Pacific Northwest National Laboratory (PNNL) for the Department of Energy (DOE) to address three basic questions concerning how typical existing electrical distribution systems could be impacted by the addition of PHEVs to residential loads. These questions are:

- How many vehicles could the existing power delivery system support in the near future?

- What time of day would PHEVs be charged?

- Where would the vehicles be charged?

This study complements other research performed for the DOE by the University of Michigan (UM) in collaboration with PNNL on various issues relating to PHEV adoption, marketability and impacts on the electric power grid. A brief review of related UM studies is presented below.

\subsection{Related Studies on PHEV Adoption and Integration}

Recent work performed by UM in collaboration with PNNL is reported in the following five document summations.

\subsubsection{Technological Barriers for Acceptable PHEV Performance and Cost (Task 1 Final Report)}

Authors Filipi et al. (Filipi et al. 2009) deal with important issues that may represent latent barriers to achieving acceptable PHEV performance and/or cost. Particularly, they discuss the contrast between Federal and "real-world" driving cycles that may be used as a basis for vehicle design. The higher demand of "naturalistic" driving has implications for several aspects of PHEV design that affect marketability. Not taking these considerations into account could result in possible consequences ranging from PHEVs 
being either underpowered or excessively expensive. This study, based on Michigan driving experience, suggests that the "real-world" contrast with Federal driving cycles may be regional.

\subsubsection{Plug-in Hybrid Electric Vehicles (Task 2a Final Report)}

The study by Curtin, Shrago, and Mikkelsen (Curtin et al. 2009) is a comprehensive review of many factors that can be expected to influence future public acceptance and market penetration potential of hybrid electric vehicles. The survey on which the study is based was performed using generally accepted questionnaire administration techniques and relevant data and statistical analysis. The results support many intuitive expectations about the significance various factors have in determining the probability that an individual may decide to purchase a hybrid vehicle, including the determination of credible price elasticity in consumer response. In addition, the study identifies several non-intuitive correlations including, for example, "consumers who purchase a PHEV are likely to trade-in vehicles that are already relatively fuel efficient.” The authors draw and justify reasonable conclusions from their work which provides a wealth of up-to-date information on the future marketability of hybrid vehicles.

\subsubsection{PHEV Marketplace Penetration (Task 2b Final Report)}

Sullivan, Salmeen, and Simon (Sullivan et al. 2009) address the marketability of PHEVs using an agent-based simulation model to characterize new vehicle penetration into the marketplace under a variety of consumer, economic and policy conditions. This model comprises four classes of agents: consumers, government, fuel producers and vehicle producers/dealers that interact with each other and the environment as software-encoded virtual decision makers. Agent-based models have been applied to many complex systems such as the spread of disease, the evolution of organisms, emergence of behavior in social systems, financial markets and organizational behavior. These applications provide general conceptual foundations for the authors' application to the automobile marketplace. The approach does not produce forecasts of future markets; rather it produces "what is possible" outcomes given sets of assumptions of how the individual agents decide. The authors make a case for concluding that this methodology can be credibly applied to estimating the penetration of PHEVs into the U. S. auto marketplace.

\subsubsection{Market Models for Predicting PHEV Adoption and Diffusion (Task 2c Final Report)}

McManus and Senter (McManus and Senter 2009) describe six models and evaluate the results they produce in predicting PHEV public acceptance and adoption. The authors assume the potential market for PHEVs is analogous to the historical precedent provided by hybrid electric vehicles (HEVs), but the products are not so similar that they can be considered simply generations of the same product. Benchmark market models with fixed saturation levels are examined and found to have weaknesses that dominate their strengths. Two alternative approaches without fixed saturation levels are also evaluated. Of these, the consideration-purchase model, focusing on the market behavior of consumers, is the market model that the authors prefer. The authors developed this model building on the strengths of the other models considered while overcoming some of their limitations. The preferred model explicitly incorporates a consumer choice 
component that can be expanded well beyond its current simplified form. The common assumptions used in this study describe the domestic market for all light vehicles for 2010 through 2050, including sales of new vehicles, growth in the installed base of all light vehicles, and scrappage rates for all light vehicles.

\subsubsection{Impact of PHEVs on the Reliability of the Electric Grid (Task 3 Final Report)}

Lee, Varuttamaseni, Rahman, and Briley (Lee et al. 2009) consider the impact of PHEV charging and the timing of this load on the reliability of the electric power grid. The concern specifically addressed is that the additional load will increase the time distribution equipment operates at elevated temperatures thereby shortening the mean service life of components as a result of accelerated aging. The study successfully applies established probabilistic risk assessment methodology to components of a realworld electric distribution system and estimates reliability indices that allow this effect to be modeled quantitatively. The authors admit that the reliability indices they derive differ from those suggested by the operating experience of the studied utility system and recommend this as a subject for further work. However, they establish that the aging effect is credible and it could, as one example, shorten mean transformer by 20 years (i.e., from 60 to 40 years). They also assess this effect as it impacts system reliability.

\subsection{Focus of the Present Study}

The present study has a close relationship to the work of Lee et al. summarized above because it expands consideration of impacts PHEVs may have on the electric power grid. This analysis answers the question of how the capacity of existing electrical distribution systems is impacted by the addition of PHEVs to residential loads. The first part of the analysis is designed to study the impact to the distribution system as a whole, using a load flow study of various PHEV penetrations to observe which, if any, components of main feeders exceed their capacity.

The second part of this analysis focuses on the impact of the additional load on the distribution transformers serving each individual load. As the principal measure of this type of impact, the peak percent loading, (provided by the relationship $\mathrm{kW}$ load/transformer kVA capacity), is estimated for the existing loads and then with the addition of PHEV load to a number of representative feeders. In both portions of the study, three electric utilities: Franklin Public Utility District (PUD), Snohomish PUD and Puget Sound Energy (PSE) collaborated by providing information that allowed systemspecific feeder modeling.

The balance of this report contains six sections. Section 2 discusses penetration and charging profile cases that a hypothetical PHEV fleet might impose on the electric distribution system. In Section 3, the feeder characterization on which impact analyses are based is presented. The analytical methodology and results of PHEV load simulations and impacts are discussed in Section 4. Key findings and conclusions are contained in Section 5 and references are listed in Section 6. 


\section{Key Assumptions}

The key assumptions that drive the outcome of the impact analysis are the projection of the penetration of PHEVs, the assumptions related to the time of day when the vehicles are likely to be recharged, and the locations where the vehicles are connected to the electric grid. In other words, the following three questions need to be answered in a plausible and defensible fashion:

1. How many vehicles are likely to be supported by the grid at a future point in time? The answer relates to the penetration rate of PHEV as a function

2. What time a day would the vehicles be charged? The answer defines the daily load profile

3. Where would the vehicles be charged? To answer this question requires some assumptions about the grid infrastructure and the availability assumptions of public charging stations and the development of charging points for vehicle owners who live in apartment complexes or higher density urban dwellings without access to an electrical outlet.

There is additional set of questions that has more recently emerged related to the rate of energy transfer to the battery in terms of $\mathrm{kW}$ of electrical demand. It is anticipated that the most common charging rate would be based on a 120-Volt (V) and 15-Ampere (A) single-phase power, which are most common in residential homes (Level 1 charging). Quick charging (Level 2 charging) would likely require charging at higher voltage and current ratings than the commonly used $120-\mathrm{V}, 15-\mathrm{A}$ circuits on residential homes ${ }^{2}$. Charging at $240 \mathrm{~V}$ and $30 \mathrm{~A}$ or even at $50 \mathrm{~A}$ would significantly increase the rate of electricity transfer to the battery, and thus, is likely to have higher impacts on the electric infrastructure both at the charging premise (in most cases the home) as well as the distribution system as a whole. The advantage would be a much shorter re-charge time.

To address these different assumptions that span a reasonable range of likely future scenarios, we defined a portfolio of scenarios for the impacts assessment. The following sections will discuss the key assumptions.

\subsection{PHEV Market Penetration}

There are many analytical approaches that attempt to model the customer acceptance and purchasing decisions of new and used vehicles [Sentech 2009; Sullivan et al. 2009; McManus and Senter 2009; Balducci 2008]. Rather than modeling and estimating a certain penetration of PHEVs for a future point in time, we framed the problem by hypothesizing a number of PHEVs per residential home (single detached homes) and then analyzing the likely impacts. Specifically, we defined a 100\% PHEV scenario, meaning that one PHEV per residential customer (home), and a 50\% scenario, in which every second home has a PHEV.

\footnotetext{
${ }^{2}$ SAE - J1772 ${ }^{\mathrm{TM}}$ Standard defines Level 1 charging as: 120-V single-phase alternating current (AC), $12 \mathrm{~A}$ on 15 A circuit or 15 A on a 20-A circuit. Level 2 charging is defined as: 240-V single-phase up to 80 A.
} 


\subsection{Charging Scenarios}

In the absence of the real-world data on charging patterns of PHEVs, one needs to postulate plausible charging scenarios that are based on driving patterns and particularly resting periods of vehicles that would allow the vehicle owner to re-charge the PHEV battery. Although currently, the Department of Energy is collecting vehicle data from retrofit PHEVs that include charging patterns, these data sets are in the early stages of covering a sufficient number of regions and customer driving patterns. Thus, they were considered not ready to be the sole sources for developing comprehensive charging profiles valid for the U.S. as a whole.

As an alternative approach to real driving data, this study developed charging profiles based on simulations derived from the U.S. Department of Transportation's 2001 Household Traveling Survey. This data set comprises representative U.S. driving patterns for privately-owned vehicles derived from individual respondents' daily traveling diaries (DOT 2001). The survey provided slightly over 35,000 samples of daily trips using light duty vehicles. Given the starting time and locations, the destinations and arrival times of each trip in the survey, we determined the resting locations of a vehicle and its arrival and departure times at that location. Of interest for the purpose of this study were only two resting locations, where any vehicle would reside for longer periods of time (i.e., more than 15 minutes) able to be plugged-in for battery charging. These two locations were a) home and b) place of work. Shorter durations, for brief errands were considered not suitable for battery charging opportunities. Furthermore, the estimated travel distance was used to determine the battery's state of charge (SOC) at the point of arrival. The SOC determined the maximum electric energy that can be transferred into the battery until the battery is fully charged.

The following six charging cases represent scenarios covering the most likely range of charging strategies to be expected when PHEVs become more common:

- Case $1-120-\mathrm{V}$ charging at home

- Case $2-120-\mathrm{V}$ charging at home and work

- Case $3-120-V$ charging at home delayed until after 10 p.m.

- Case 4 - 50/50 120-V/240-V charging at home

- Case 5 - 50/50 120-V/240-V charging at home and work

- Case 6 - 50/50 120-V/240-V charging at home delayed until after 10 p.m.

In all six cases, except for cases 2 and 5, the location of the vehicle charging is exclusively at home. Cases 2 and 5 have additional charging locations at work considered. Because no information exists regarding the precise work location, we eliminated the opportunity of the charging at the work place entirely and focused solely on charging at home to estimate the associated impacts on the distribution as a result of additional PHEV load at the residential customers location. Modifications for the cases 2 and 5 load profiles became necessary. The work-site related charging was eliminated from the charging profile such that only charging at home was considered, which for the most part occurs during the hours of 4:00 p.m. and 6:00 a.m. The modified cases are now called Case 2M and Case 5M and are defined as follows: 
- Case $2 \mathrm{M}-120-\mathrm{V}$ charging at home and work - home only

- Case 5M - 50/50 120-V/240-V charging at home and work - home only.

Figures 2-1, 2-2 and 2-3 compare the loads and load timing imposed on a domestic feeder by a single PHEV in each of the above charging cases. All curves represent the actual load that would be measured at the battery of the PHEV assuming that the battery charging circuit has an efficiency of 87\% (Duvall 2002). Load duration in each case accounts for the transfer of sufficient energy to recharge the PHEV battery following a typical daily driving pattern. Each curve is modified to represent the actual load that would be seen at the secondary of the distribution transformer serving the individual residence. For the "Charge at Home and Work" curves (Cases 2, 2M, 5 and 5M), only the residential, or "charge at home" contribution was used.

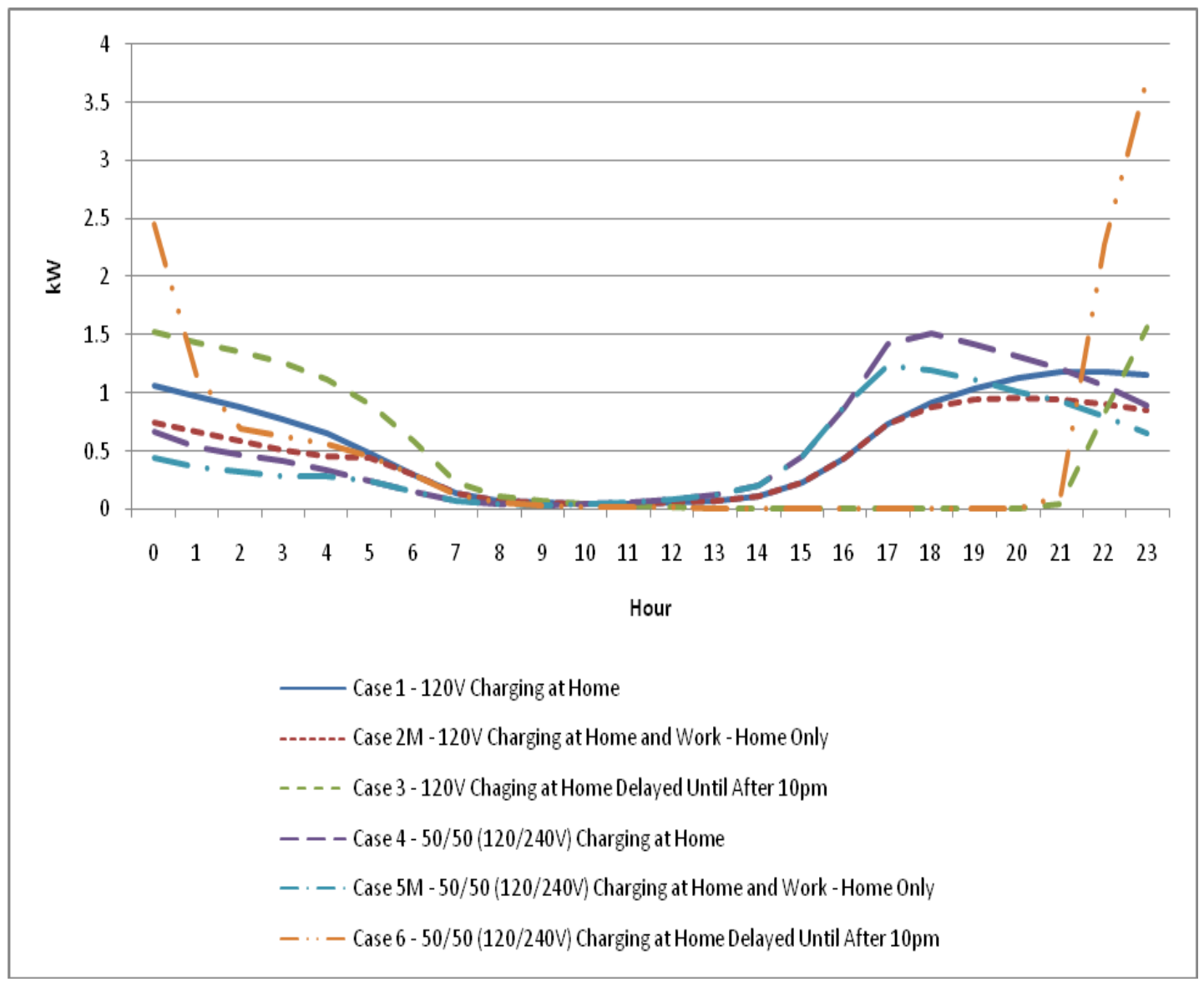

Figure 2-1: PHEV Charging Profiles derived from the DOT Household Travel Survey Data Set (DOT 2001). Load profiles represent a diversified load. 


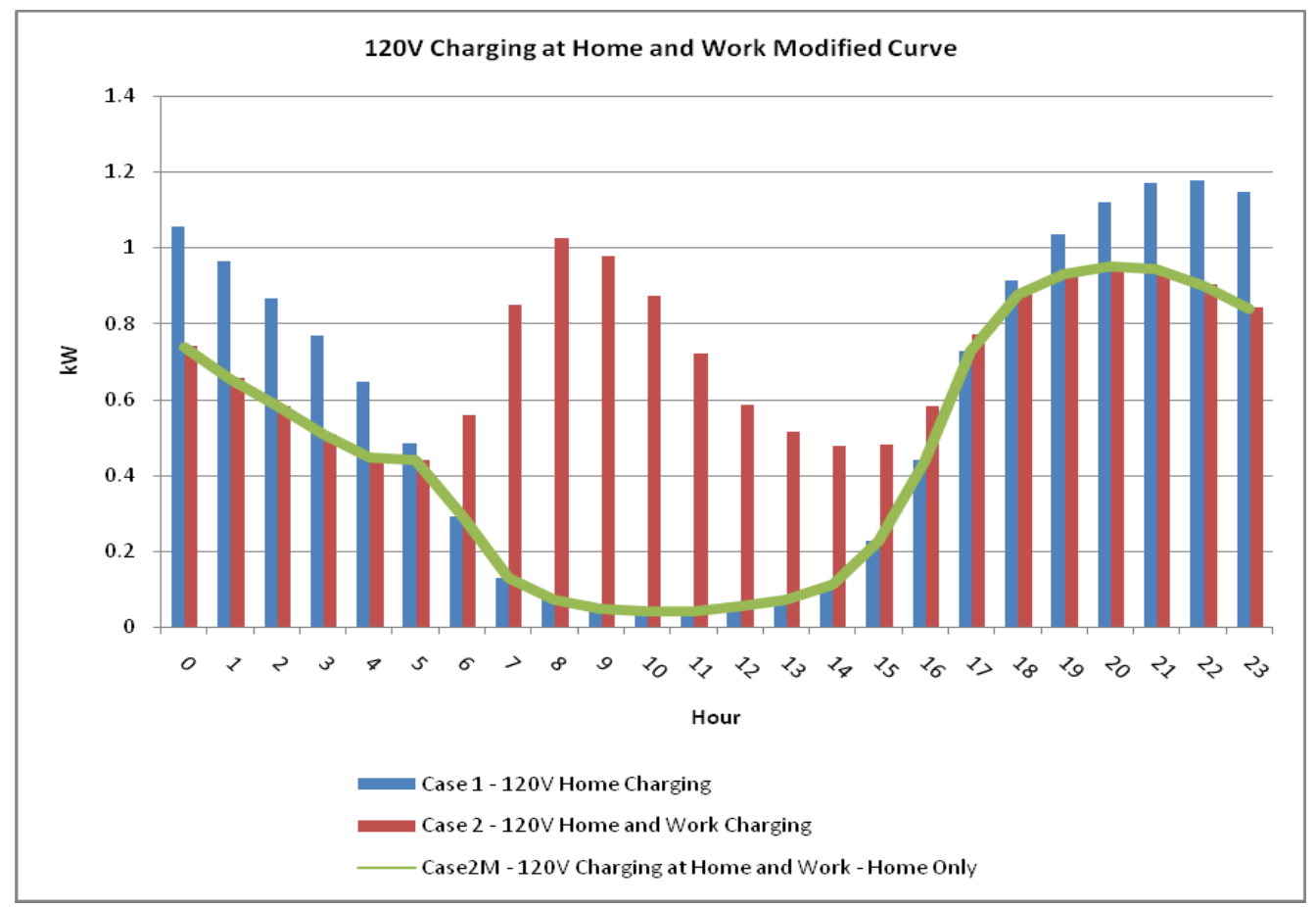

Figure 2-2: Modified Case 2 Charging Curve

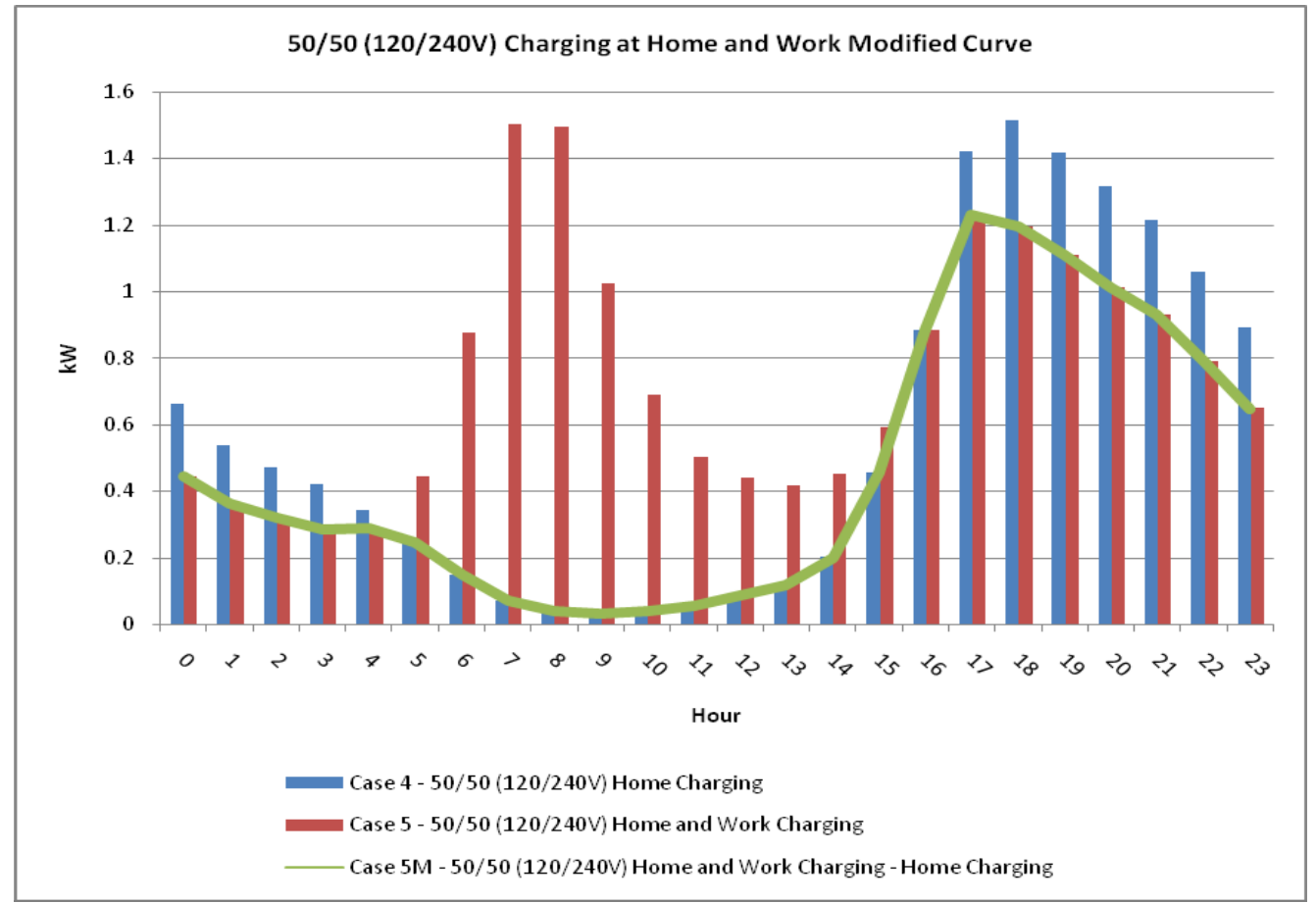

Figure 2-3: Modified Case 5 Charging Curve 


\section{Feeder Characterization}

To assess the differential impacts of PHEV charging, it was necessary to establish a baseline characterization of the domestic feeders involved in terms of representative hourly load profiles and load composition. As noted earlier, three electric utilities: Franklin PUD, Snohomish PUD and Puget Sound Energy (PSE) collaborated by providing information that allowed system-specific feeder modeling. Baseline feeder characterization is presented below for each of the collaborating utilities.

\subsection{Feeder Load Composition}

As the basis for the analysis, 34 of Franklin PUD's feeders, 8 of Snohomish PUD's feeders, and 8 of PSE's feeders were considered

The Franklin PUD data set represented all feeders in its service territory. Because of the relatively small size compared to the other collaborating load serving entities, we decided to use the entire data set. For Snohomish PUD and PSE, because of the large size of their respective service territory and the available data, a small subset of primarily residential feeders were selected for this analysis. PSE was interested in analyzing two feeders with a mixed composition of commercial and residential load customers. The breakdown of the feeders and their load composition by customer type are shown in Figure 3-1 through Figure 3-3.

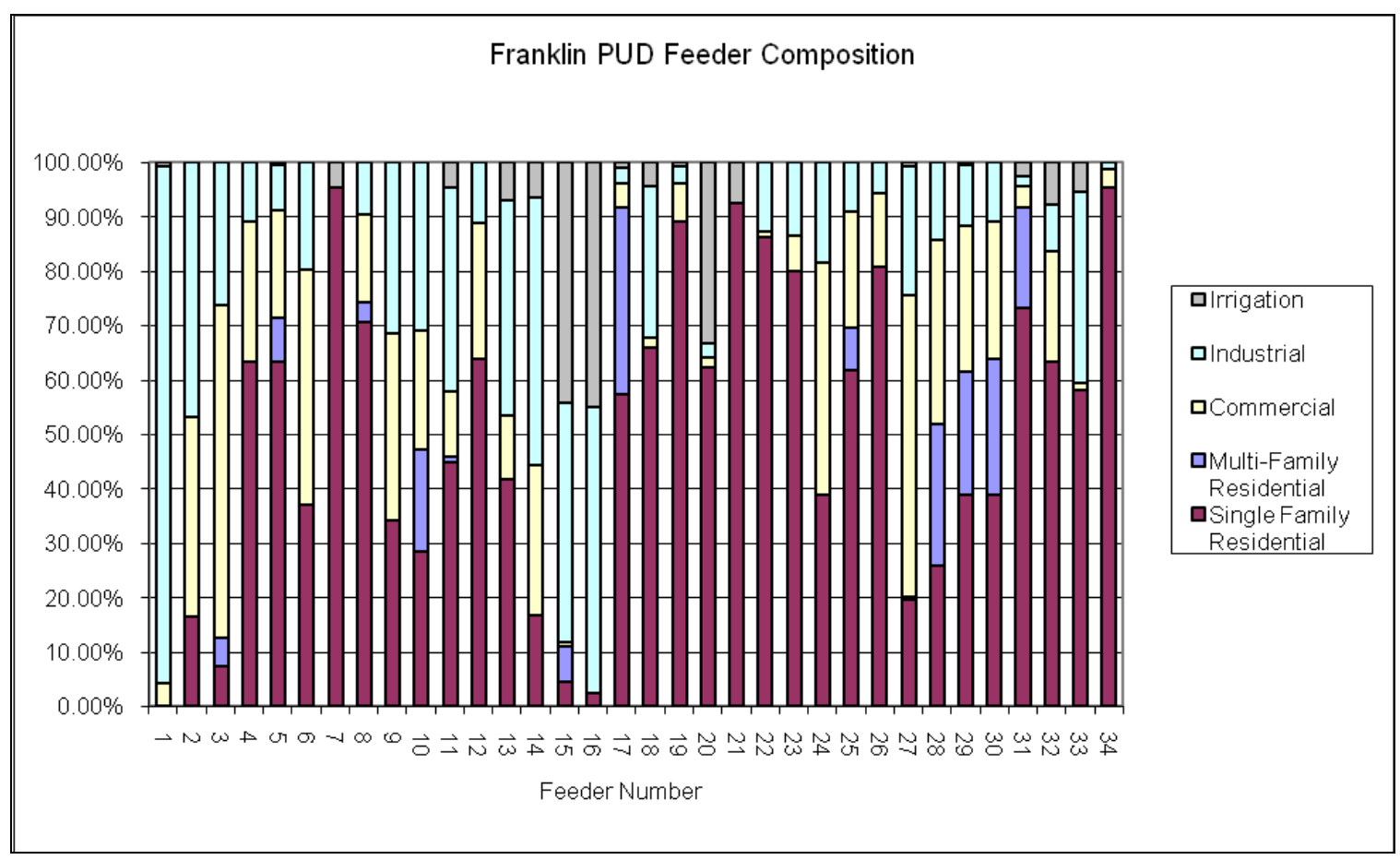

Figure 3-1: Feeder Load Composition for Franklin PUD 


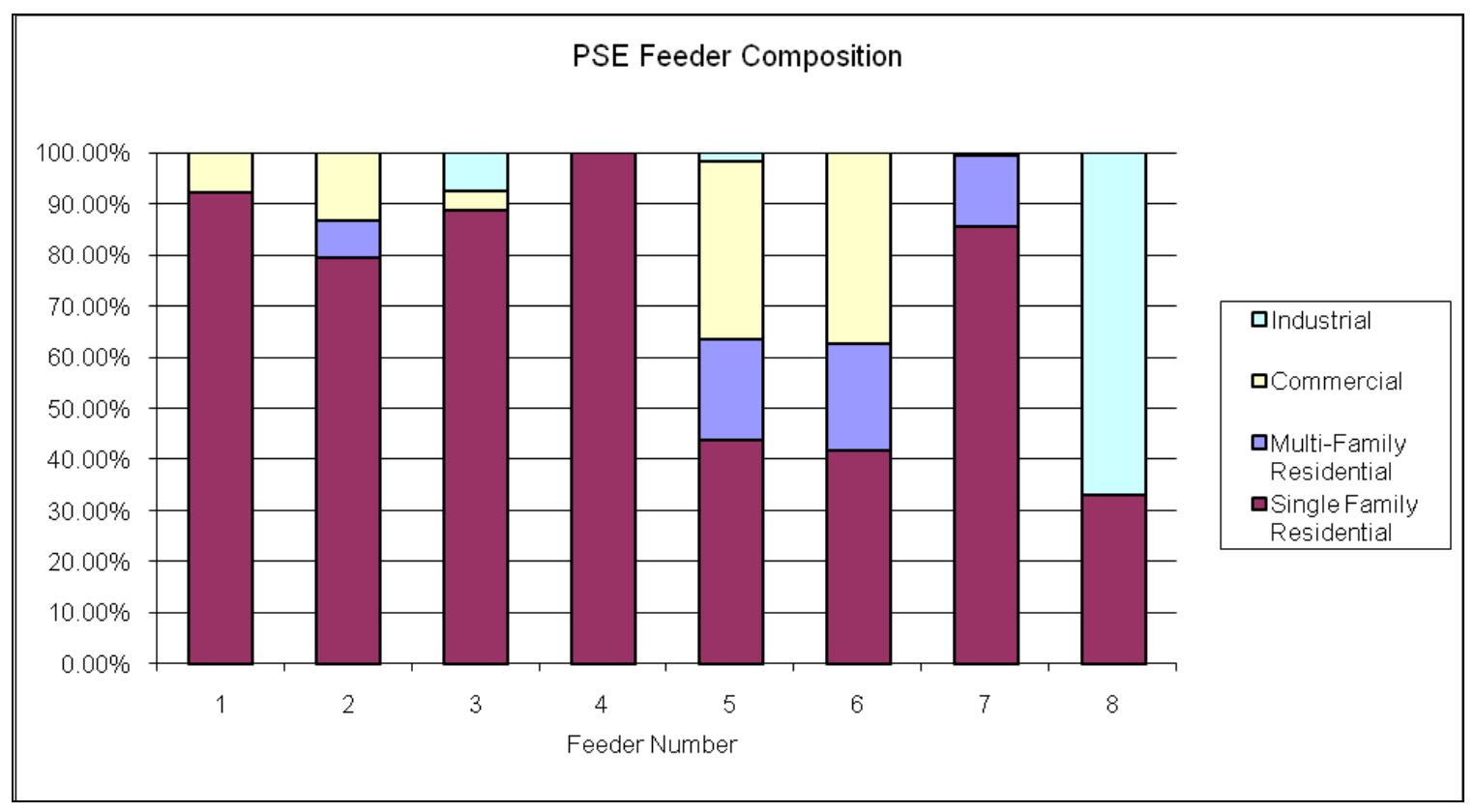

Figure 3-2: Feeder Load Composition for PSE

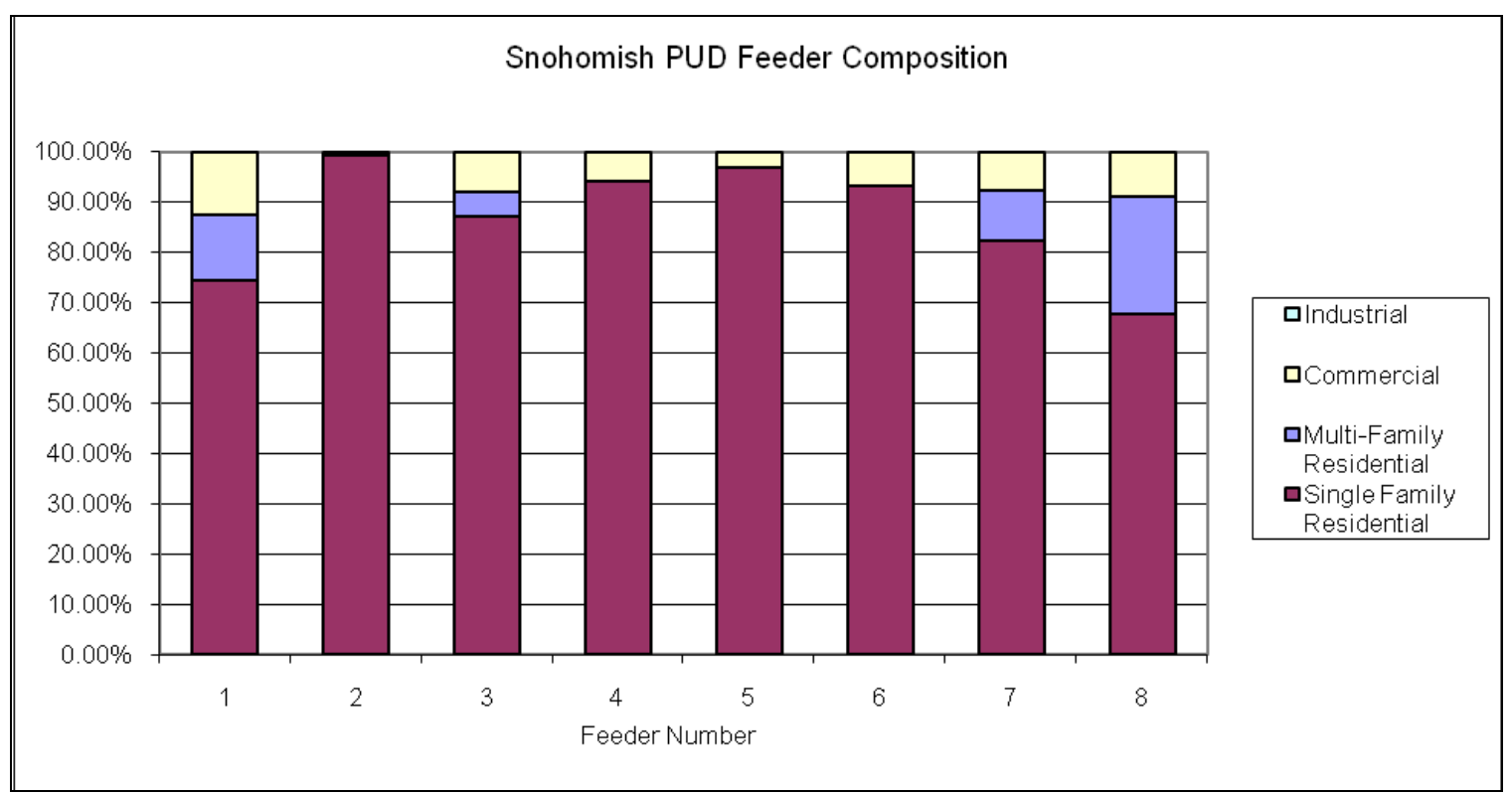

Figure 3-3: Feeder Load Composition for Snohomish PUD 


\subsection{PUD Load Shapes}

Baseline load shapes for the Franklin PUD and Snohomish PUD systems were based on the default load curves supplied with the SynerGEE analysis package (SynerGEE 2009). The validity of the load profiles were confirmed by the planning engineers of both load serving entities. They were sufficiently representative of average load behavior without representing the conditions of a specific season. Figure 3-4 through Figure 3-5 illustrate the hourly load profile for feeders serving residential customers. The residential load shape in Figure 3-6 denotes the residential characteristic modified by using natural gas for heating. Figure 3-7 and Figure 3-8 show the baseline feeder load shape for the commercial and industrial sectors. Although we assumed that PHEV were only charged at the premises of residential customers, load profiles by commercial and industrial were required for the load flow analysis because most feeders served a mix of the residential/commercial/industrial customer segments.

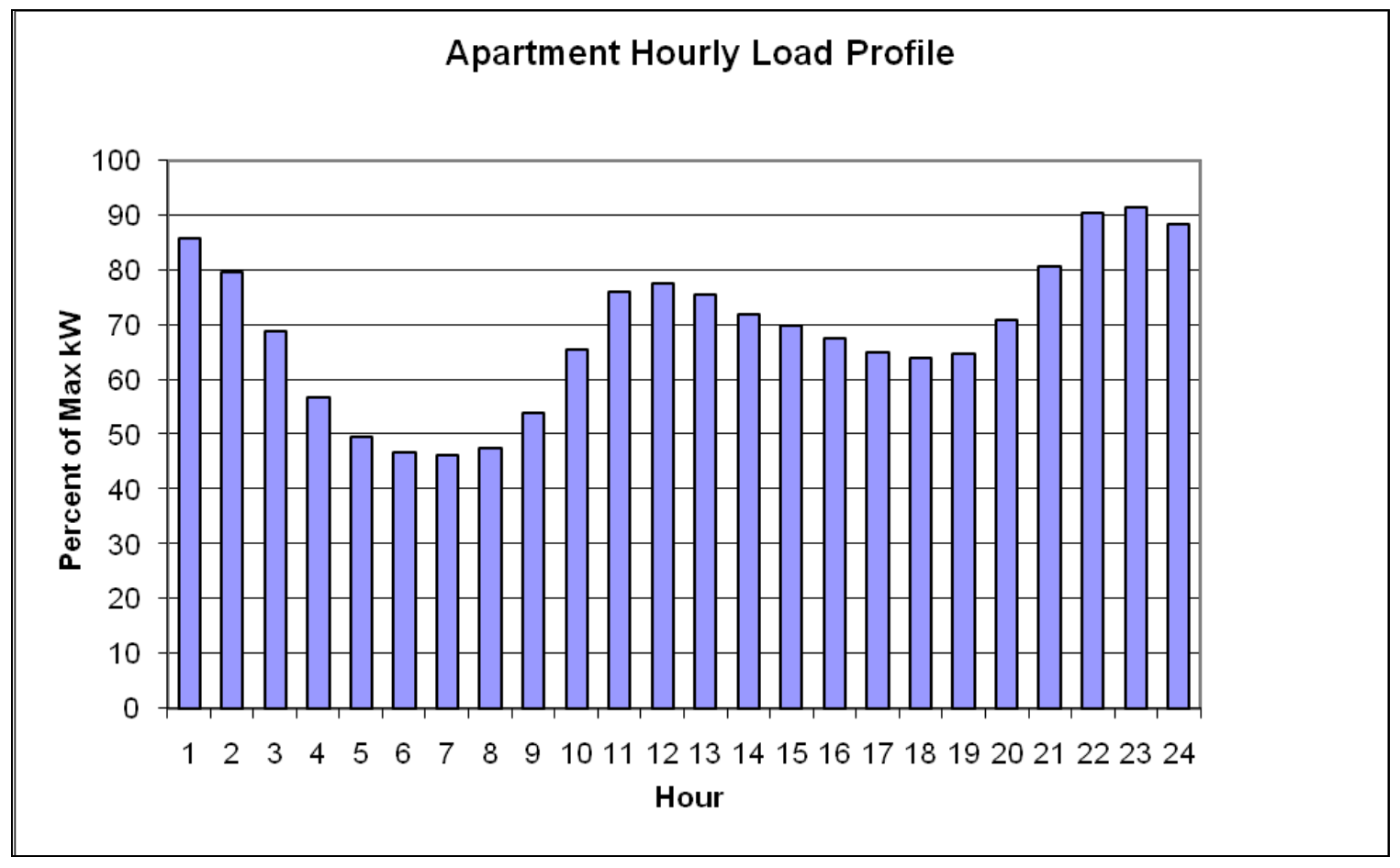

Figure 3-4: Franklin and Snohomish PUD Load Shape for Apartment Loads 


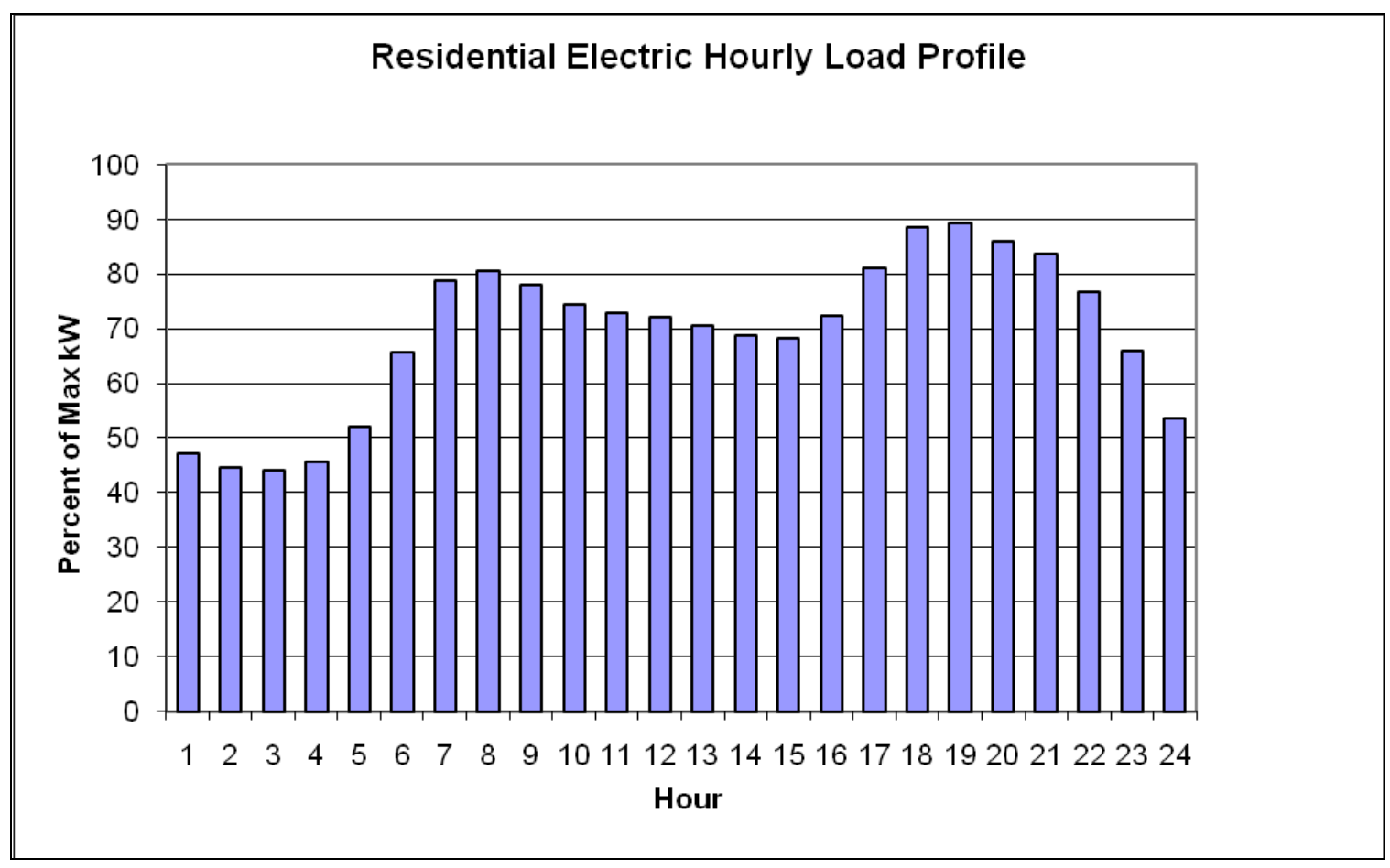

Figure 3-5: Franklin and Snohomish PUD Load Shape for Residential Electric Heating Loads

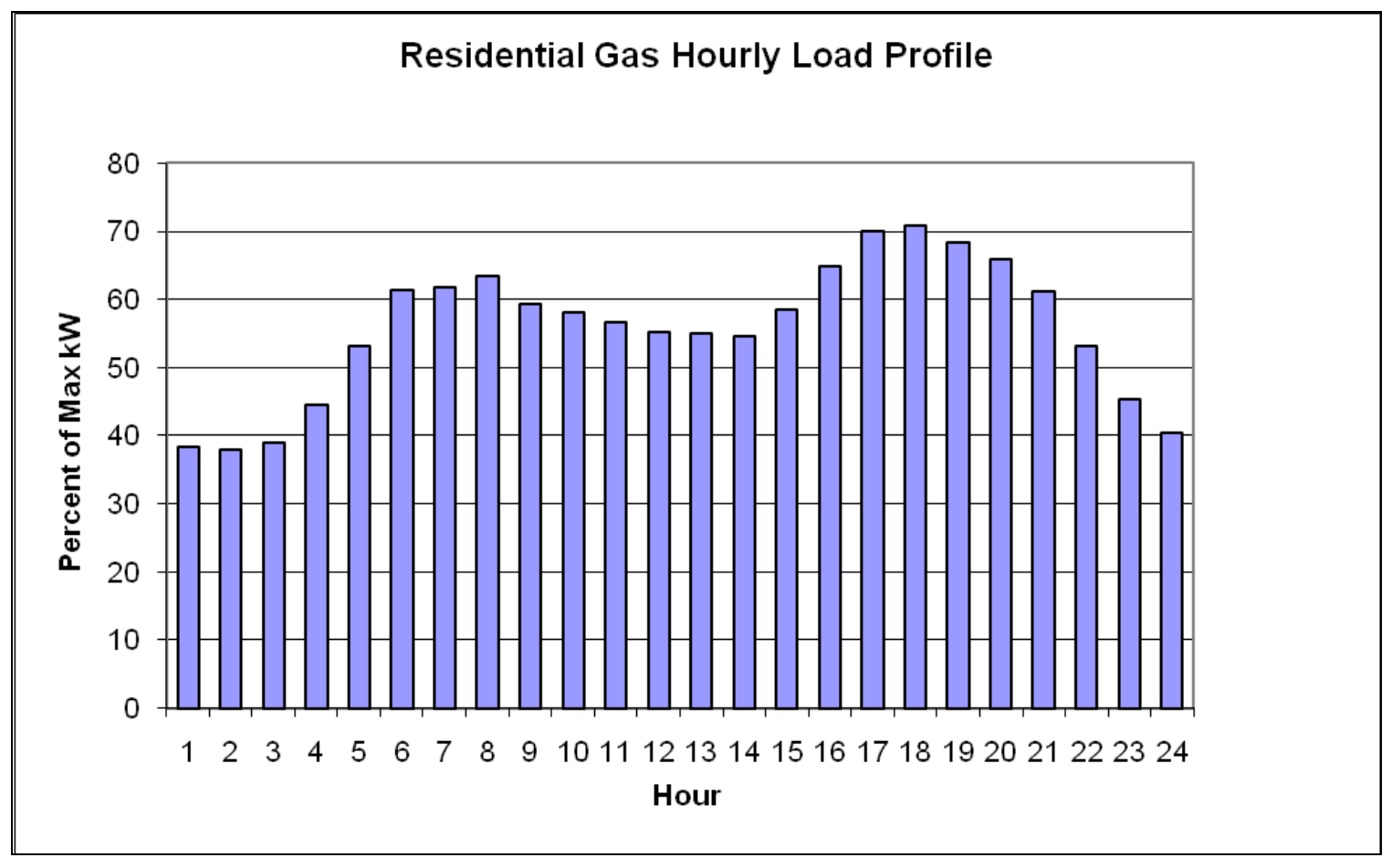

Figure 3-6: Franklin and Snohomish PUD Load Shape for Residential Gas Heating Loads 


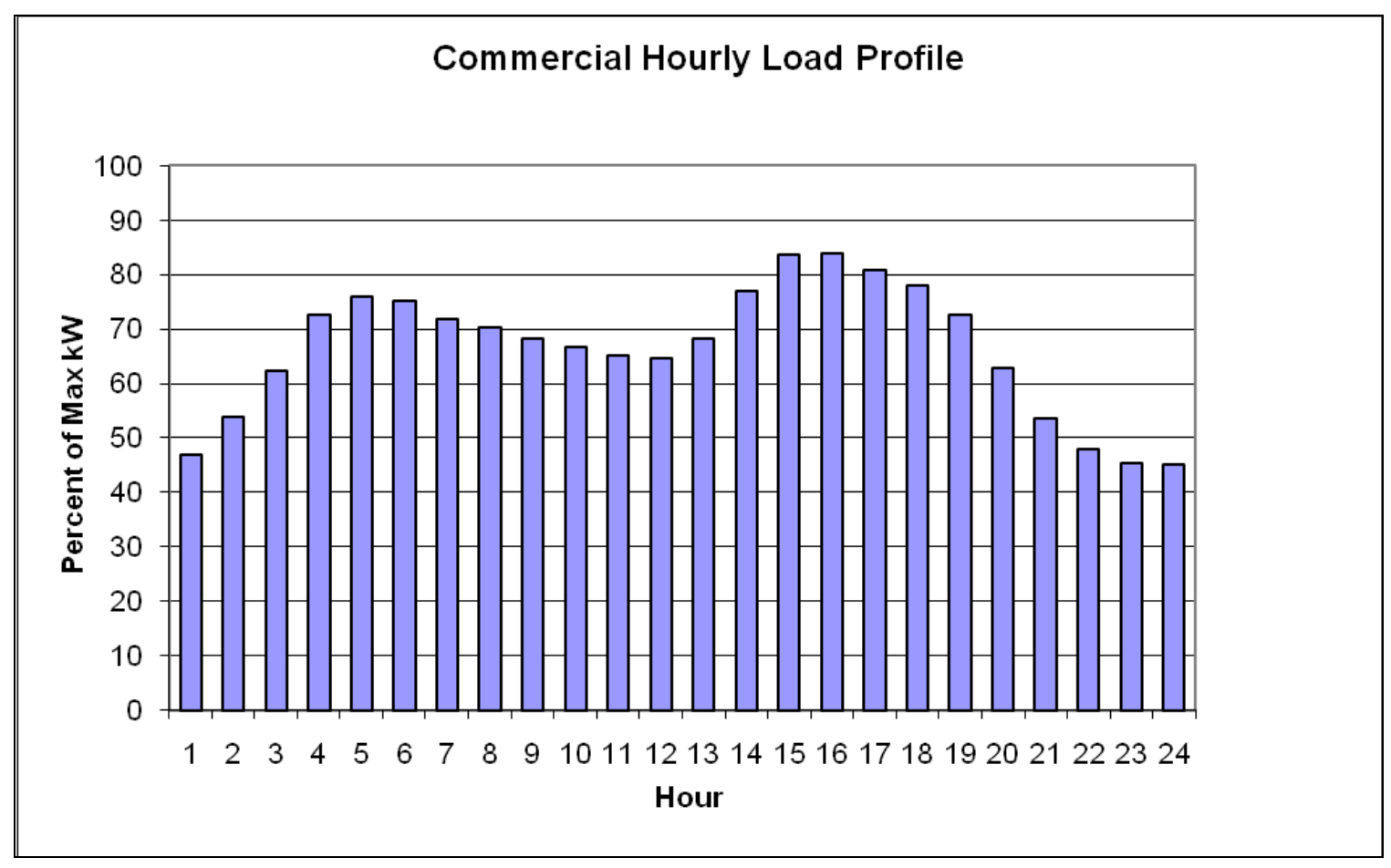

Figure 3-7: Franklin and Snohomish PUD Load Shape for Commercial Loads

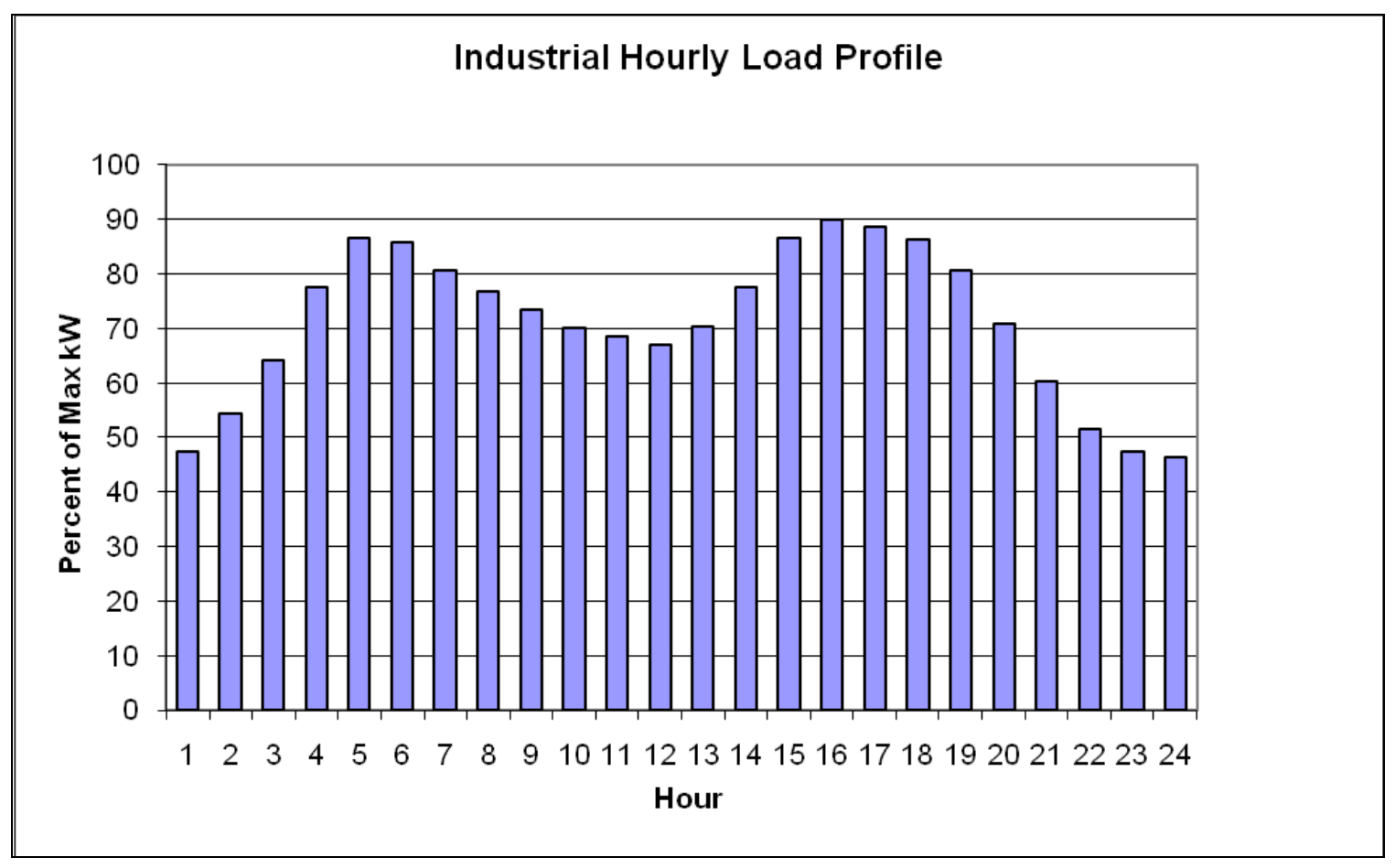

Figure 3-8: Franklin and Snohomish PUD Load Shape for Industrial Loads 


\subsection{PSE Load Shape}

Hourly load shapes for the PSE system were also derived from SynerGEE curves with the exception of the residential load profile. This curve is based on actual measured customer load profiles as provided by PSE. An example of PSE's residential load profile is shown in Figure 3-9 representing average winter peak loading conditions.

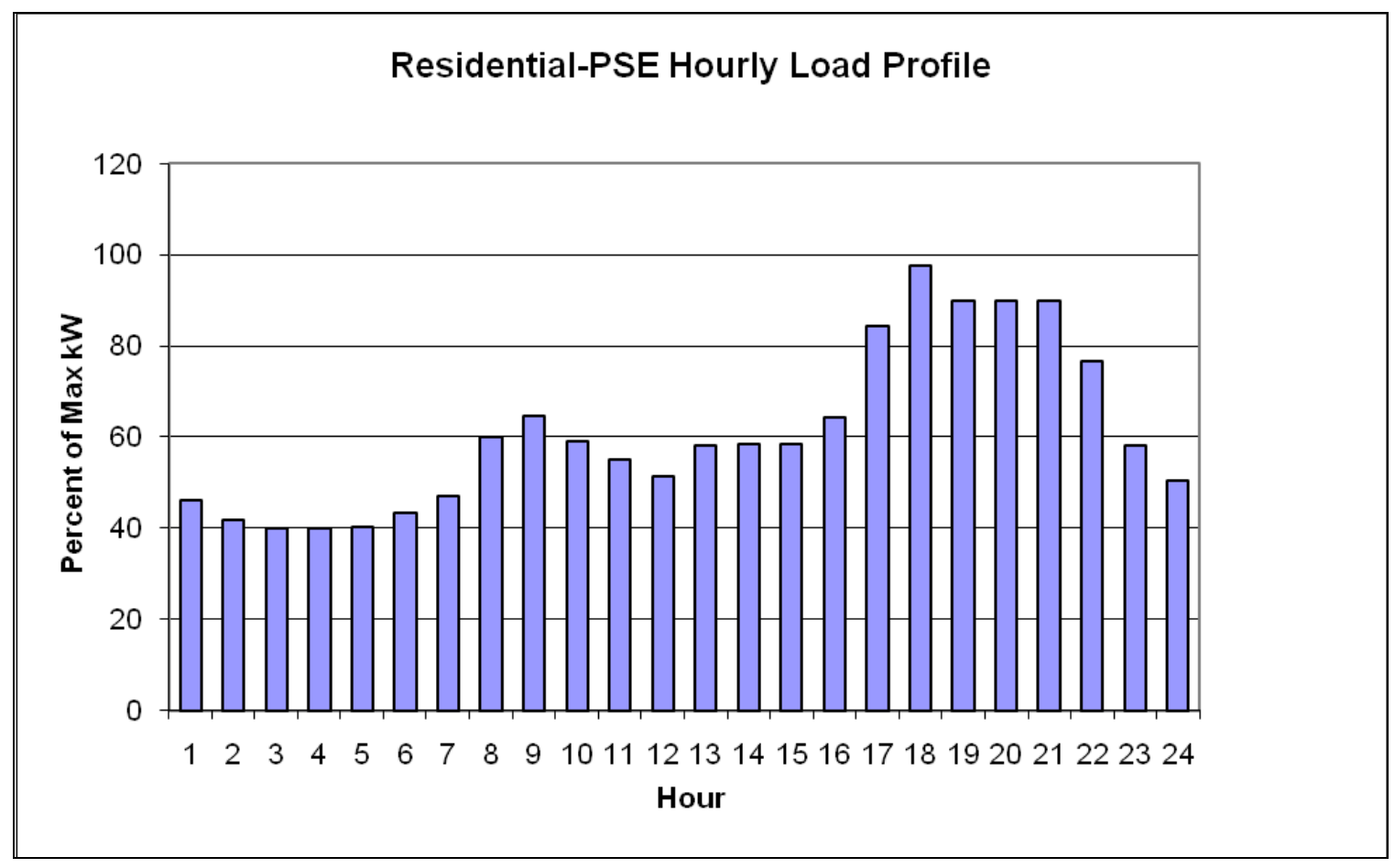

Figure 3-9: Load Shape for PSE Residential Loads 


\section{Methodology and Results}

An analysis of PHEV impact was performed on each feeder, as characterized in Section 3. The PHEV charging profiles were superimposed onto the feeder baseload conditions and load configurations. The impacts at two levels of hypothetical PHEV load penetration, $50 \%$ and $100 \%$ were investigated. A penetration of $100 \%$ means that every residential customer (non multi-residential customer) owns a PHEV and charges it at home. A penetration of $50 \%$ assumes that every other residential customer has a PHEV. The PHEV distribution at the $50 \%$ penetration level was uniformly distributed across all residential customers to avoid load concentration.

The annual load growth of all other loads was not considered in the analysis. It was assumed that both the number of customers as well as their particular load characteristics were frozen at the 2008 level. Further details of the methodology are described below.

\subsection{Study Methodology}

The analysis is based on several primary assumptions:

- PHEVs are distributed evenly through the system

- Specific areas were not assumed to have a higher concentration of PHEVs

- PHEVs are charged only at single family residences.

For Franklin PUD ${ }^{3}$ and Snohomish PUD, ${ }^{4}$ it was assumed that each customer was allocated a service capacity of $7.5 \mathrm{kVA}$ by each distribution transformer. Dividing this value into the nominal capacity of the transformer determined how many customers were attached to each transformer. For the PSE analysis, the actual number of connected customers at each transformer was available in the model and, therefore, was used in the study.

\subsubsection{Issues Considered}

The addition of significant electrical load, such as a PHEV, at multiple individual residences can contribute potentially to overloading components of the entire feeder depending on the timing and diversity of the new load. The rated capacities of existing feeder components will have been chosen to handle the projected load at any residence based on the average value of expected "normal” loads such as heating and cooling equipment, resistive elements such as water heaters and electric ranges, and standard lighting. The sizing of the distribution transformer that serves each residence is based on these expectations. In turn, all feeder components upstream of the distribution transformer are generally sized to supply downstream transformers operating at full nameplate capacity. Nameplate capacity generally exceeds the actual load for many hours in the day and is only fully exploited during peak periods. Thus, it should be generally feasible to control the timing of the PHEV demand so that this additional load can be served within the rated capacities of existing feeder equipment.

\footnotetext{
${ }^{3}$ M. Hay, private communication, Franklin PUD, September 2007

${ }^{4}$ R. Fletcher, private communication, Snohomish PUD, June 2007
} 
Feeder equipment and transformers, in particular, operating at overload capacity generally shortens their lives. By considering the amount of time new loads on a feeder causes overrated operation and the duration of overload conditions, the tendency for reducing component life expectancy can be illustrated.

\subsubsection{Analytical Approach and Results Presentation}

The above issues were addressed in two distinct studies. For the study on distribution system infrastructure impacts, load flow studies were done with PHEV loads applied at single family residences. A total of 24 hourly load flow analyses were performed using the SynerGEE analysis package (SynerGEE 2009) for the following combination of cases and conditions:

- $\quad$ Each of the six charging scenarios described in Section 2.2

- PHEV penetration levels of $50 \%$ and $100 \%$.

The results were used to determine whether or not the rated capacity of any feeder components (i.e., conductors, switches, fuses, and other protection and control devices) was exceeded. From this study, the total feeder current was also found.

In the second study on the adequacy of distribution transformer capacity, load flow analyses were also performed for each hour to compare the rated kVA of each transformer to the peak load it experienced.

The results of both studies are summarized in utility-specific figures presented in the following sections.

\subsection{PHEV Impacts on Infrastructure Loading}

The figures in this section show the infrastructure loading impacts caused by charging PHEVs at $50 \%$ and $100 \%$ penetration levels at single-family residences on each of the modeled feeders.

\subsubsection{Franklin PUD}

The distribution system components that failed from overloading and the number of feeders affected are indicated in Figures 4-1 and 4-2 for the various charging cases and PHEV penetration rates. 


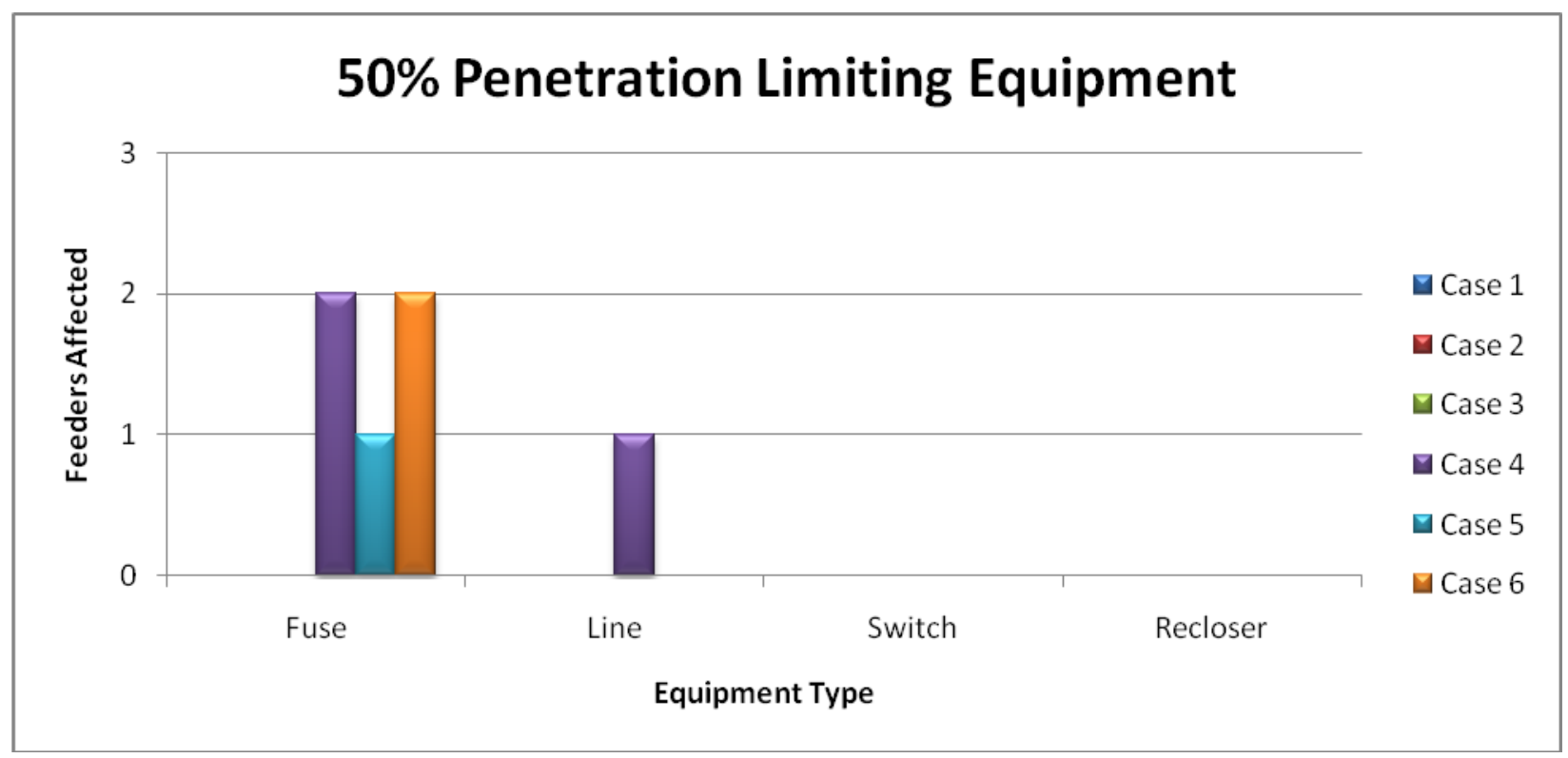

Figure 4-1: Number of Franklin PUD Feeders with Equipment Failures by Type for 50\% PHEV Penetration

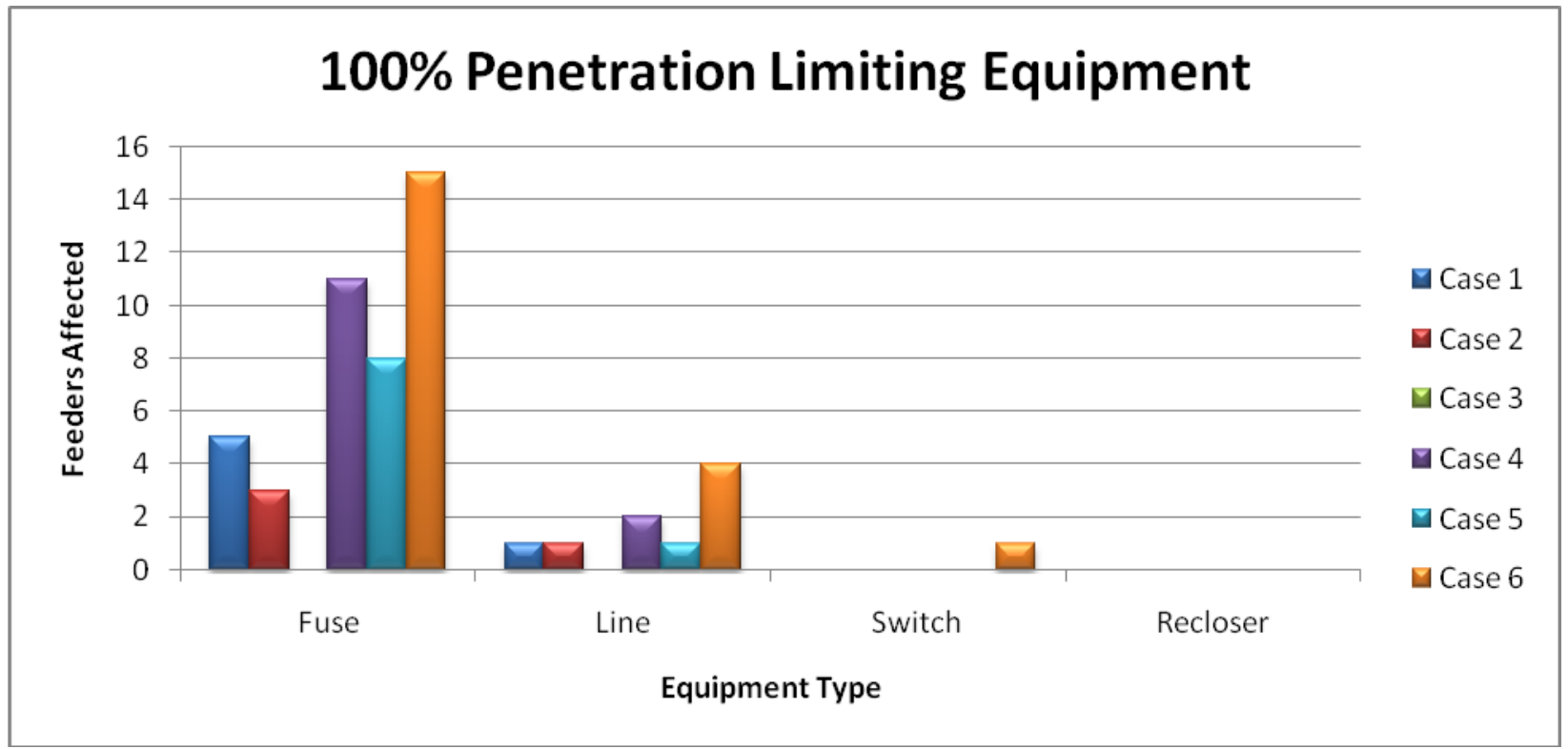

Figure 4-2: Number of Franklin PUD Feeders with Equipment Failures by Type for 100\% PHEV Penetration

The number of feeders able to support the two penetration rates for the six different charging cases with no equipment failures in the Franklin PUD study are shown in Figure 4-3. 


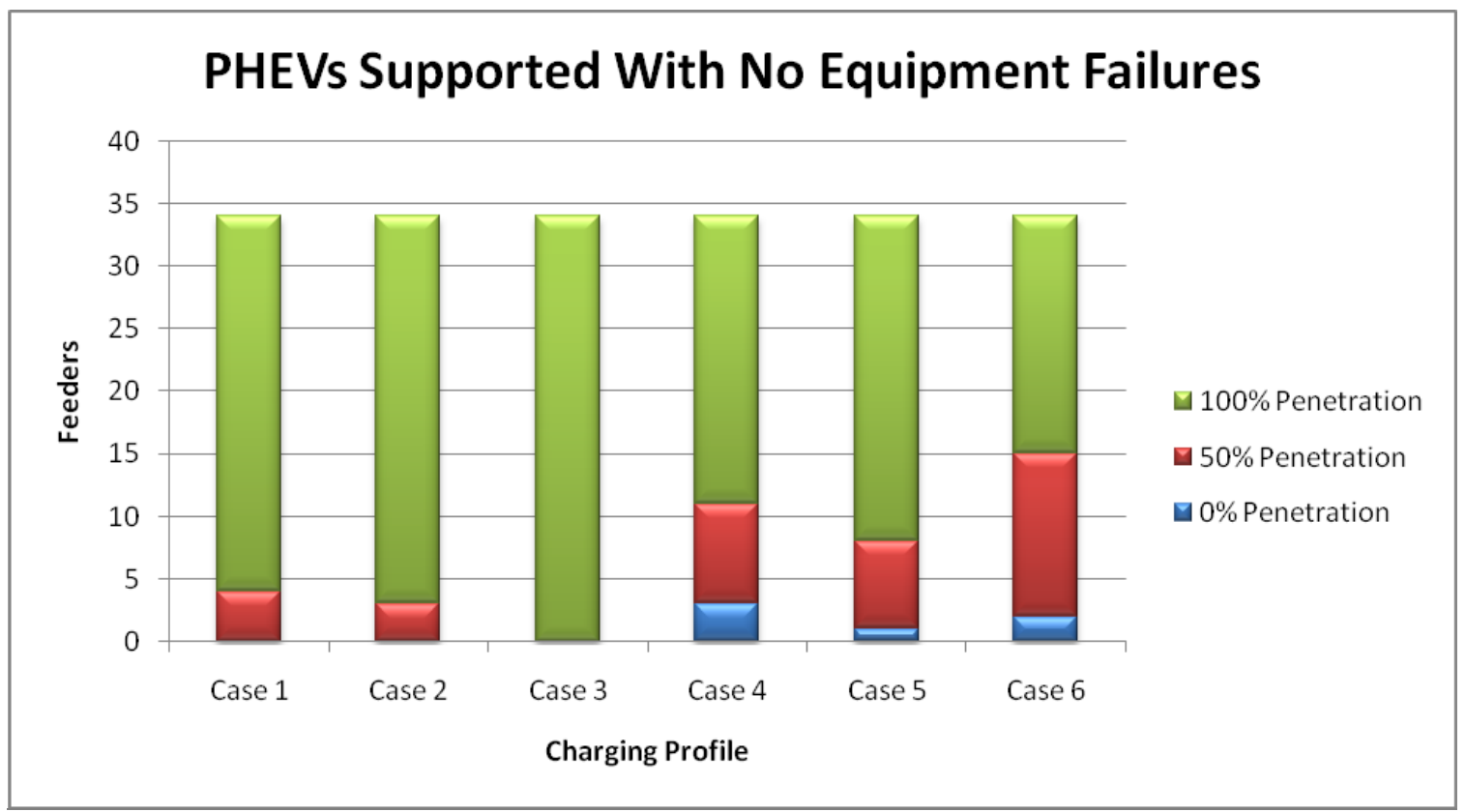

Figure 4-3: Number of Franklin PUD Feeders Supporting PHEV Penetrations With No Equipment Failures

In this and the similar figures that follow, green, red and blue bars represent, respectively, feeders that can tolerate $100 \%, 50 \%$ and $0 \%$ PHEV penetration in each charging scenario without increasing the rate of distribution system equipment failures. Thus, Figure 4-3 shows all 34 Franklin PUD feeders can support 100\% penetration in Case 3. In contrast, the Case 6 charging scenario shows that only 19 of these feeders tolerate $100 \%$ penetration (green bar), 13 feeders would support 50\% (red bar) and 2 feeders would not support any level of PHEV penetration (blue bar) without increasing equipment failure rates.

Load curves for a representative Franklin PUD feeder comparing the base load to the various charging profiles for the two penetration rates are shown in Figure 4-4 and Figure 4-5 


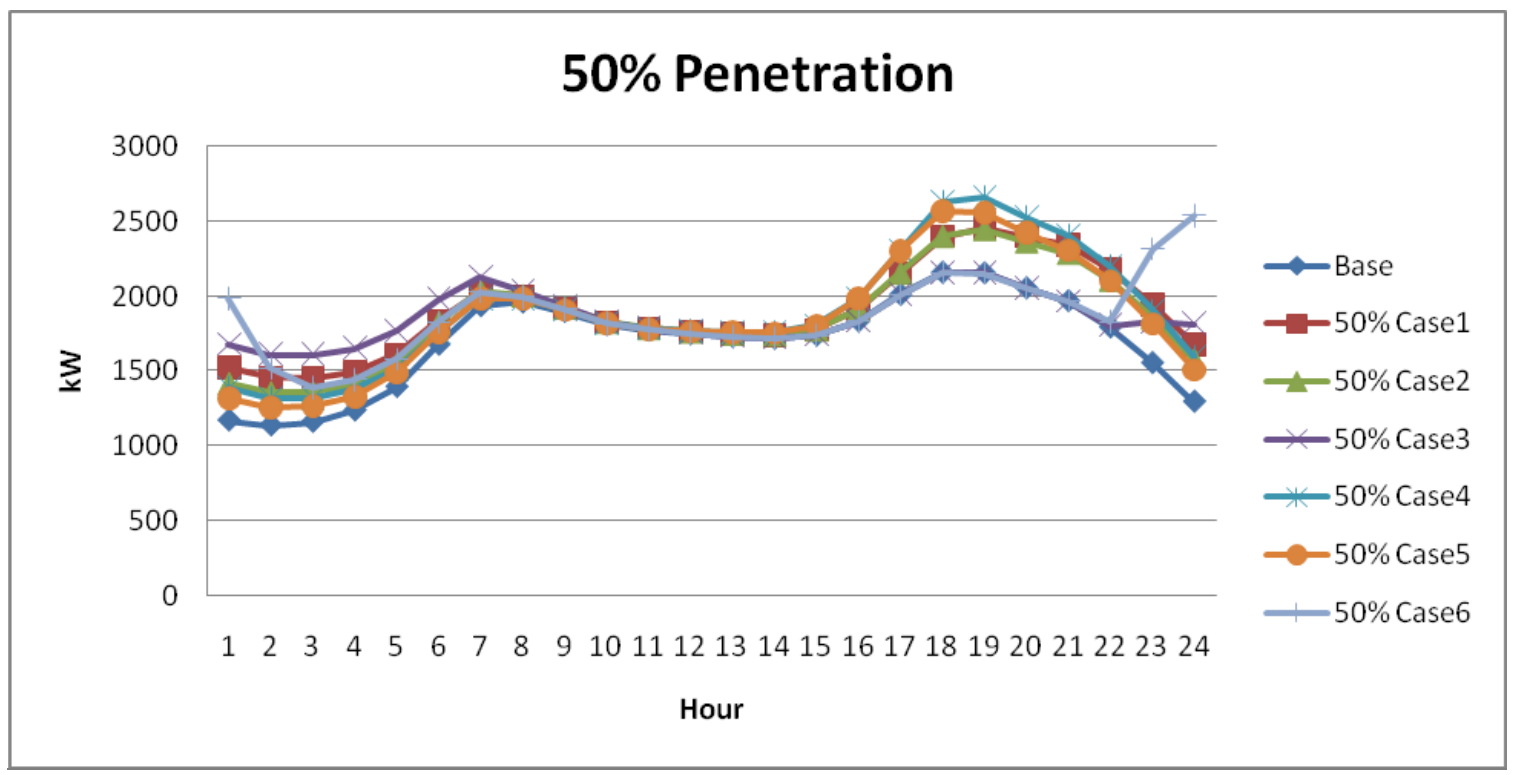

Figure 4-4: Franklin PUD Representative Feeder Load Curve for 50\% PHEV Penetration

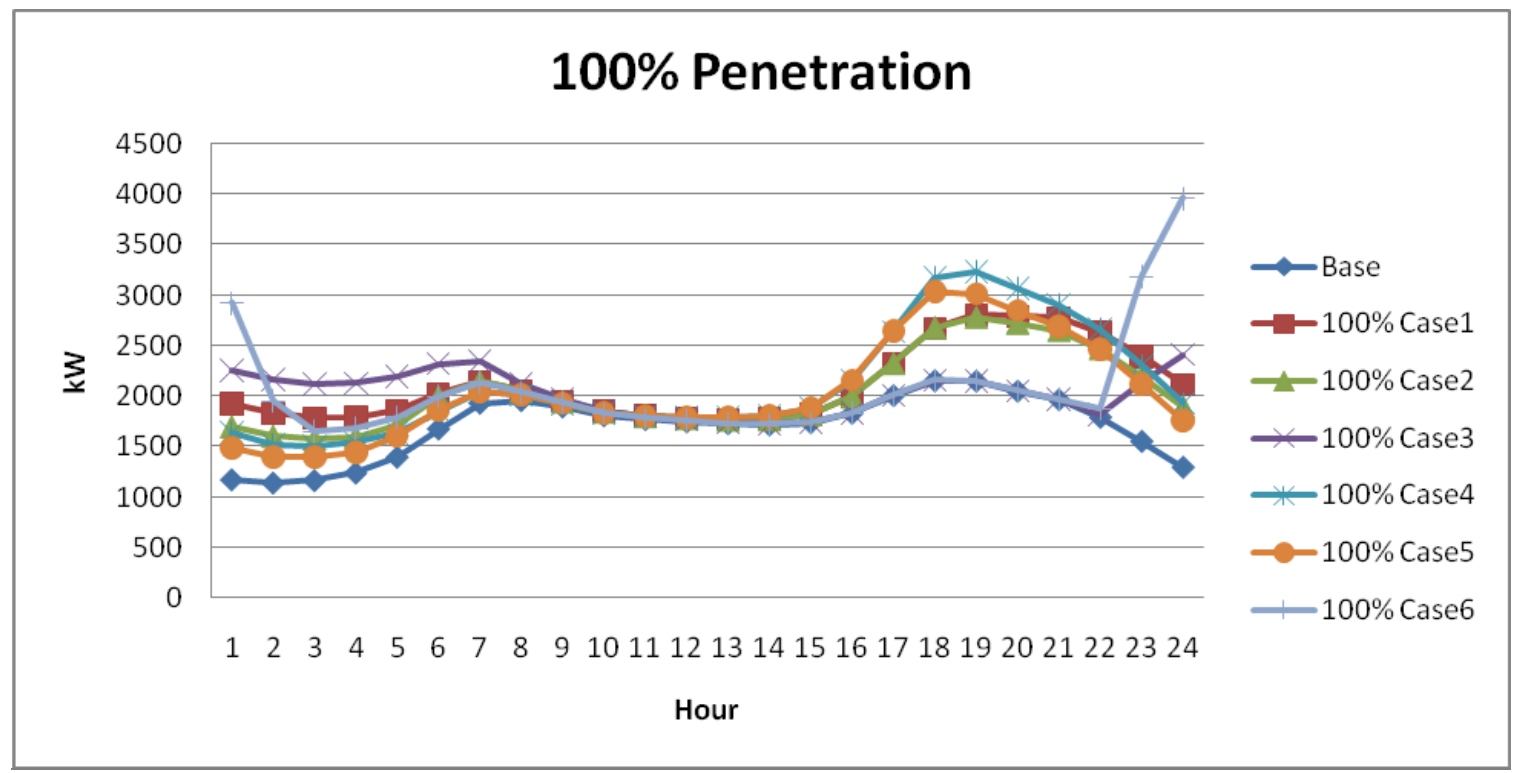

Figure 4-5: Franklin PUD Representative Feeder Load Curve for 100\% PHEV Penetration

\subsubsection{PSE Distribution System}

The devices that are prone to failure as a result of overloading are shown in Figures 4-6 and 4-7 for the various charging cases and penetration rates considered in the PSE system study 


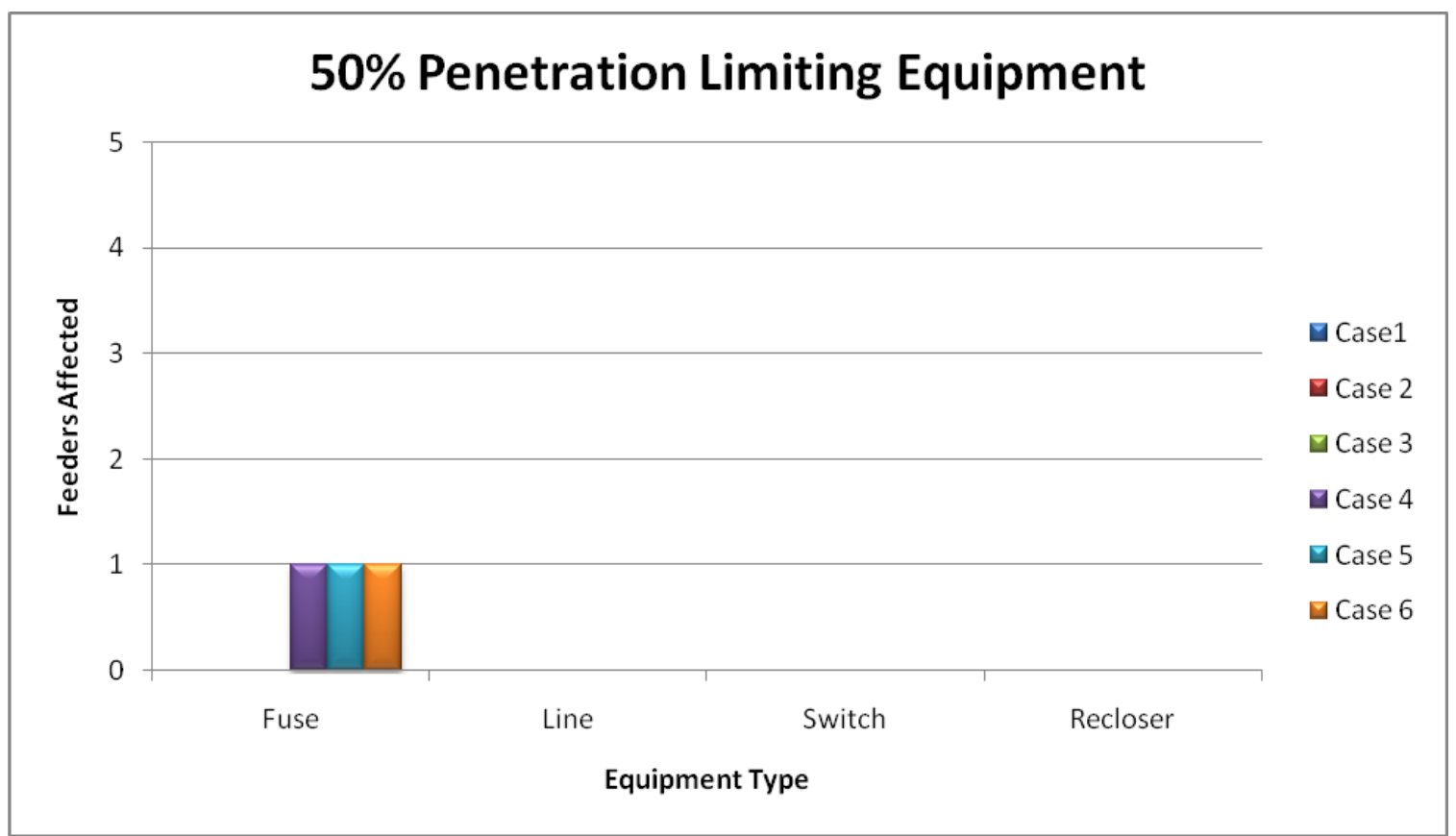

Figure 4-6: Number of PSE Feeders with Equipment Failures by Type for 50\% PHEV Penetration

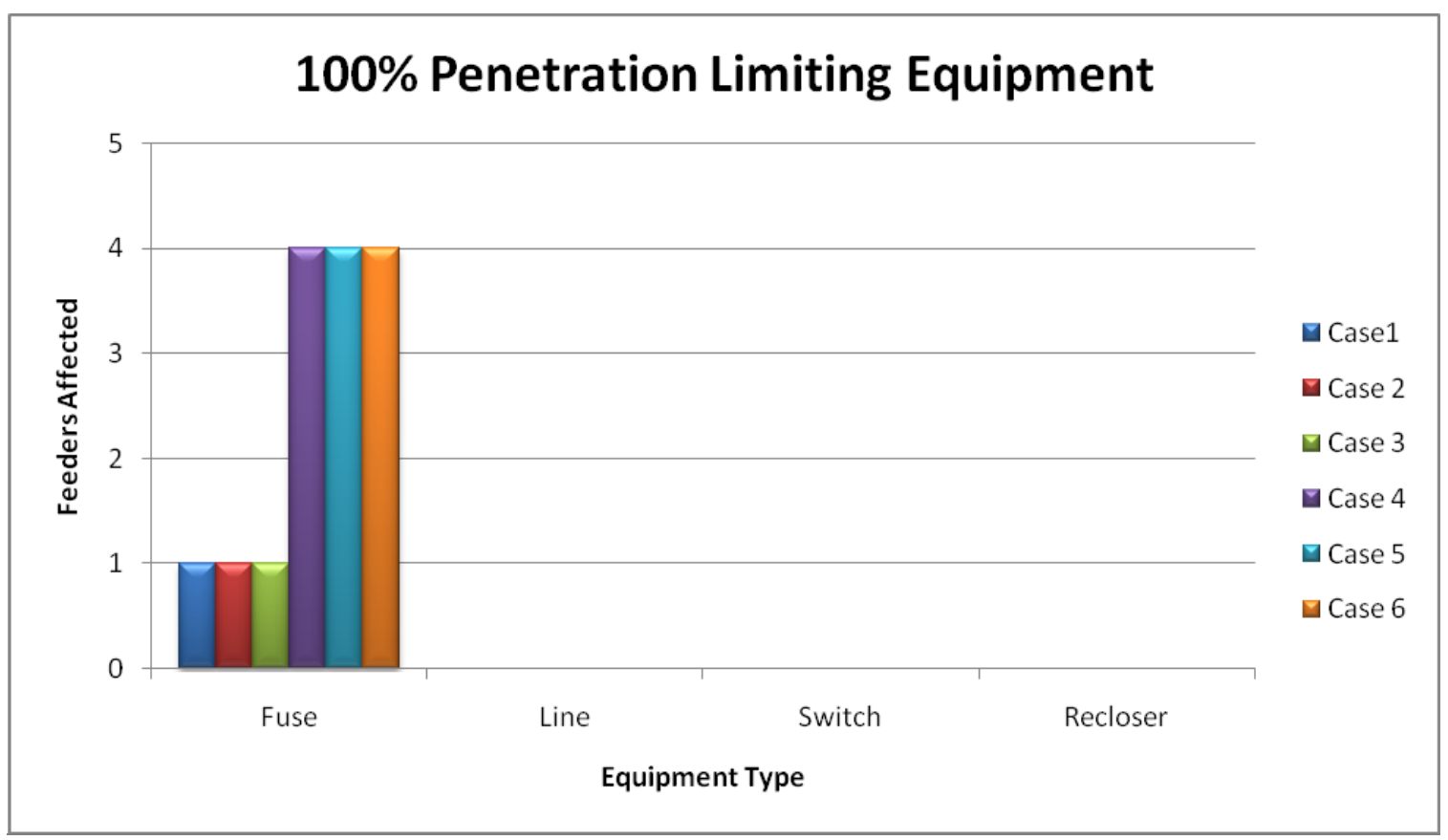

Figure 4-7: Number of PSE Feeders with Equipment Failures by Type for 100\% PHEV Penetration

The number of feeders able to support the two PHEV penetration rates for the six different charging cases with no equipment failures are shown in Figure 4-8. 


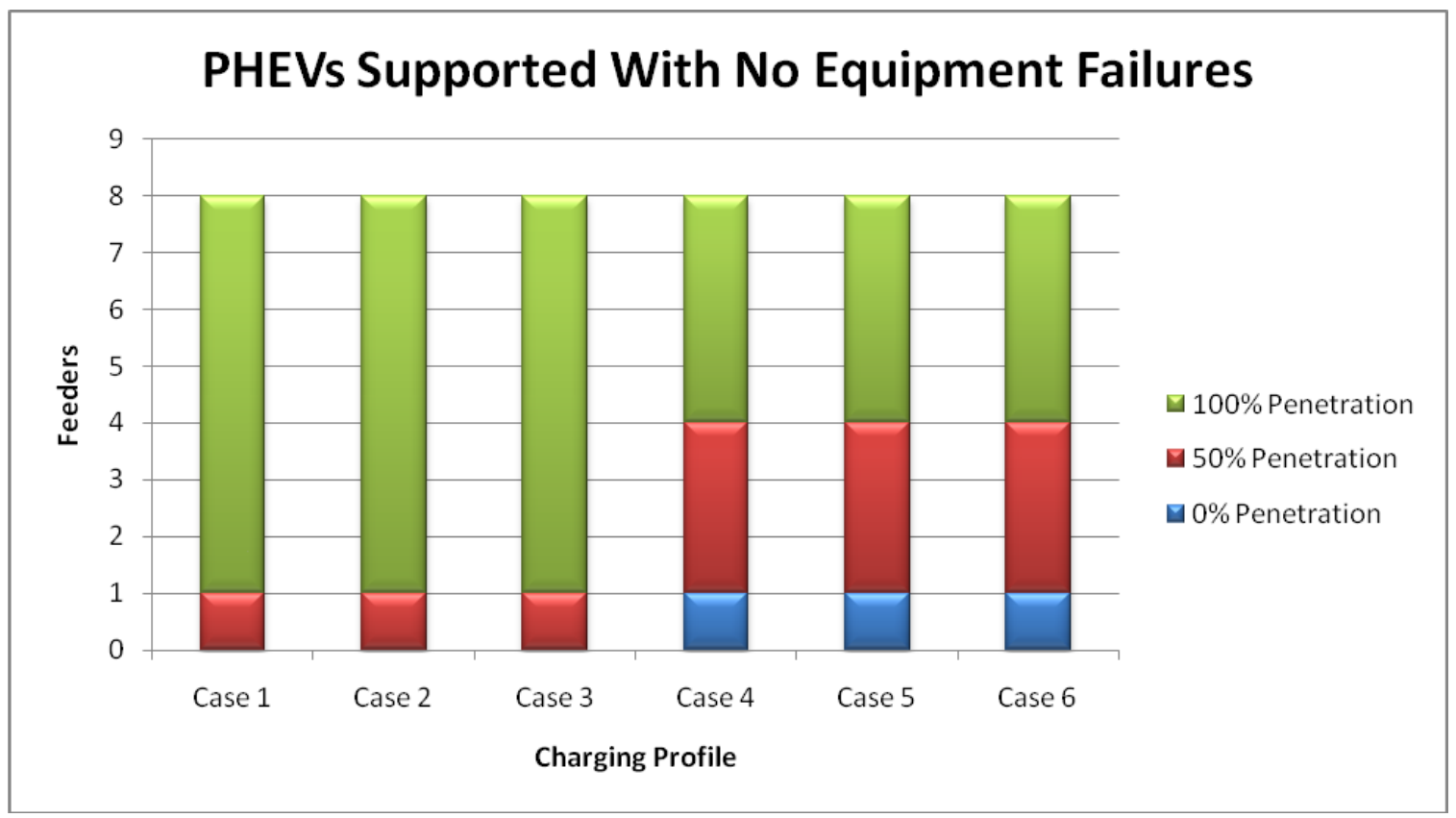

Figure 4-8: Number of PSE Feeders Supporting PHEV Penetrations With No Equipment Failures (note, total number of feeders is eight)

The load curves for a representative feeder comparing the base load to the various charging profiles for the two penetration rates in the PSE study are shown in Figures 4-9 and 4-10.

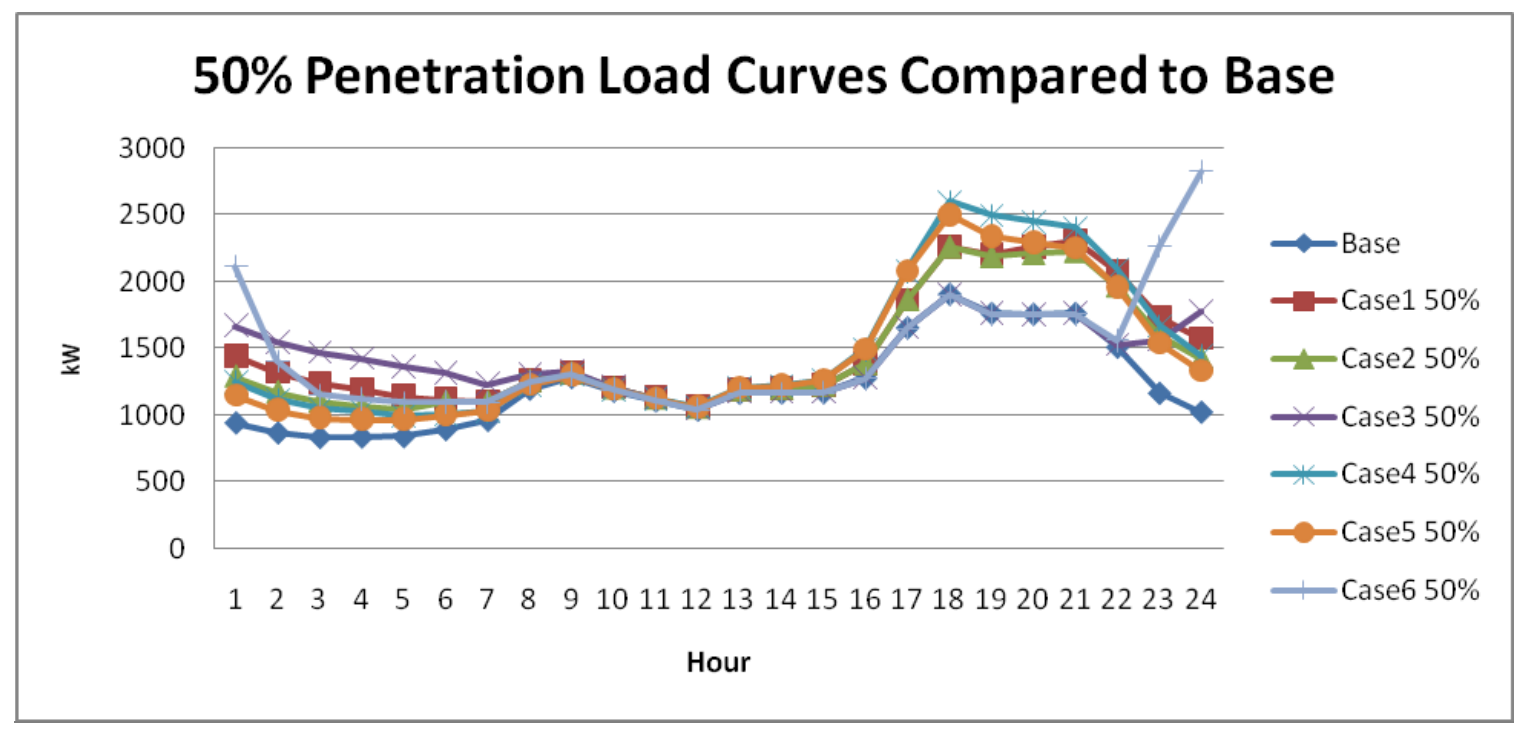

Figure 4-9: PSE Representative Feeder Load Curve for 50\% PHEV Penetration 


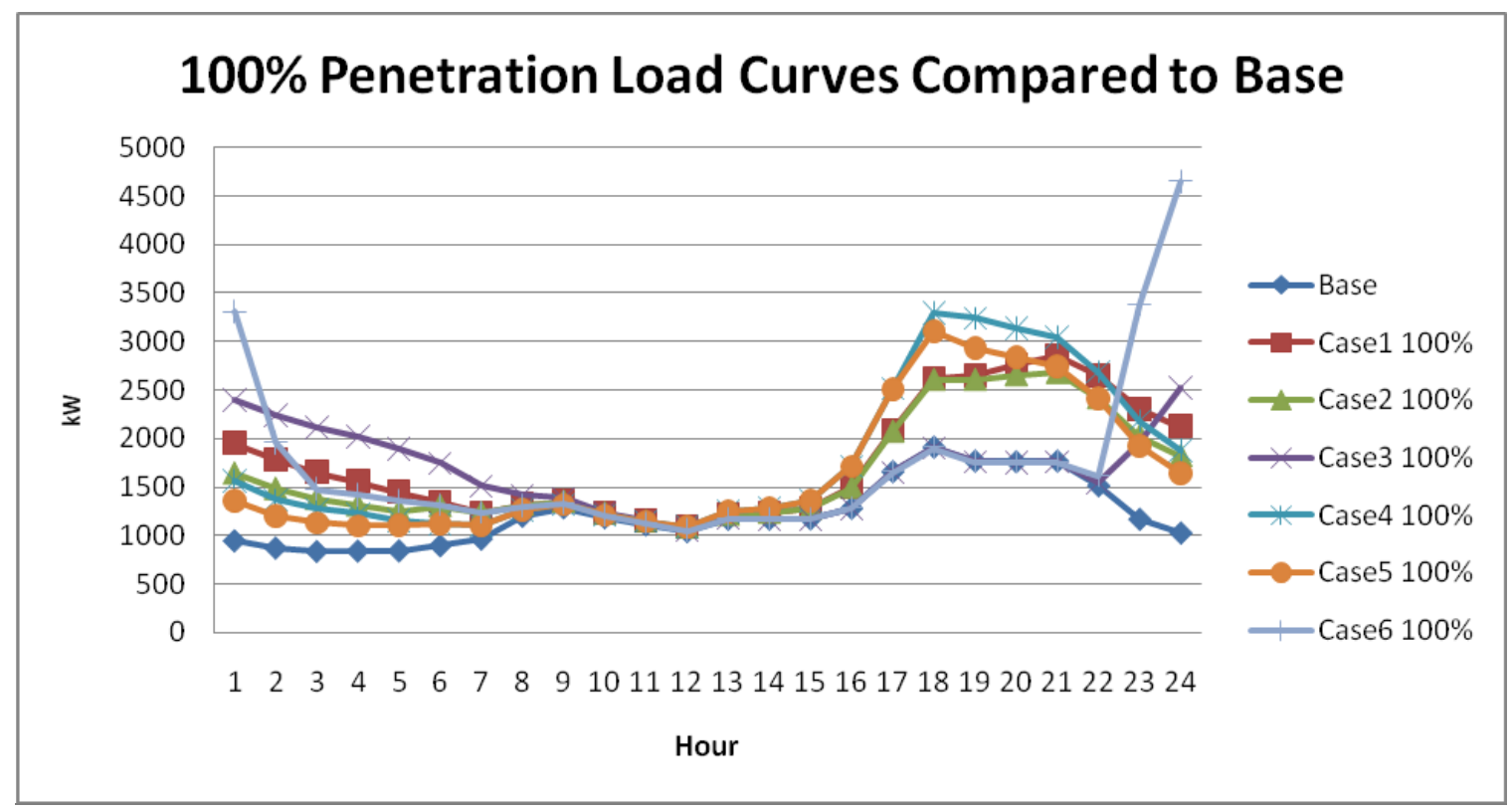

Figure 4-10: PSE Representative Feeder Load Curve for 100\% PHEV Penetration

\subsubsection{Snohomish PUD}

In the Snohomish PUD study, no device capacities were exceeded for the 50\% PHEV penetration rate in all of the eight representative residential feeders. The devices that failed from overloading at the 100\% PHEV penetration rate are listed in Figure 4-11 for the various charging cases.

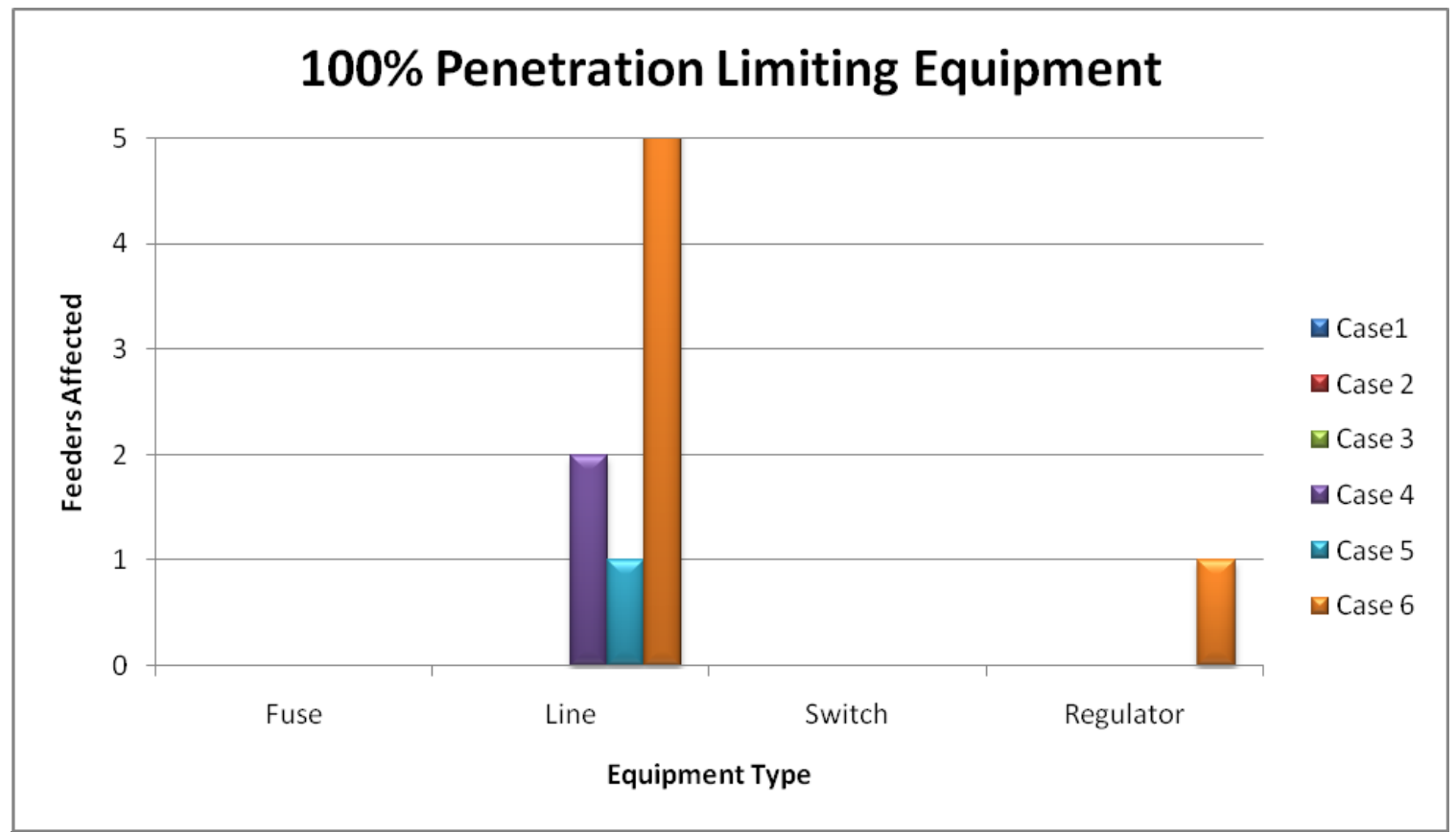

Figure 4-11: Number of Snohomish PUD Feeders with Equipment Failures by Type for 100\% PHEV Penetration 
The number of feeders able to support the two penetration rates for the six different charging cases with no equipment failures in the Snohomish PUD study are shown in Figure 4-12.

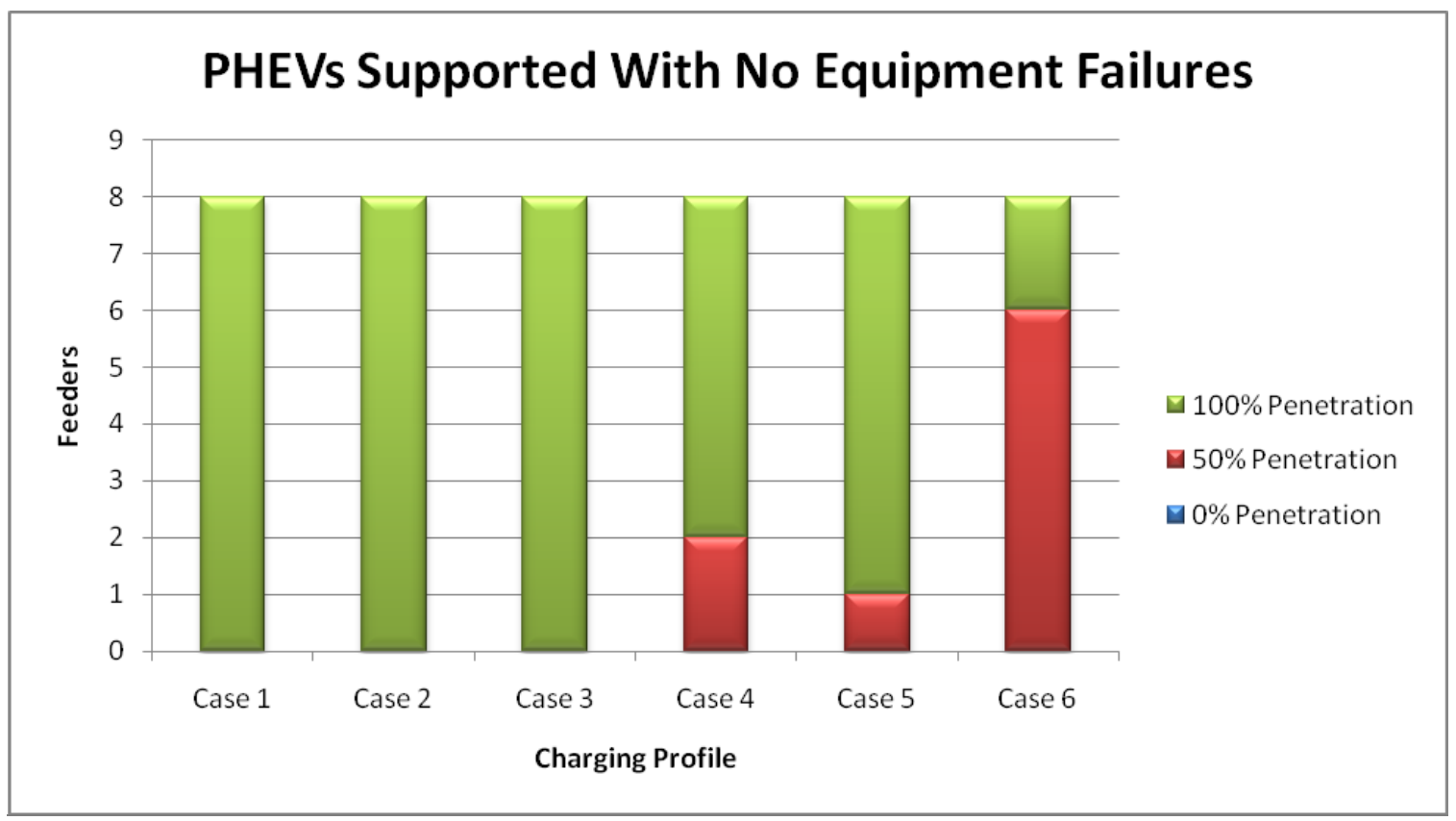

Figure 4-12: Number of Snohomish PUD Feeders Supporting PHEV Penetrations with No Equipment Failures (note, total number of feeders is eight)

The load curves for a representative feeder comparing the base load to the various charging profiles for the two penetration rates in the Snowhomish study are shown in Figures 4-13 and 4-14.

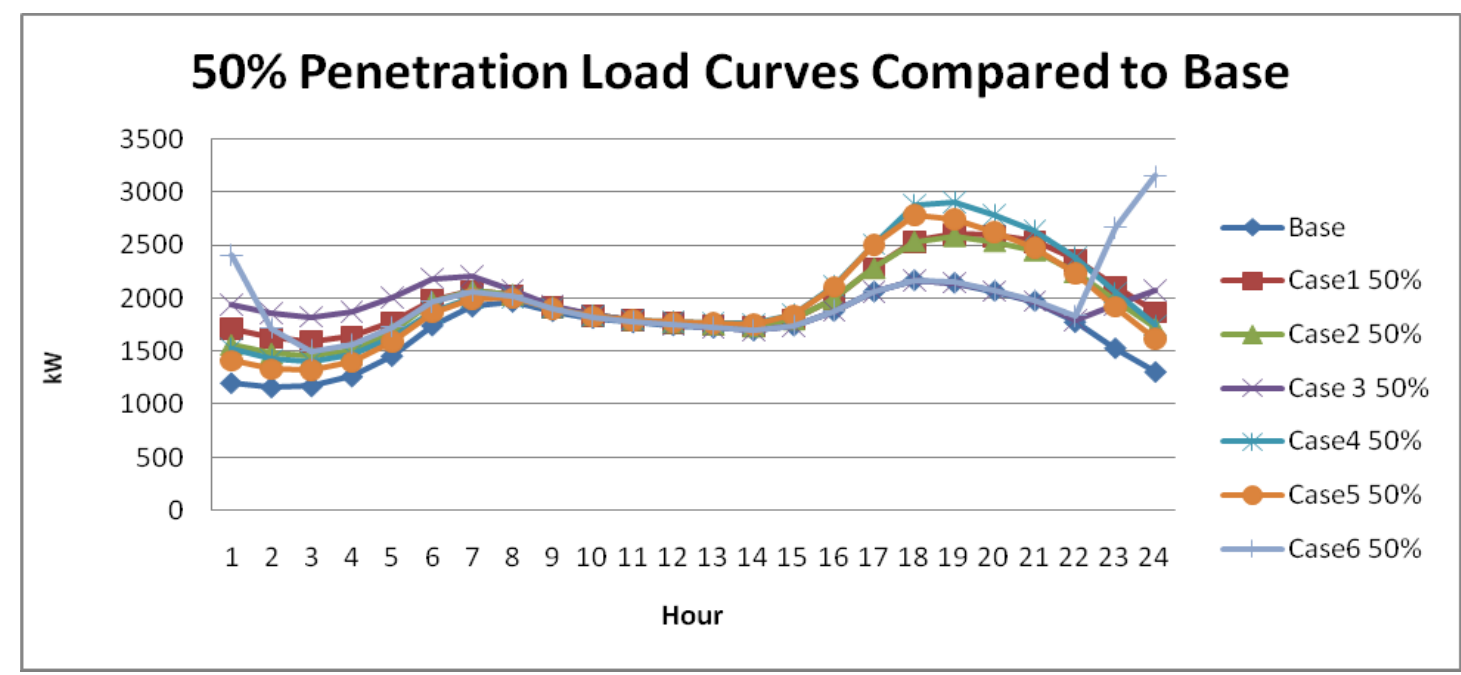

Figure 4-13: Snohomish PUD Representative Feeder Load Curve for 50\% PHEV Penetration 


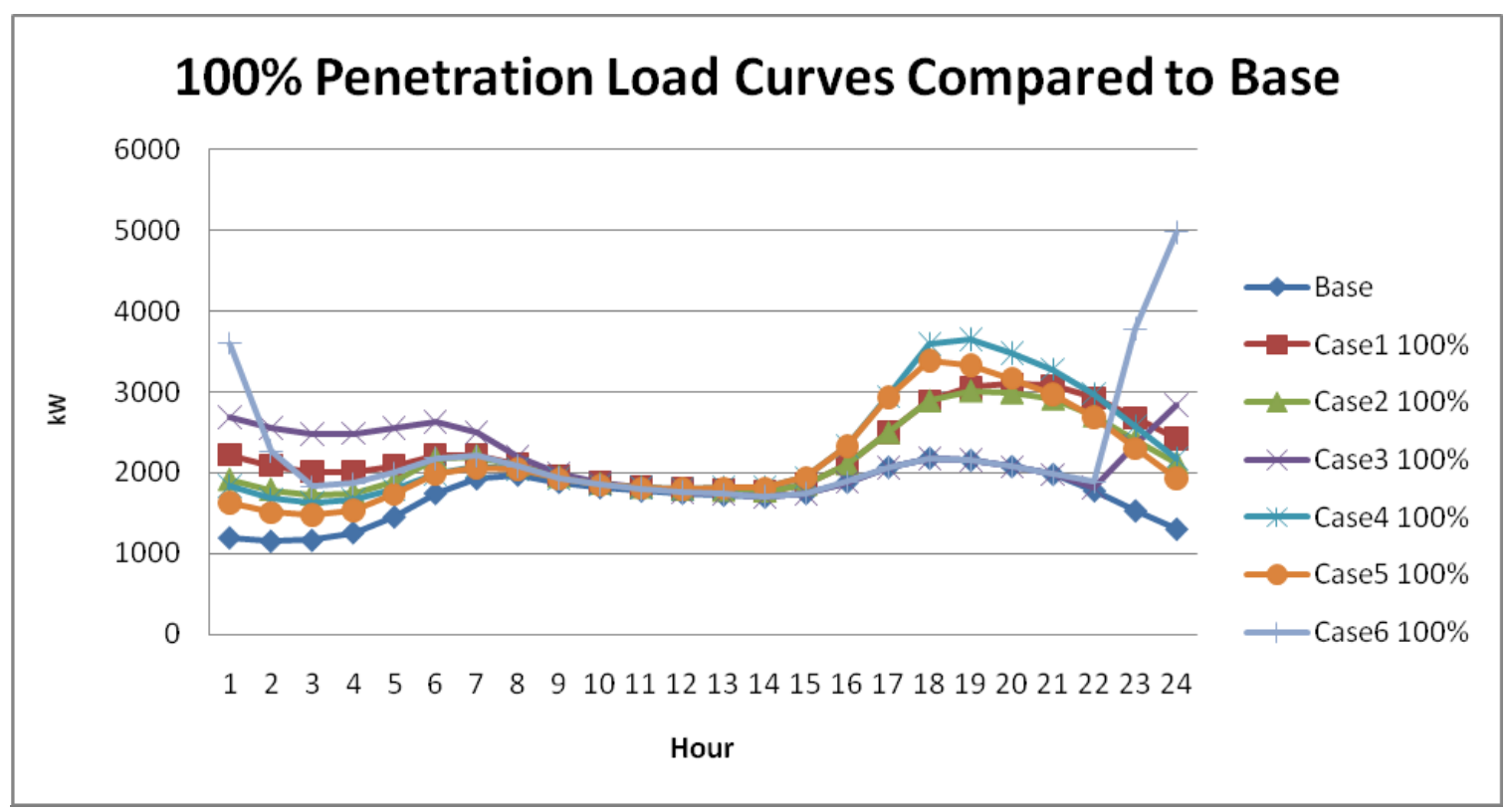

Figure 4-14: Snohomish PUD Representative Feeder Load Curve for 100\% PHEV Penetration

\subsection{Fast Charge Infrastructure Impacts}

In an earlier analysis (Schneider, et al. 2008), a quick charging scenario was investigated for feeders in the Pacific Northwest. In the quick charging scenario, it is assumed that all PHEVs would begin charging system-wide within a 3-hour period directly after people arrive home from work. The resulting charging profile is shown below in Figure 4-15. Impacts on the electrical distribution infrastructure of the quick charge scenario were evaluated using the same methodology as described above and presented below.

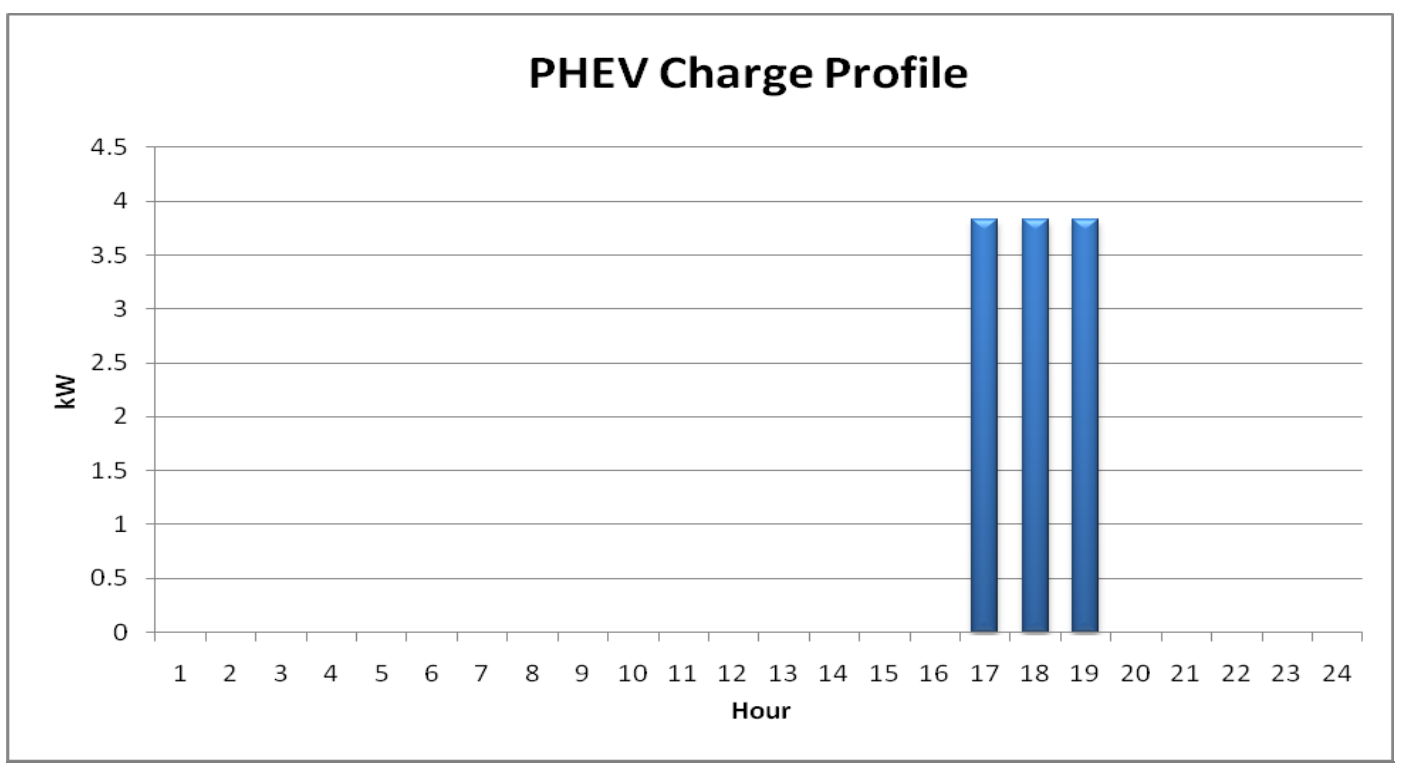

Figure 4-15: Quick Charge Scenario Charging Profile 


\subsubsection{Franklin PUD Results for Quick Charging}

Similar to the presentation of results in the previous section, equipment failures, feeder penetration support, and load curves are shown for Franklin PUD in Figures 4-16 to 4-18.

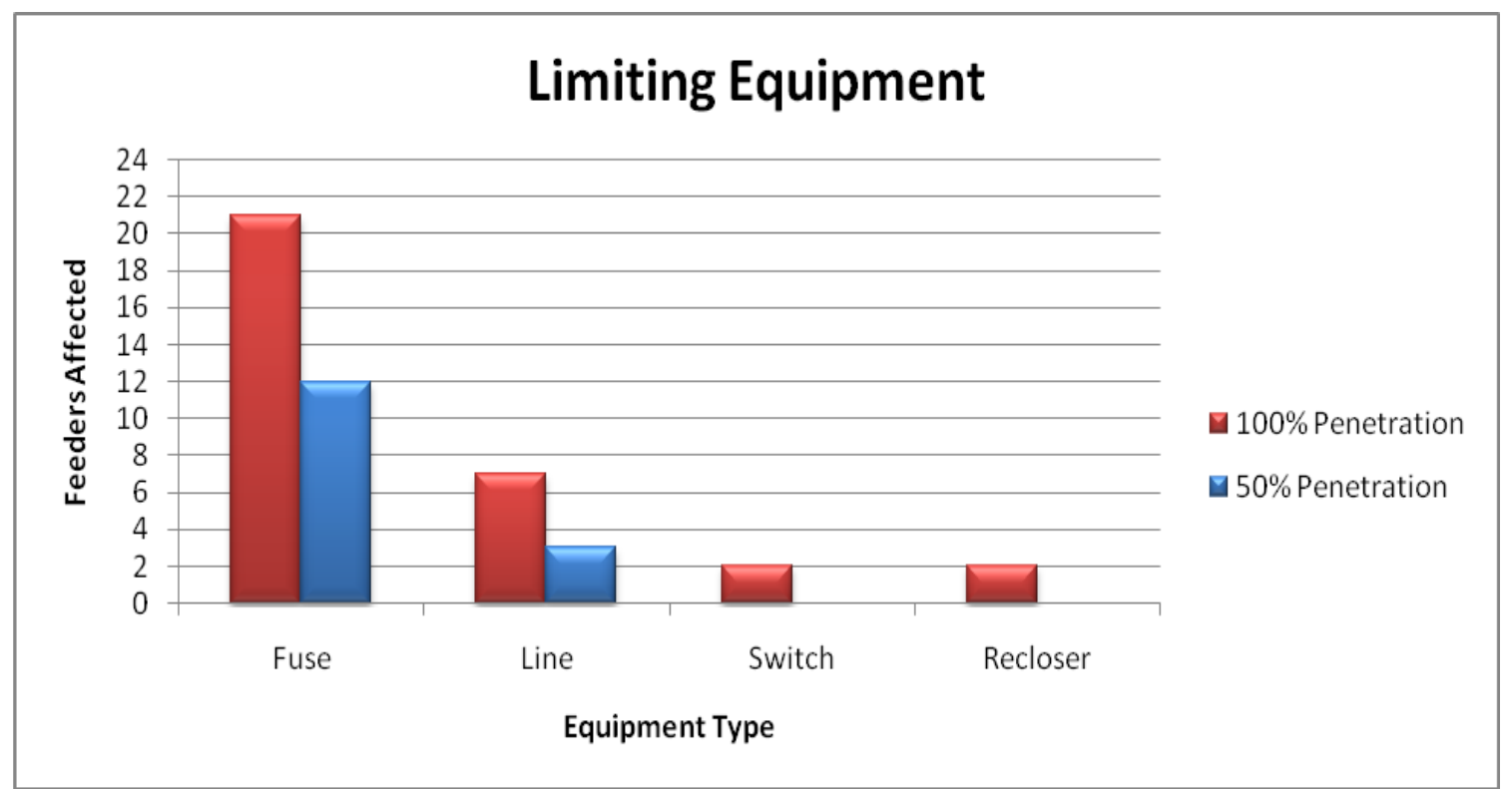

Figure 4-16: Number of Franklin PUD Feeders with Equipment Failures by Type in Quick Charge Scenario

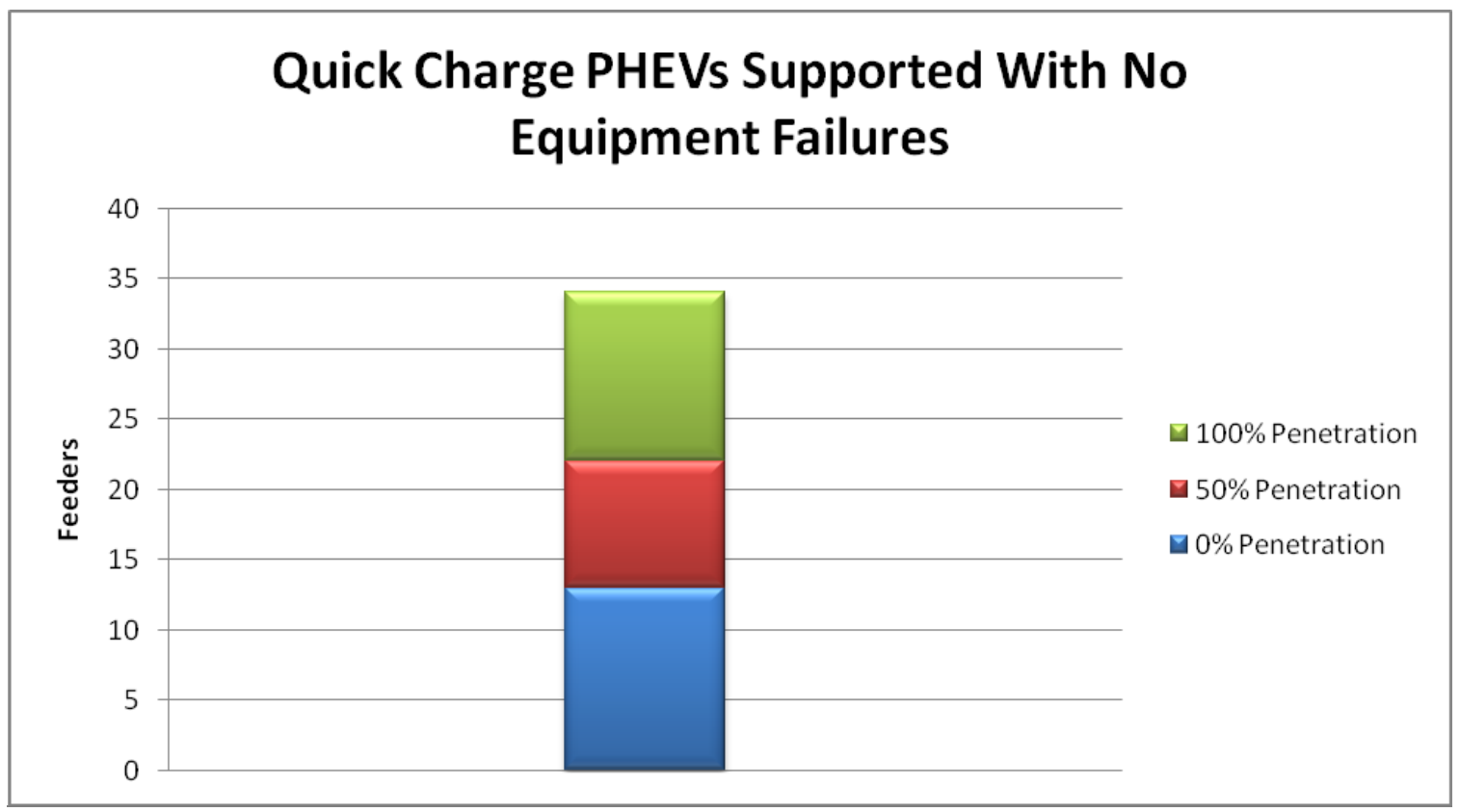

Figure 4-17: Number of Franklin PUD Feeders Supporting PHEV Penetrations With No Equipment Failures in Quick Charge Scenario 


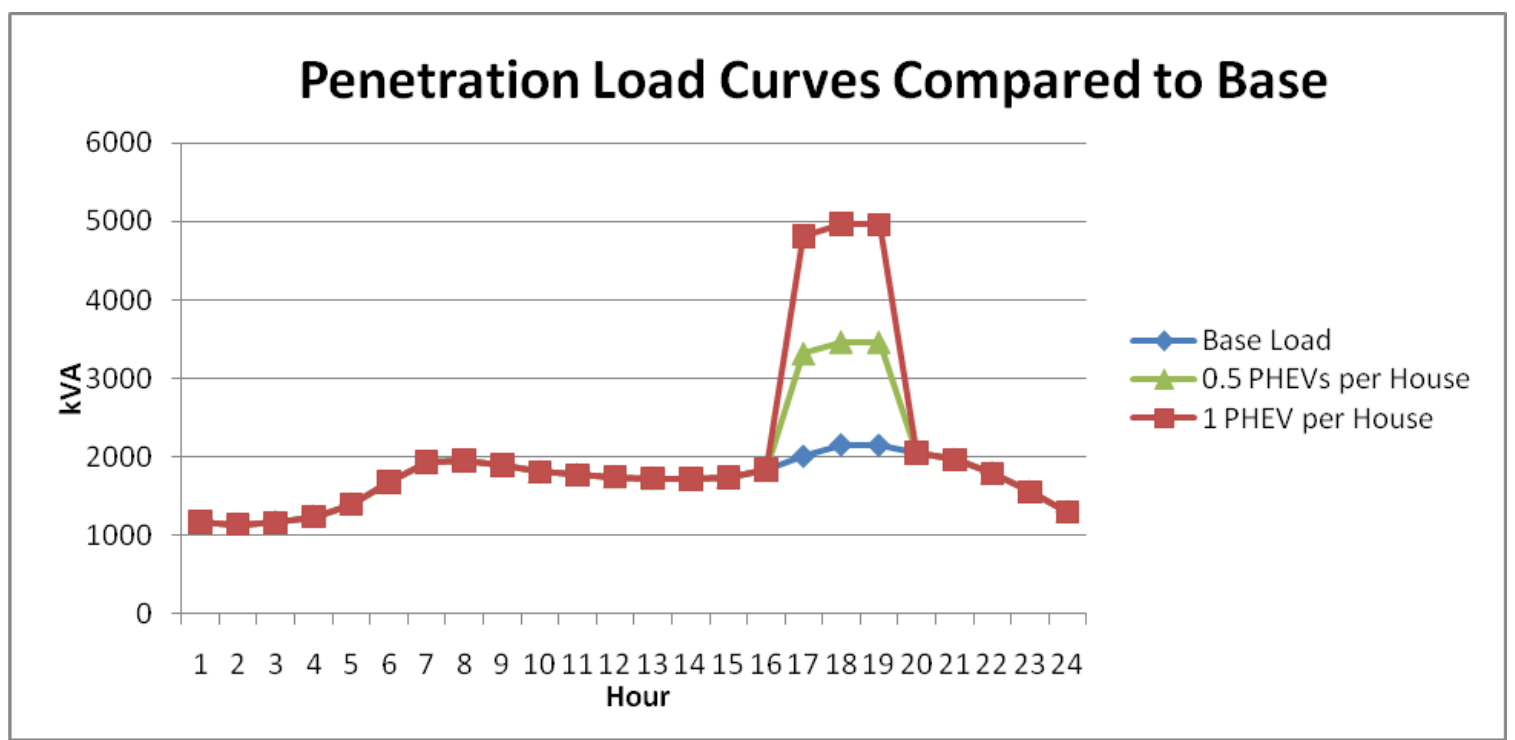

Figure 4-18: Franklin PUD Representative Feeder Load Curve in Quick Charge Scenario

\subsubsection{PES Results for Quick Charging}

The equipment failures, feeder penetration support, and load curves for the PSE system are shown in Figures 4-19 to 4-21.

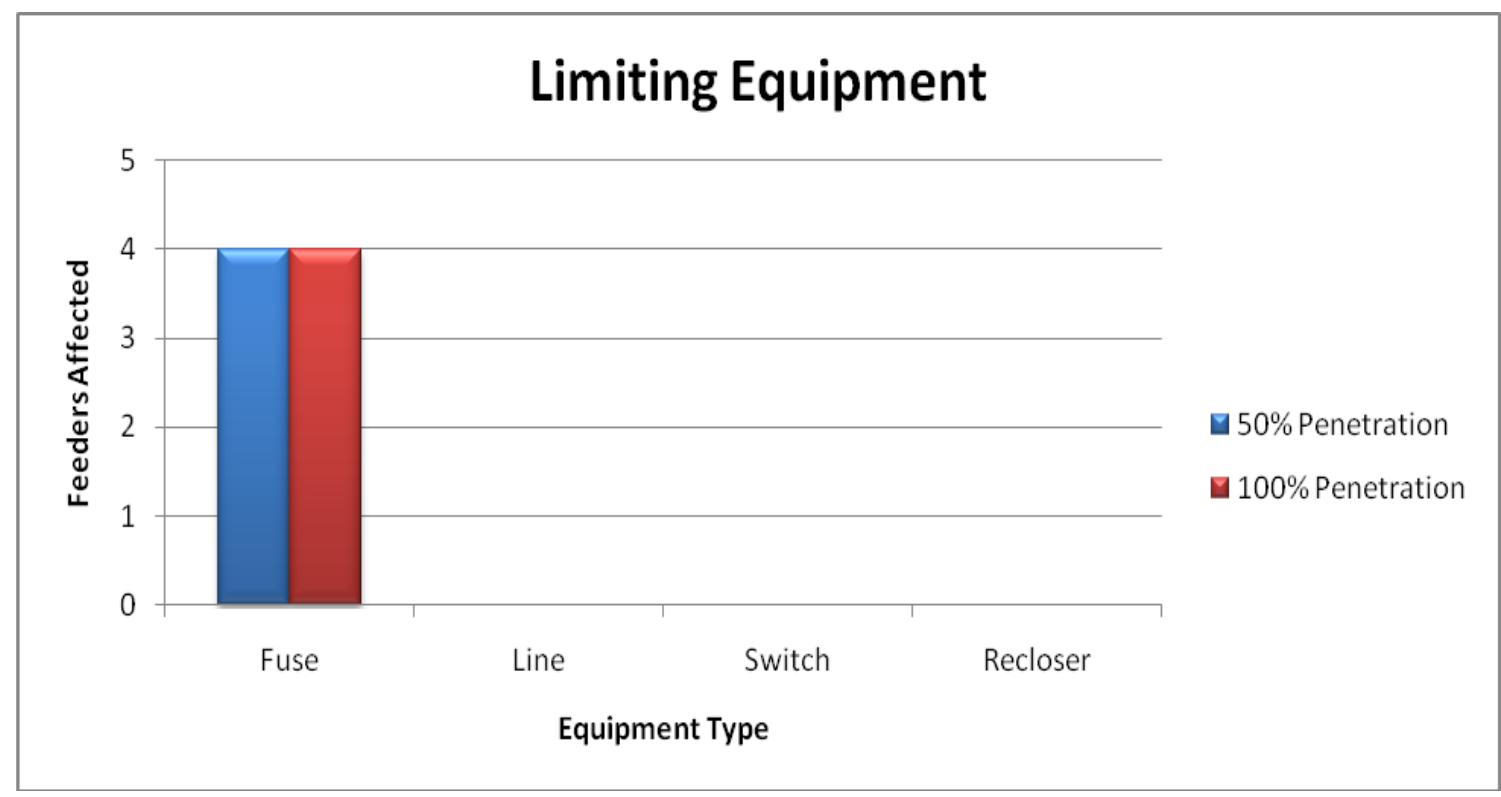

Figure 4-19: Number of PSE Feeders Supporting PHEV Penetrations With Equipment Failures by Type in Quick Charge Scenario 


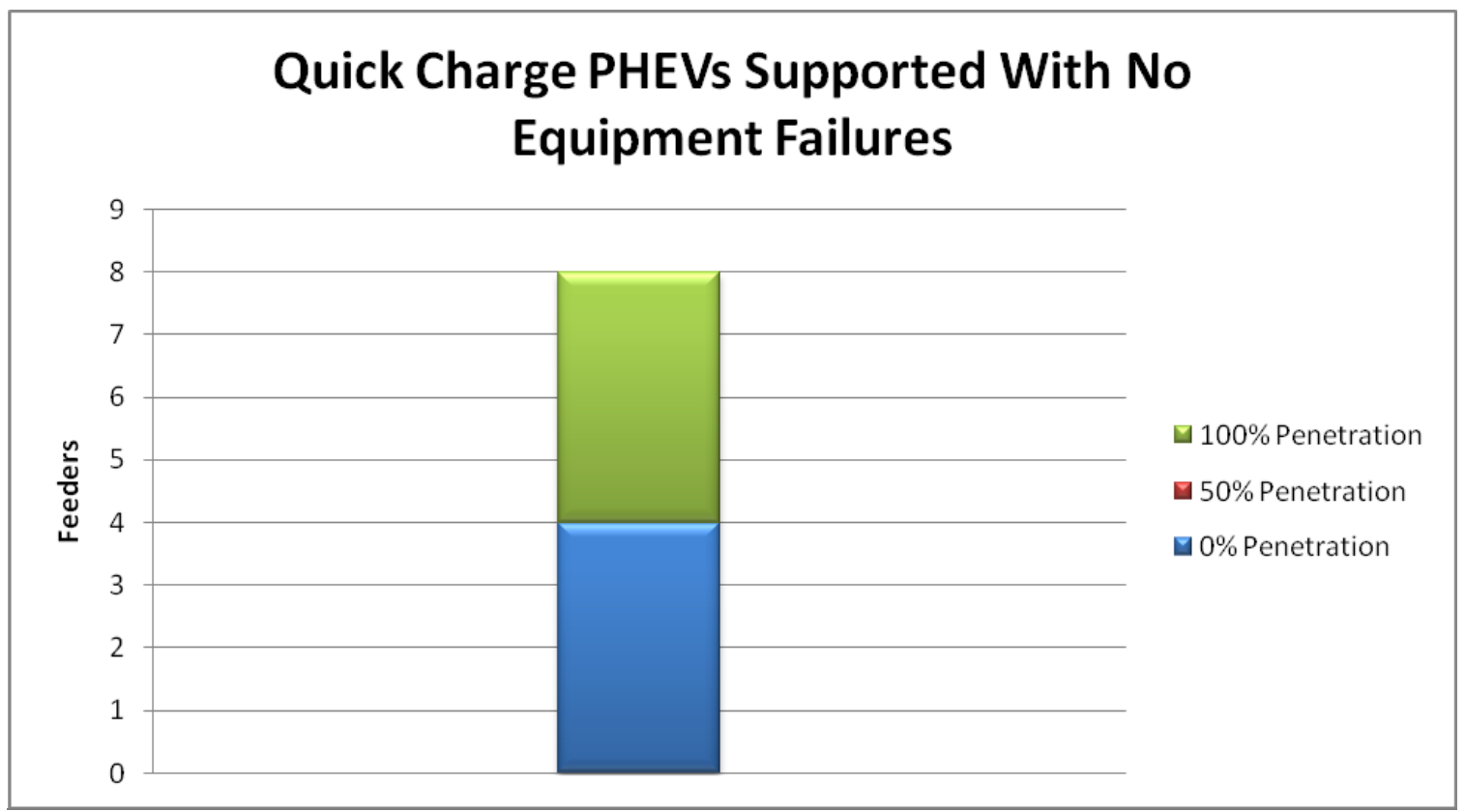

Figure 4-20: Number of PSE Feeders with No Equipment Failures in Quick Charge Scenario

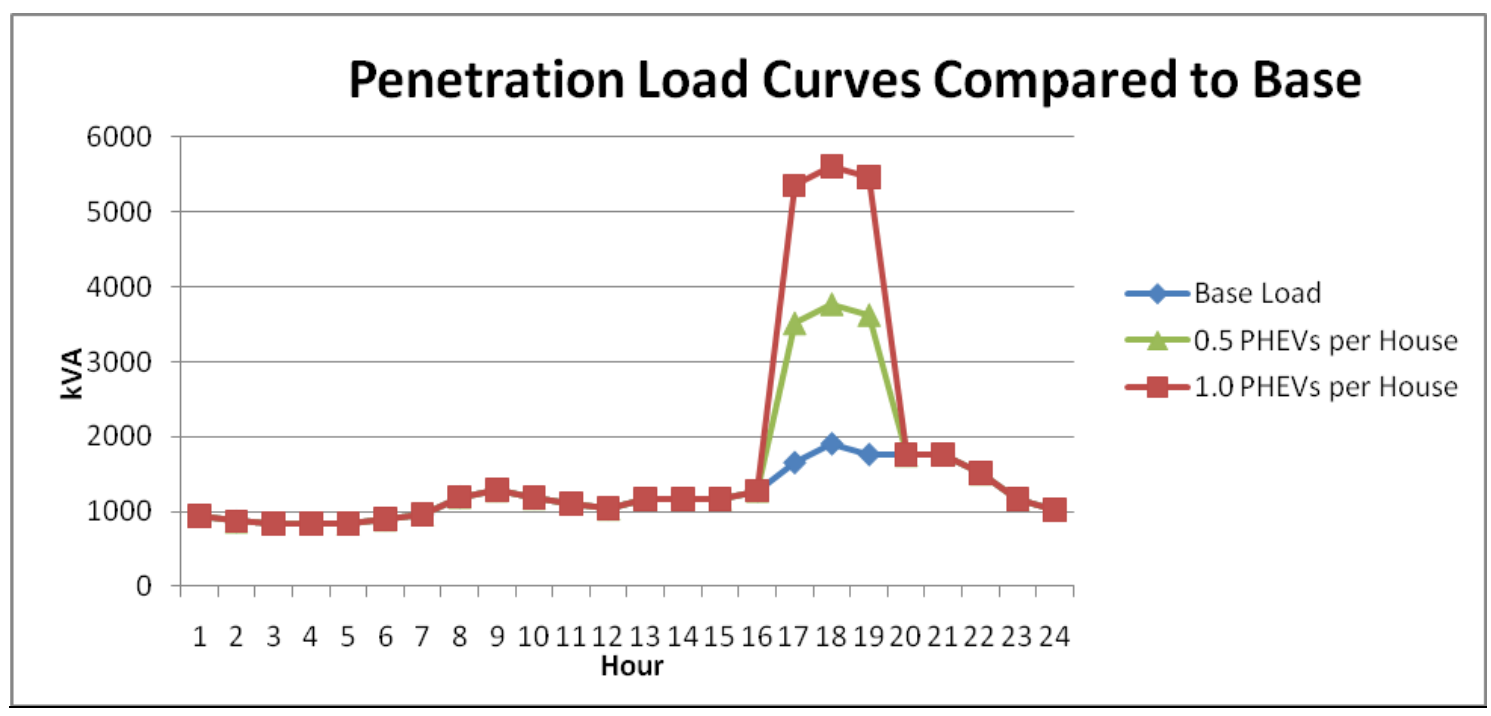

Figure 4-21: PSE Representative Feeder Load Curve for Quick Charge Scenario 


\subsubsection{Snohomish PUD Results for Quick Charging}

Snohomish PUD equipment failures, feeder penetration support, and load curves are shown in Figures 4-22 to 4-24 for the quick charge scenario.

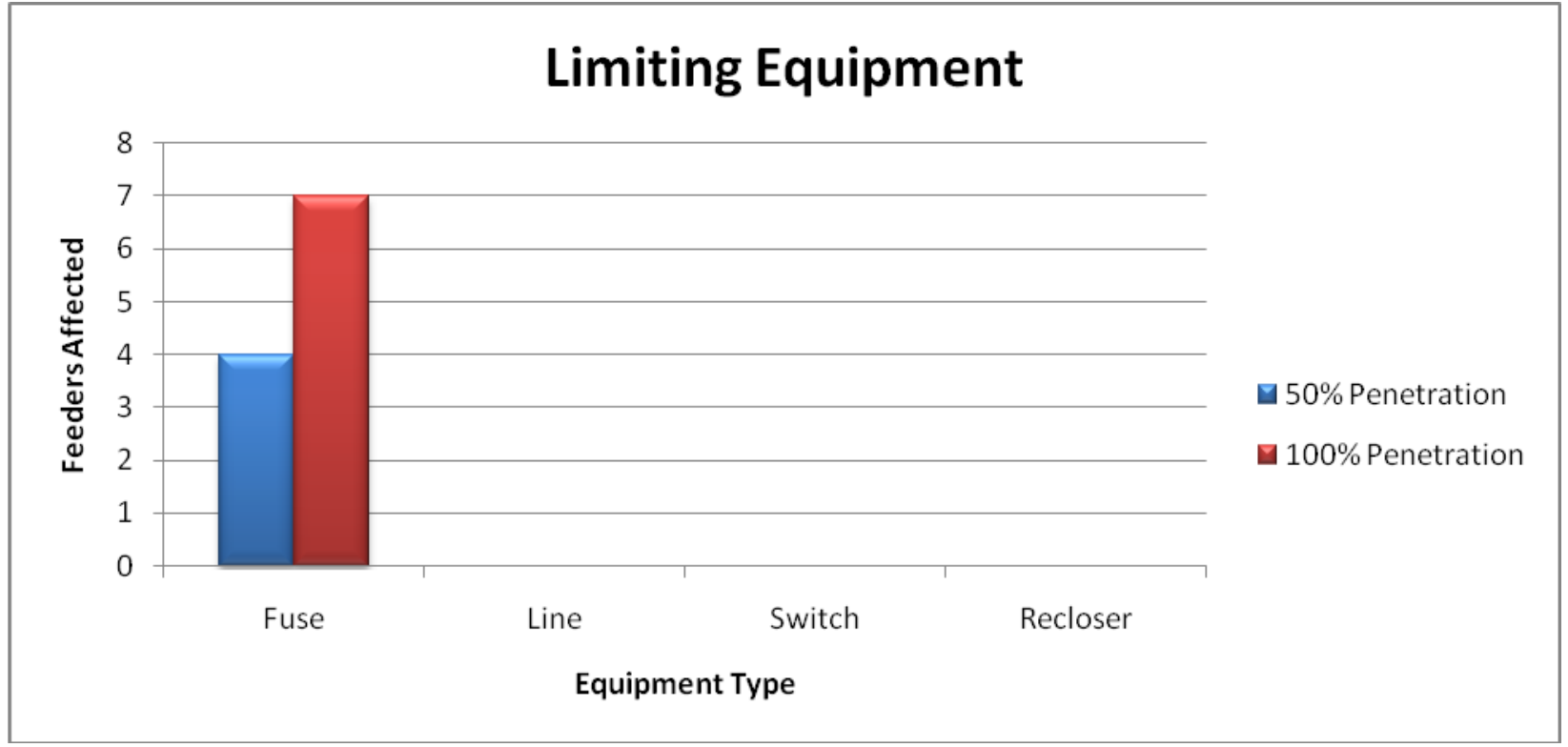

Figure 4-22: Number of Snohomish PUD Feeders Supporting PHEV Penetrations With Equipment Failures by Type in Quick Charge Scenario

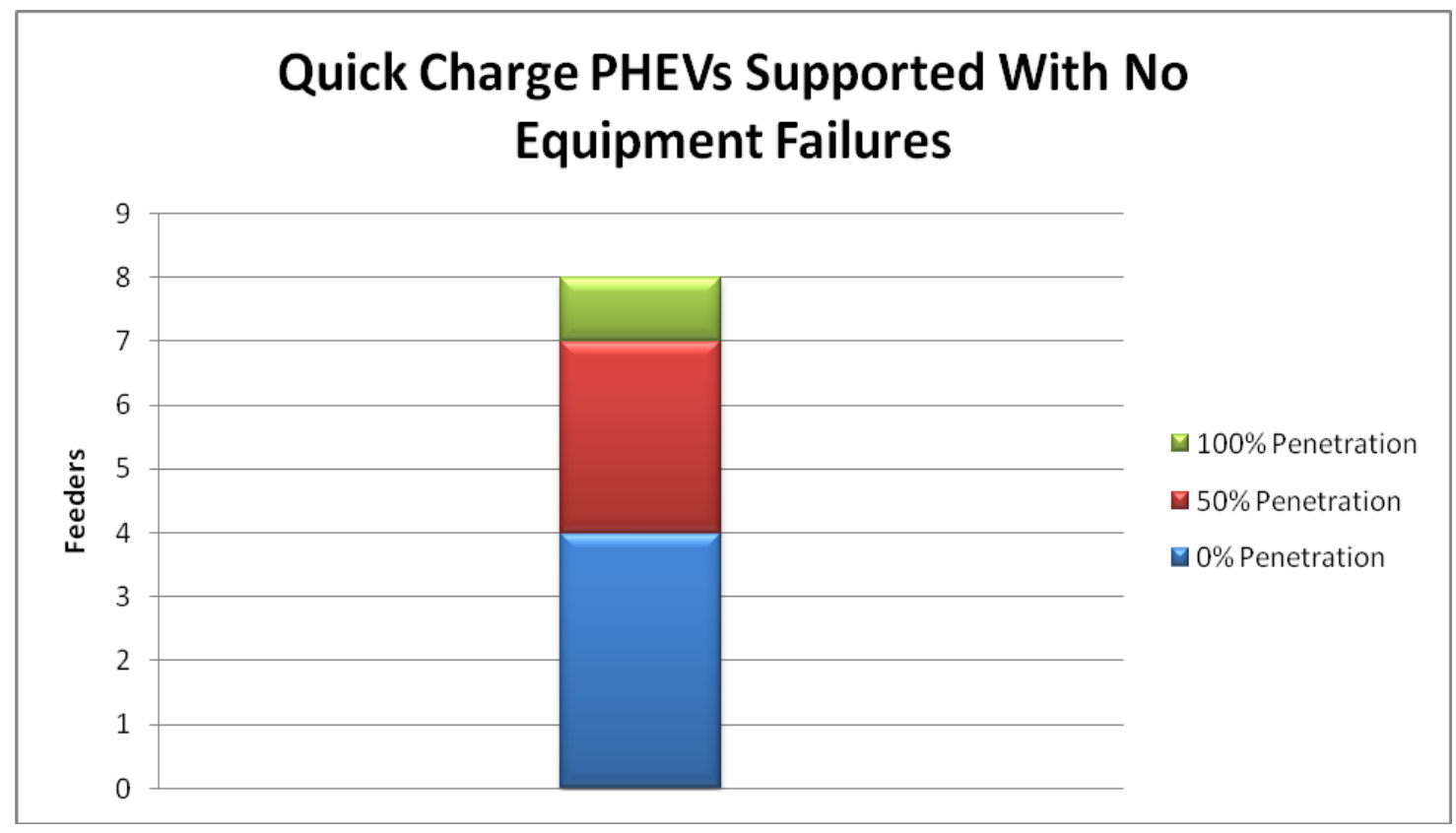

Figure 4-23: Number of Snohomish PUD Feeders with No Equipment Failures in Quick Charge Scenario 


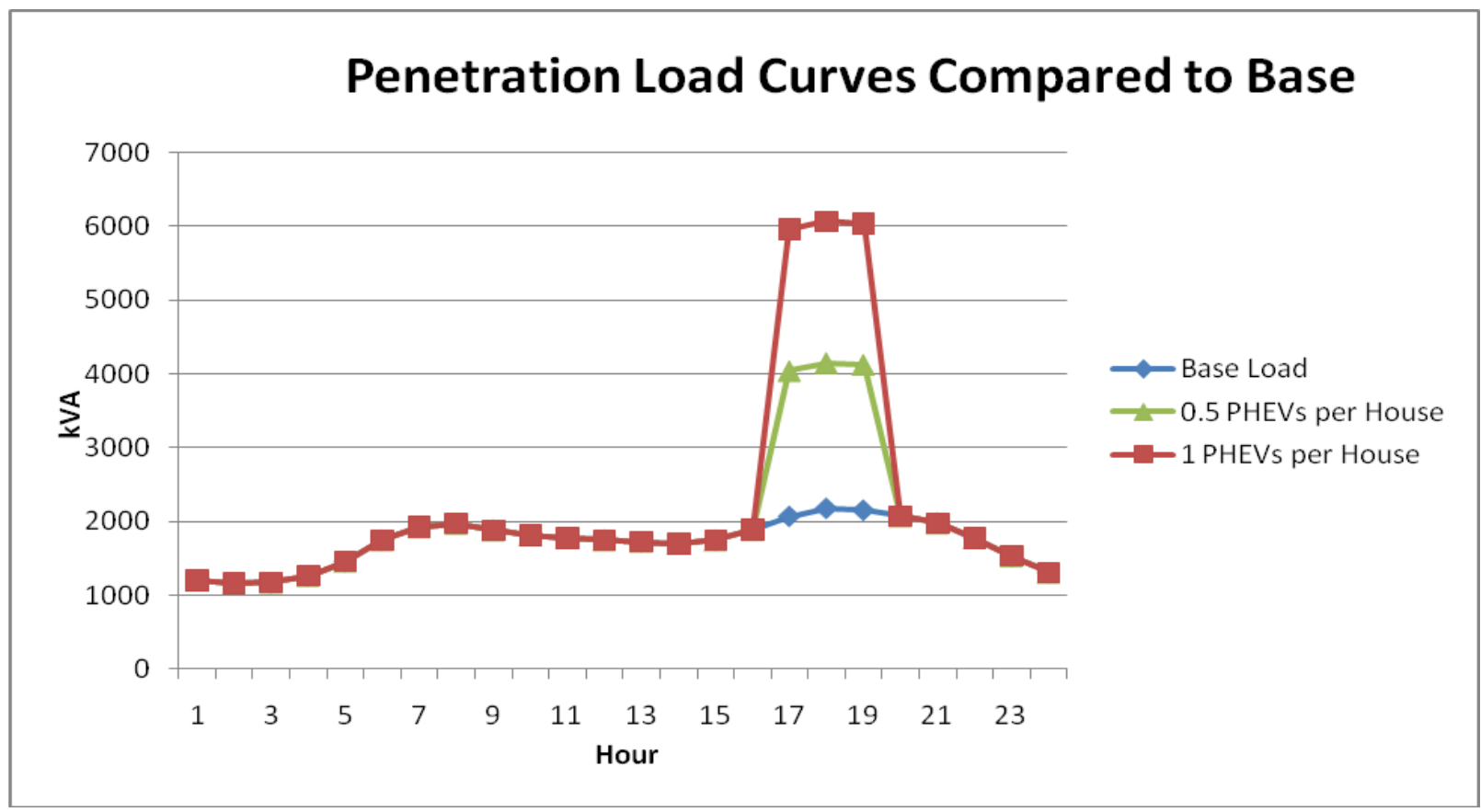

Figure 4-24: Snohomish PUD Representative Feeder Load Curve for Quick Charge Scenario

\subsection{Impacts on Secondary Distribution System Transformers}

The addition of a PHEV load can have a more significant impact on the individual distribution transformers than on the system as a whole. While overloading a transformer may not have obvious immediate impacts, when a transformer is loaded beyond its nameplate rating, the life of the transformer will be diminished based on the duration and the severity of the overload condition (IEEE Std. C57.91). In the second part of this study, load flow analyses were performed for each hour of a typical day to compare the rated $\mathrm{kVA}$ of each transformer with the peak load it experienced. The results are shown below.

\subsubsection{Franklin PUD Results for Transformers Analysis}

Franklin PUD loaded transformer capacity for the various charging cases and PHEV penetration rates are shown in Figures 4-25 to 4-30 in terms of number of transformers versus percentage of rated capacity. 


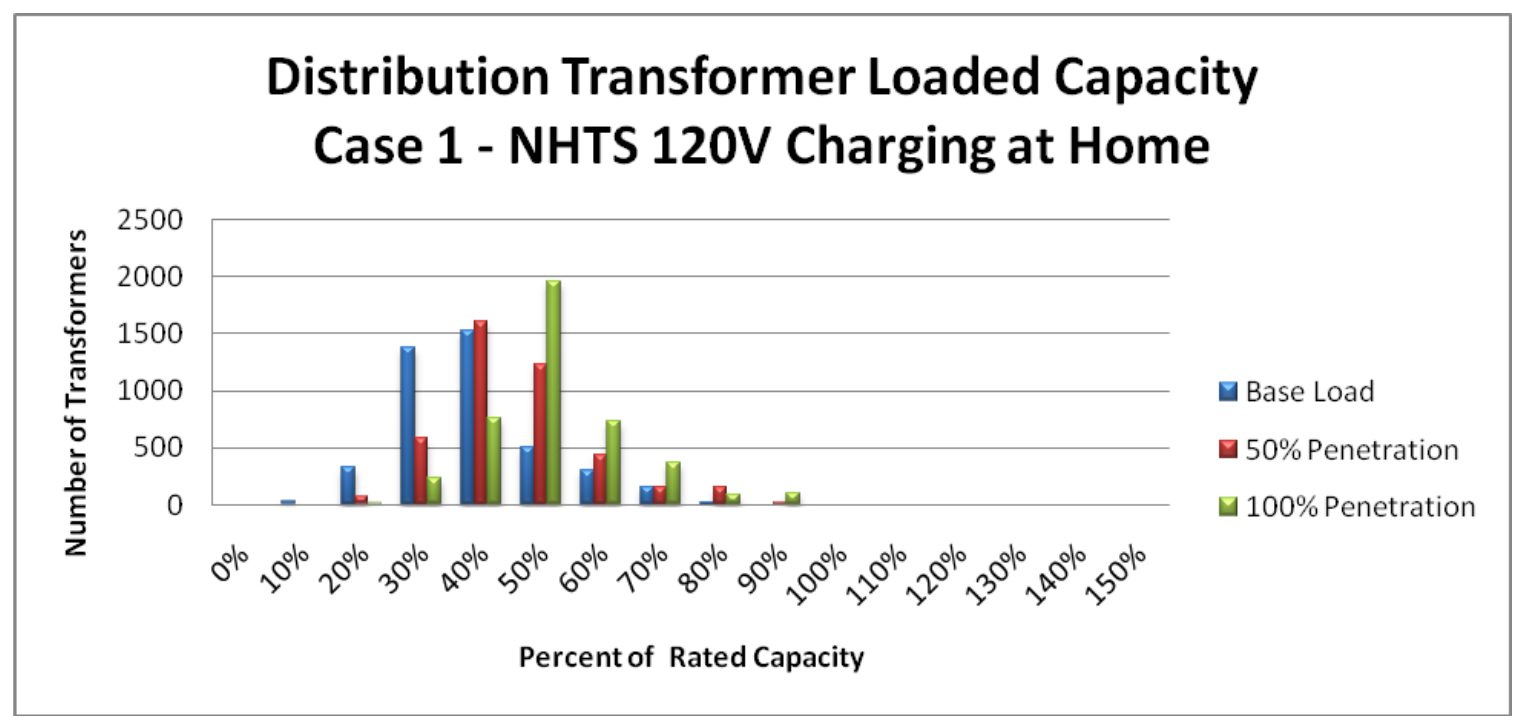

Figure 4-25: Franklin PUD Transformer Loading for Case 1

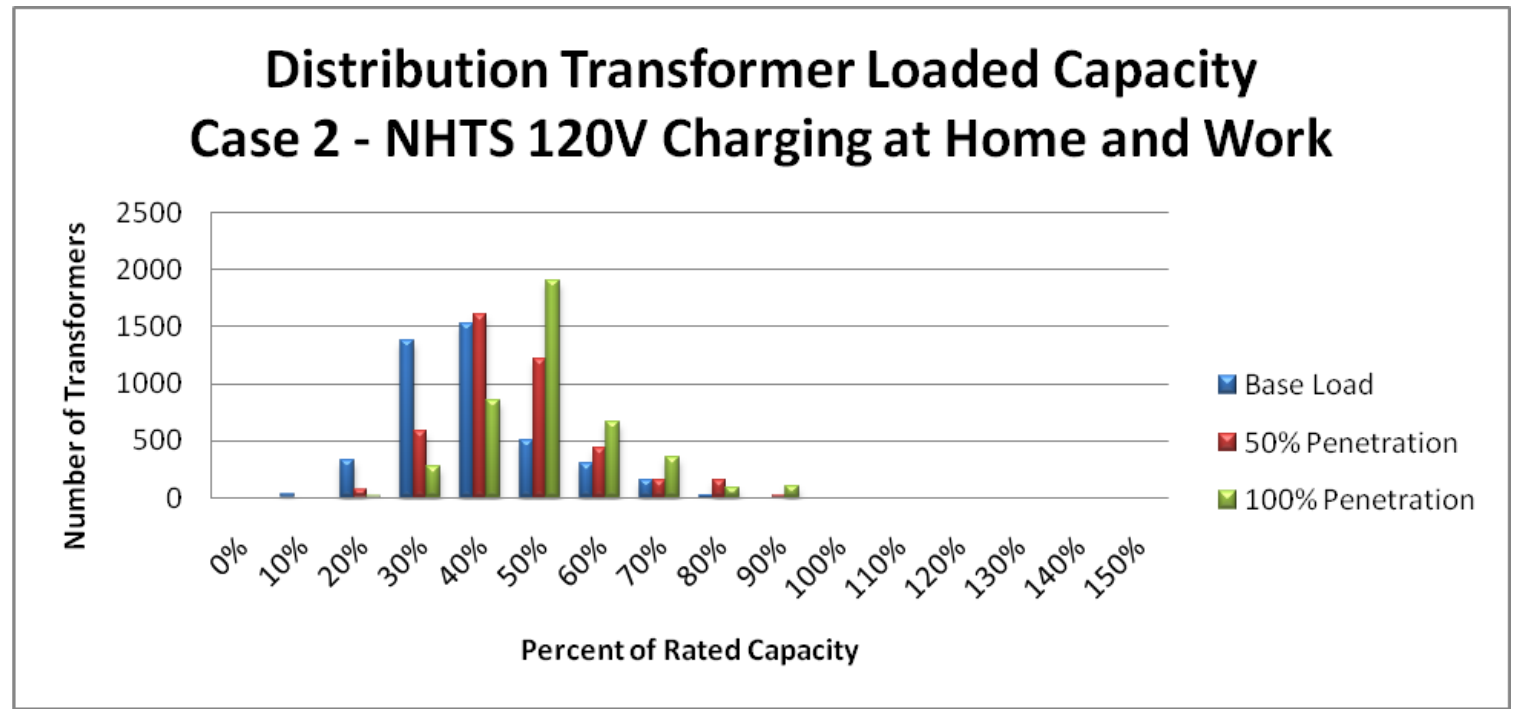

Figure 4-26: Franklin PUD Transformer Loading for Case 2 


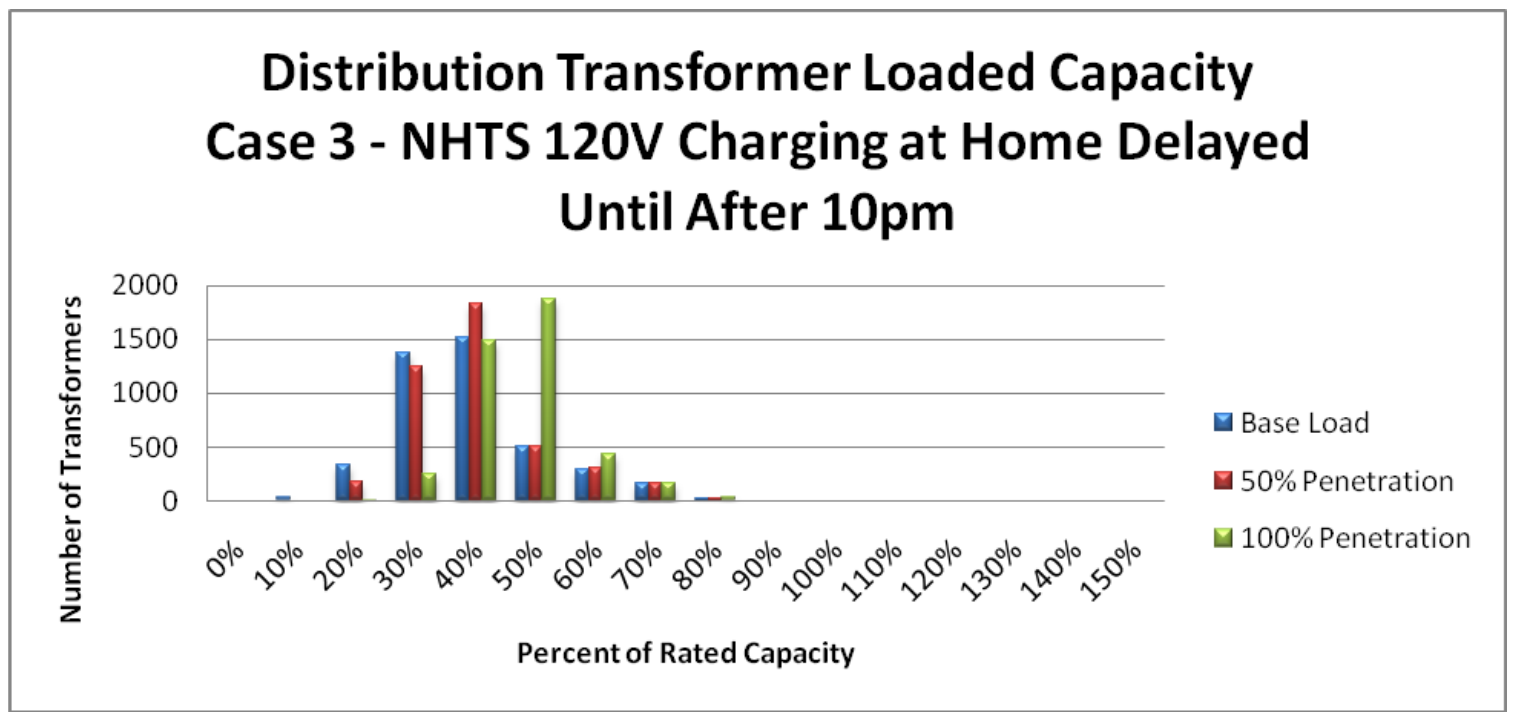

Figure 4-27: Franklin PUD Transformer Loading for Case 3

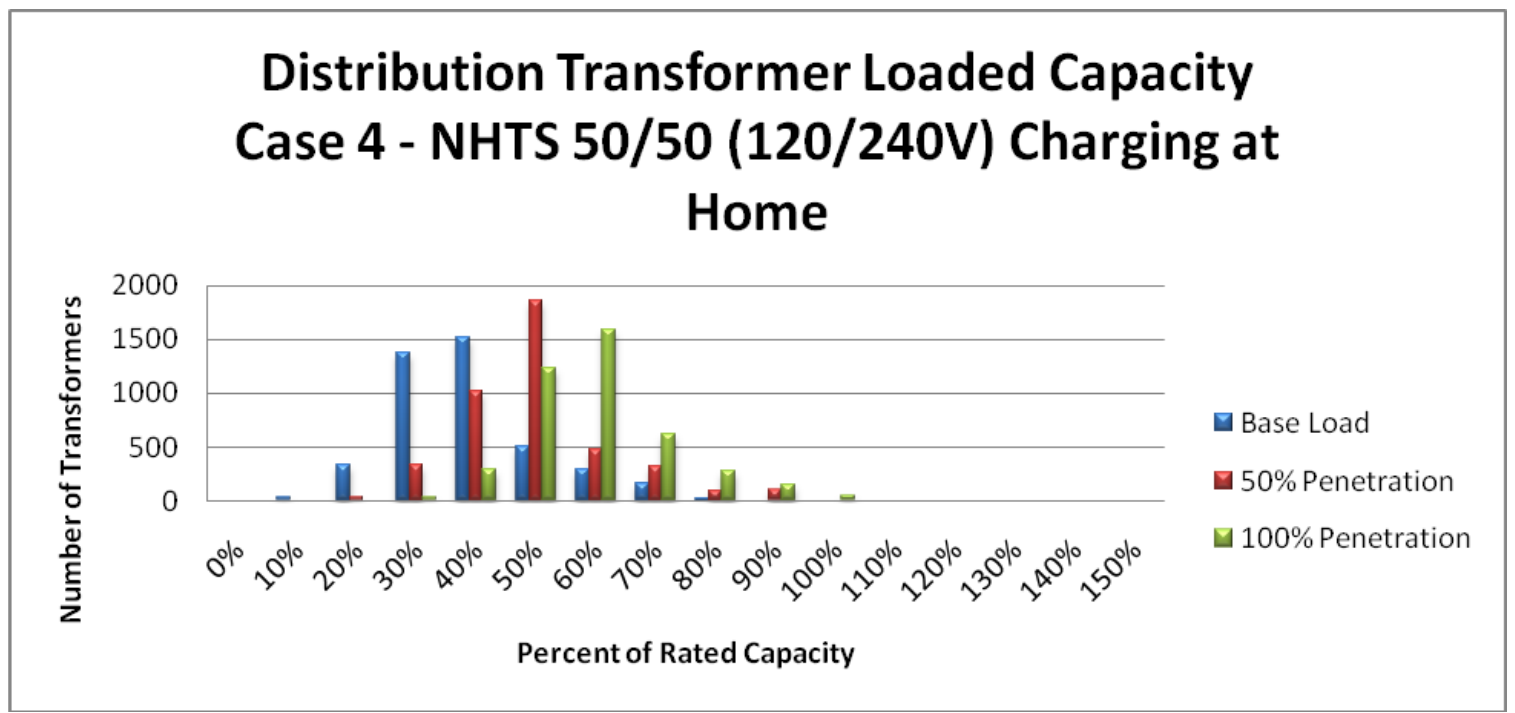

Figure 4-28: Franklin PUD Transformer Loading for Case 4 


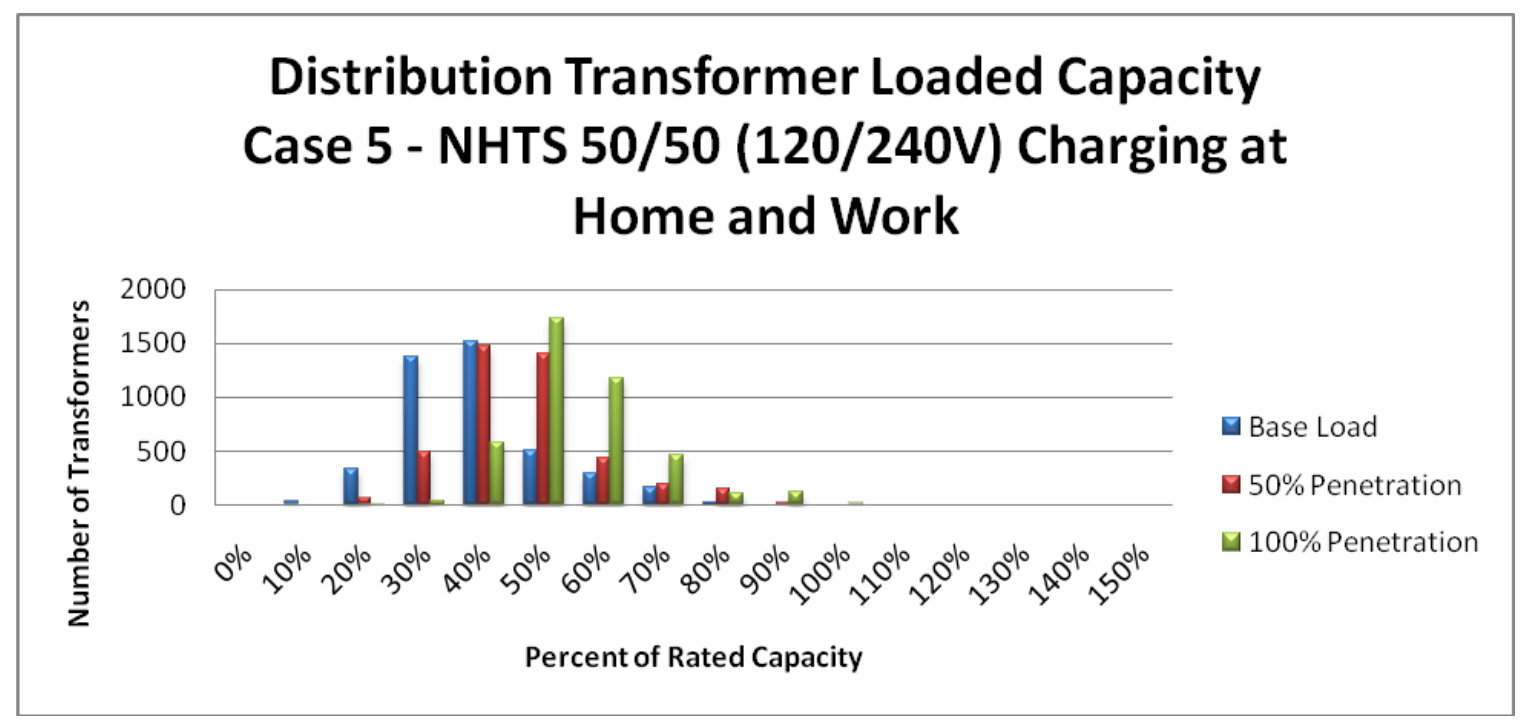

Figure 4-29: Franklin PUD Transformer Loading for Case 5

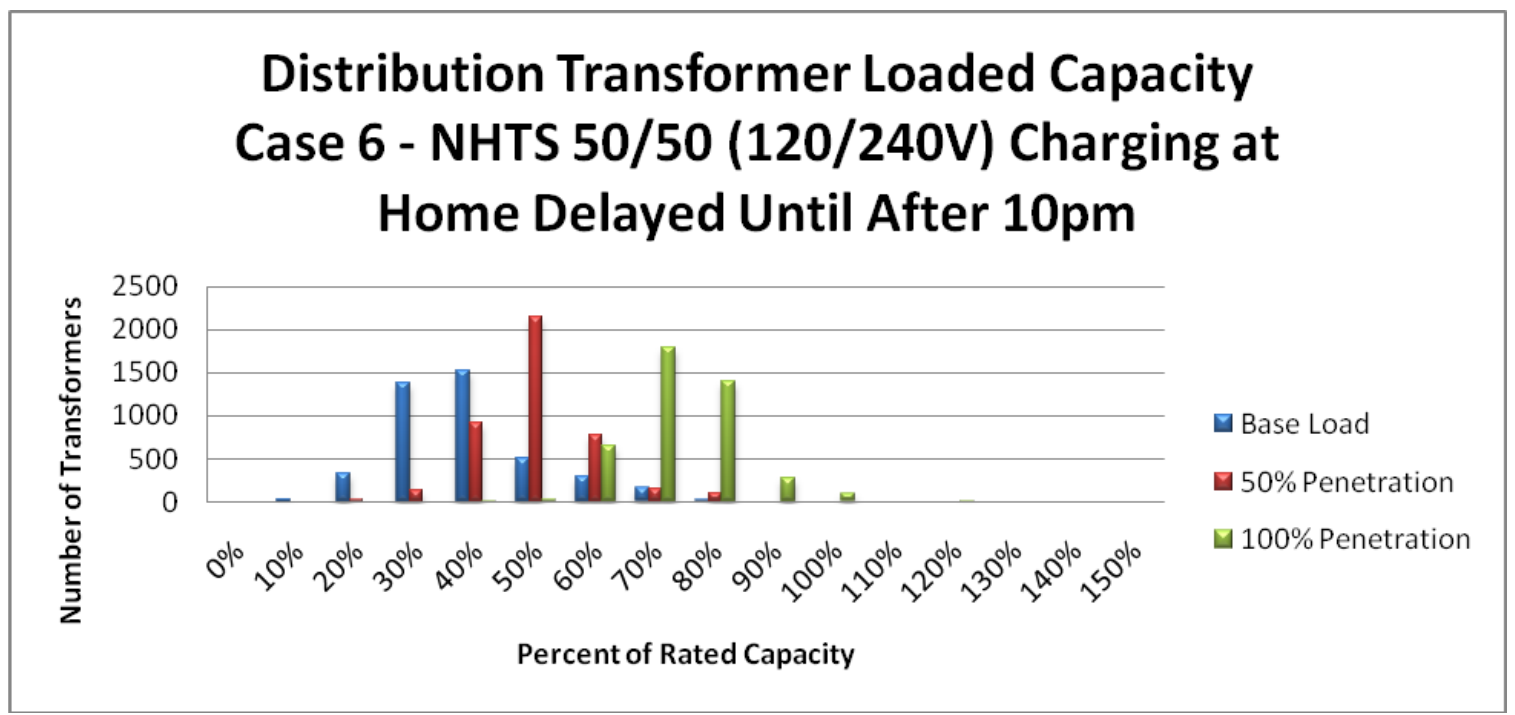

Figure 4-30: Franklin PUD Transformer Loading for Case 6

\subsubsection{PSE Results for Transformers Analysis}

Plots of the PSE transformer loaded capacity for the various charging cases and penetration rates are similarly shown in Figures 4-31 to 4-36. 


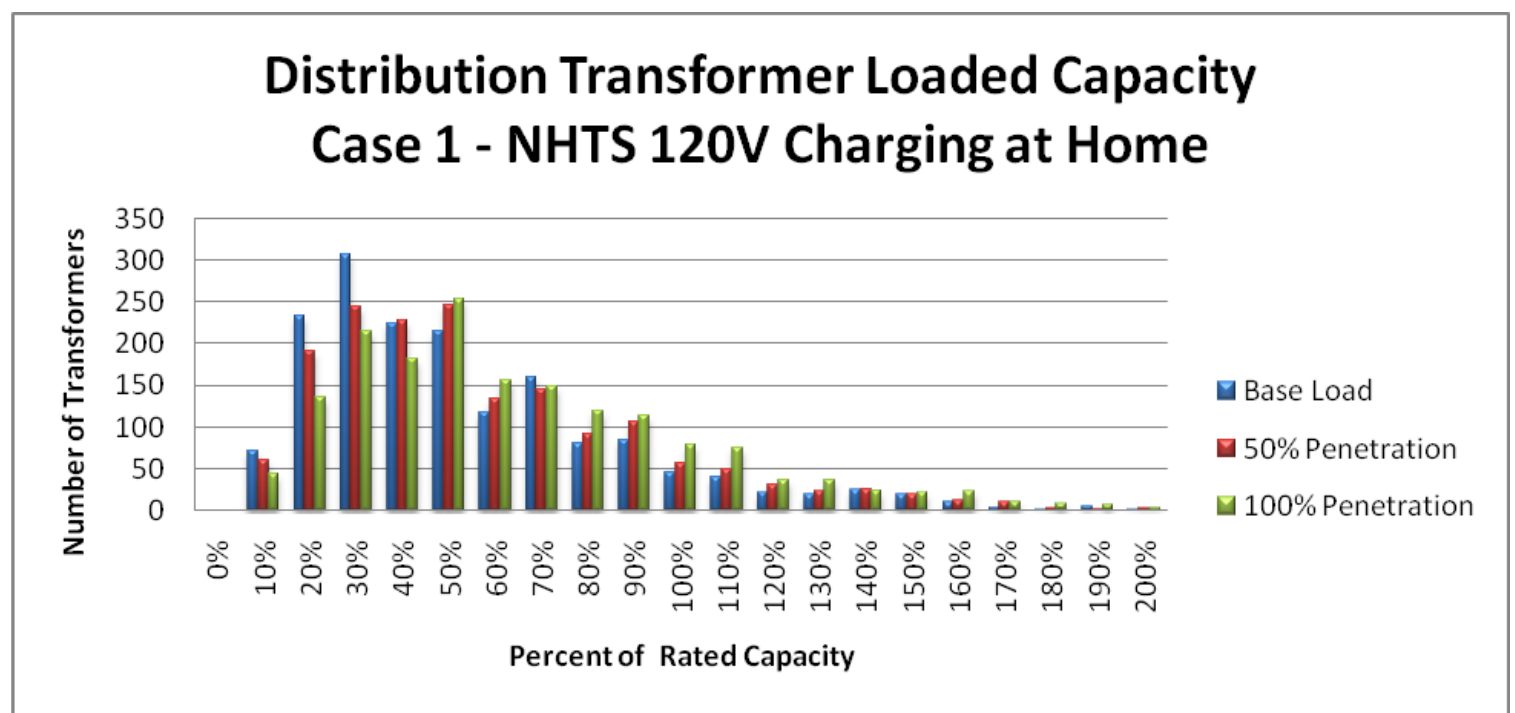

Figure 4-31: PSE Transformer Loading for Case 1

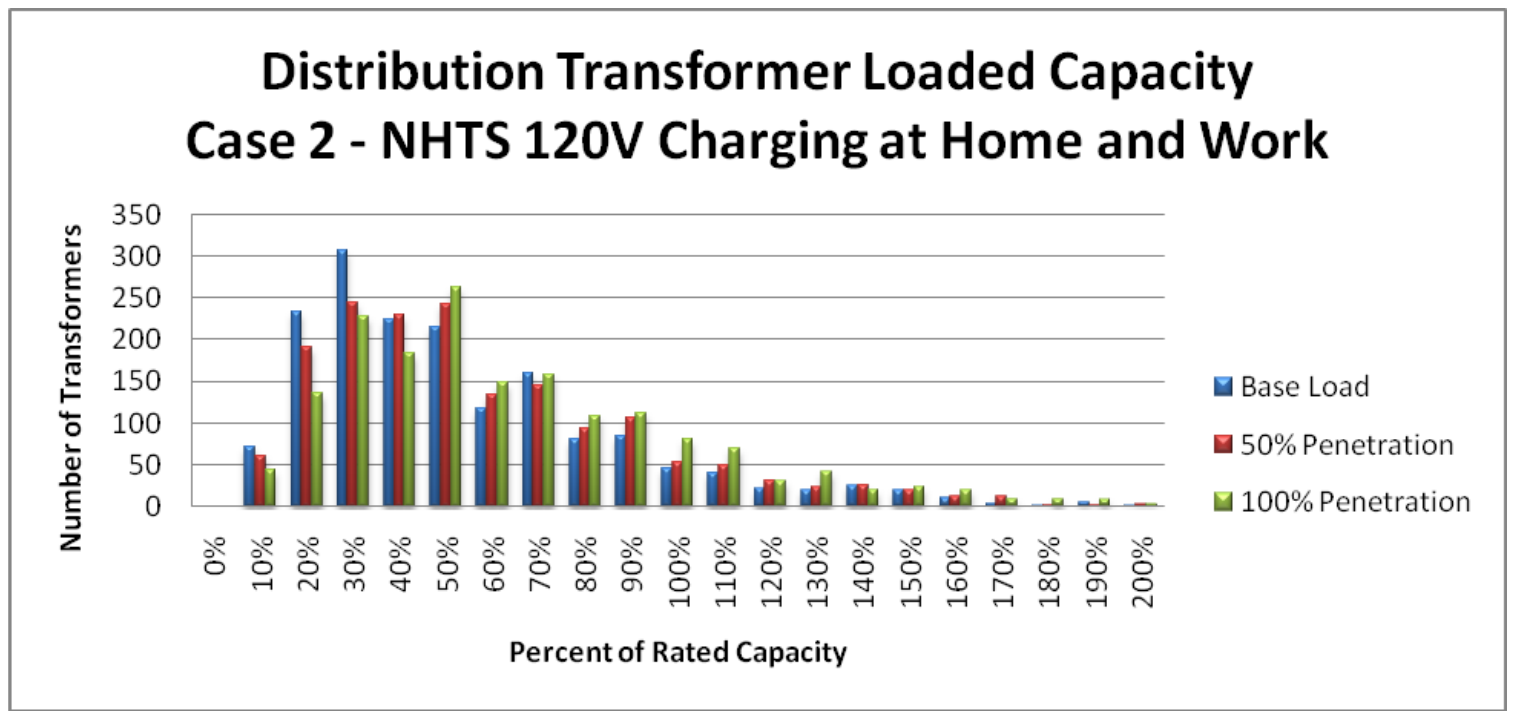

Figure 4-32: PSE Transformer Loading for Case 2 


\section{Distribution Transformer Loaded Capacity Case 3 - NHTS 120V Charging at Home Delayed Until After 10pm}

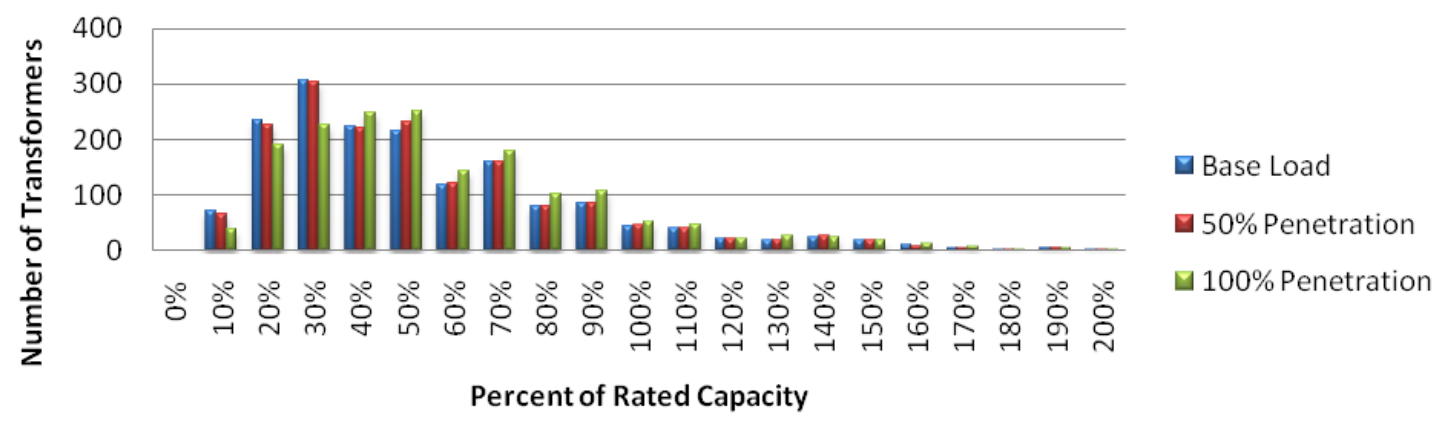

Figure 4-33: PSE Transformer Loading for Case 3

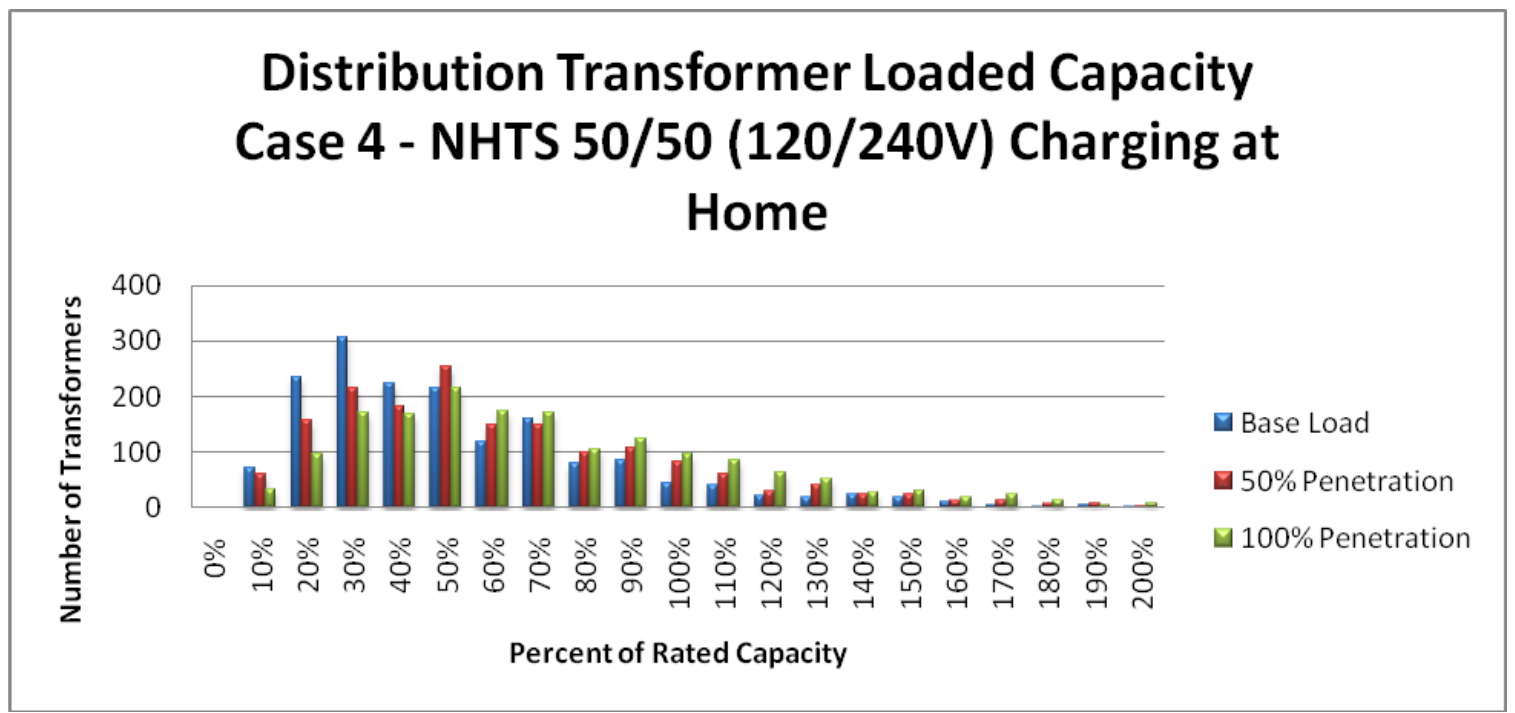

Figure 4-34: PSE Transformer Loading for Case 4 


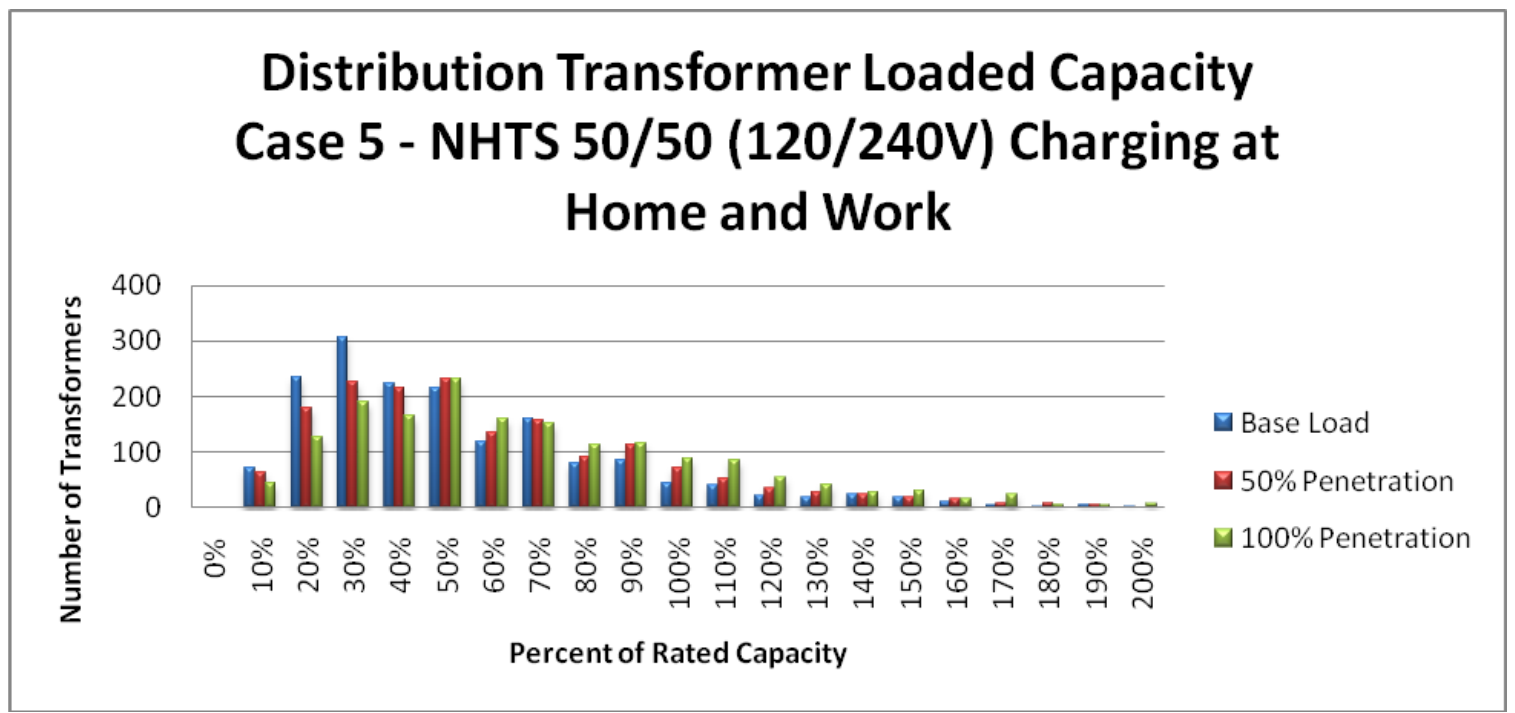

Figure 4-35: PSE Transformer Loading for Case 5

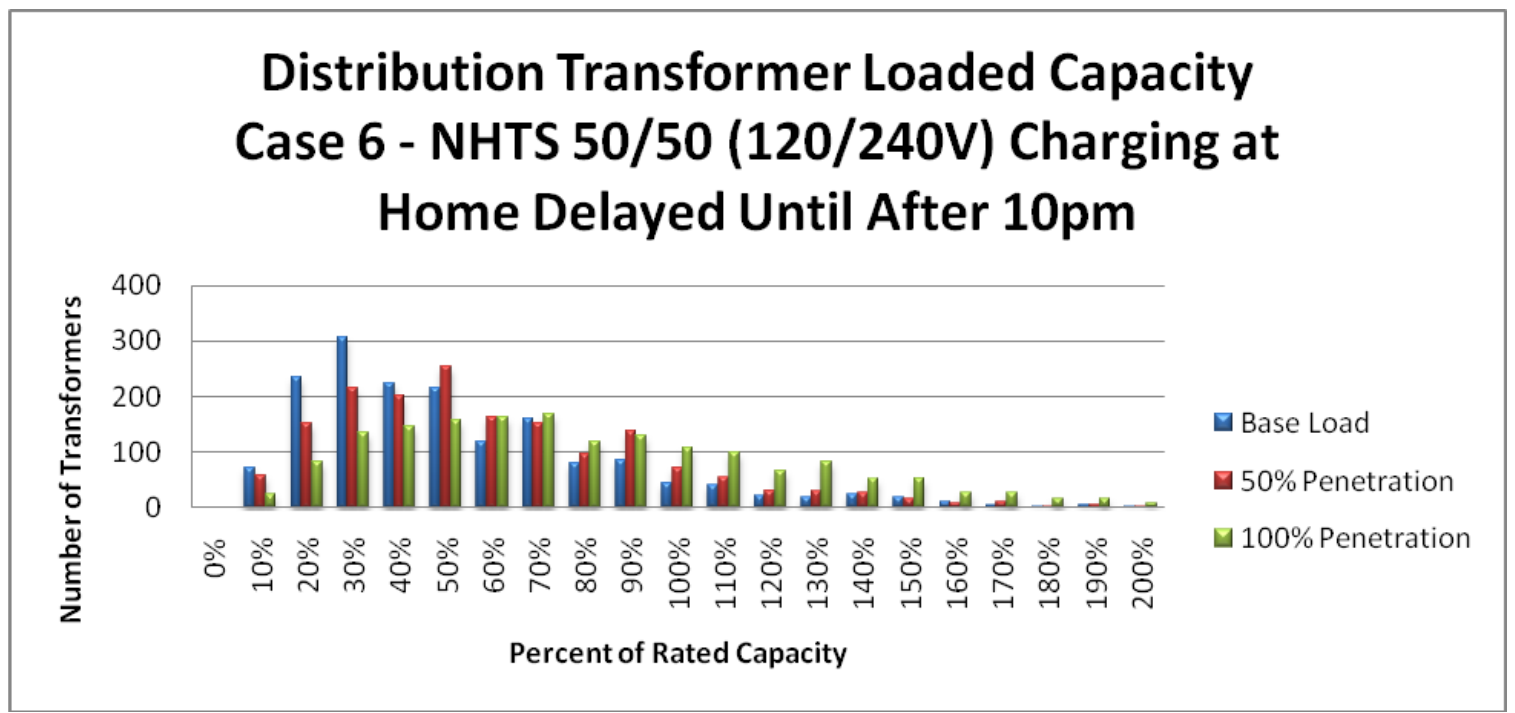

Figure 4-36: PSE Transformer Loading for Case 6

\subsubsection{Snohomish PUD Results for Transformers Analysis}

Finally, plots of Snohomish PUD transformer loaded capacity for the various charging cases and PHEV penetration rates are shown in Figures 4-37 to 4-42. 


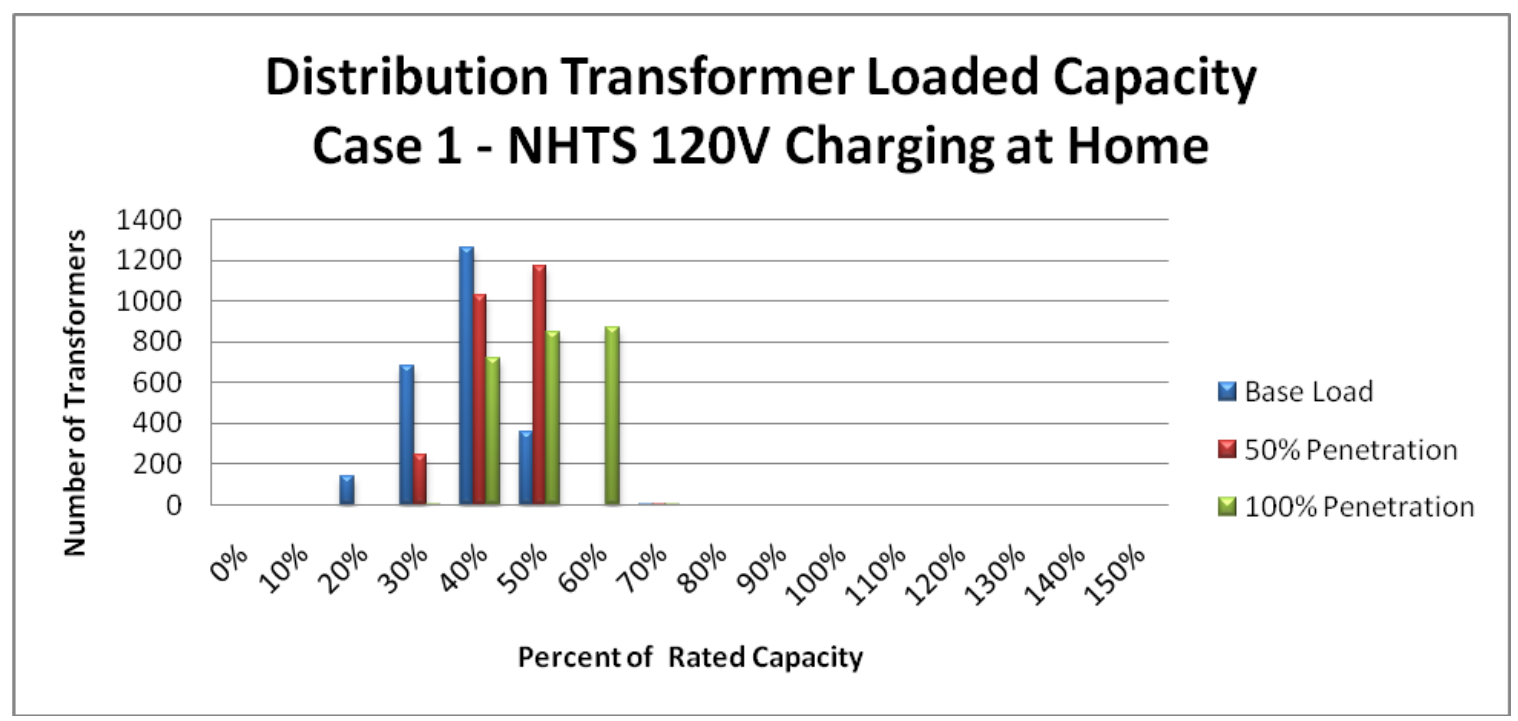

Figure 4-37: Snohomish PUD Transformer Loading for Case 1

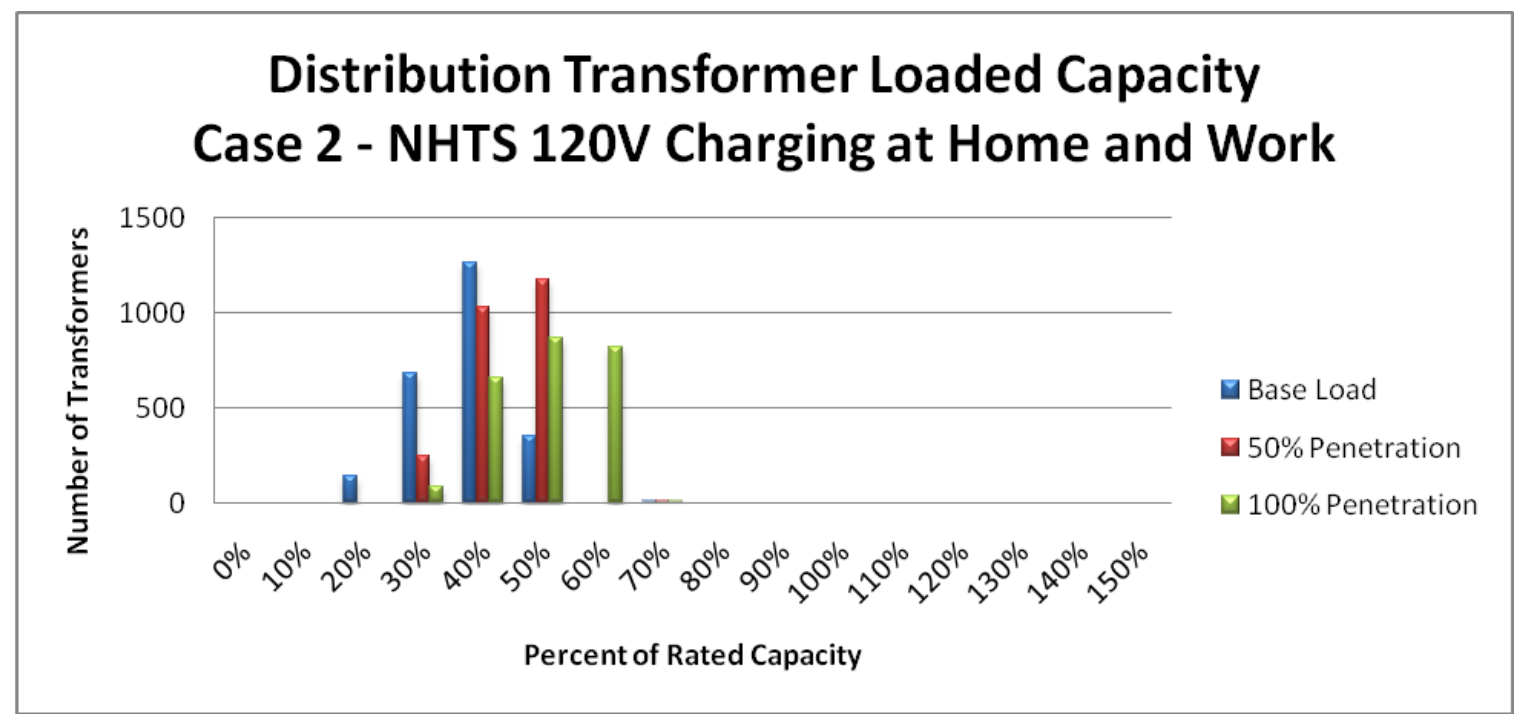

Figure 4-38: Snohomish PUD Transformer Loading for Case 2 


\section{Distribution Transformer Loaded Capacity \\ Case 3 - NHTS 120V Charging at Home Delayed Until After 10pm}

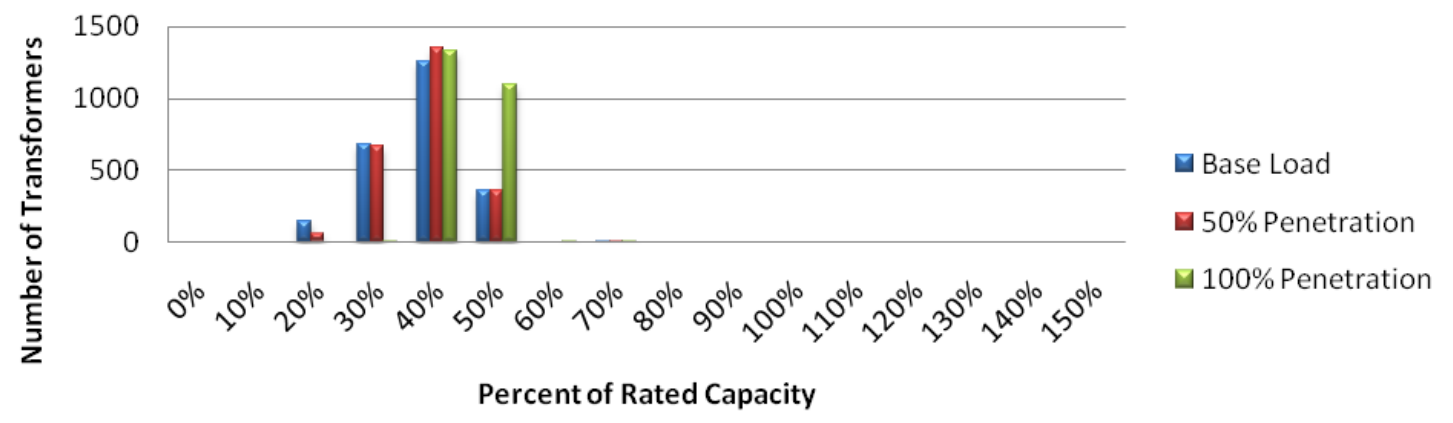

Figure 4-39: Snohomish PUD Transformer Loading for Case 3

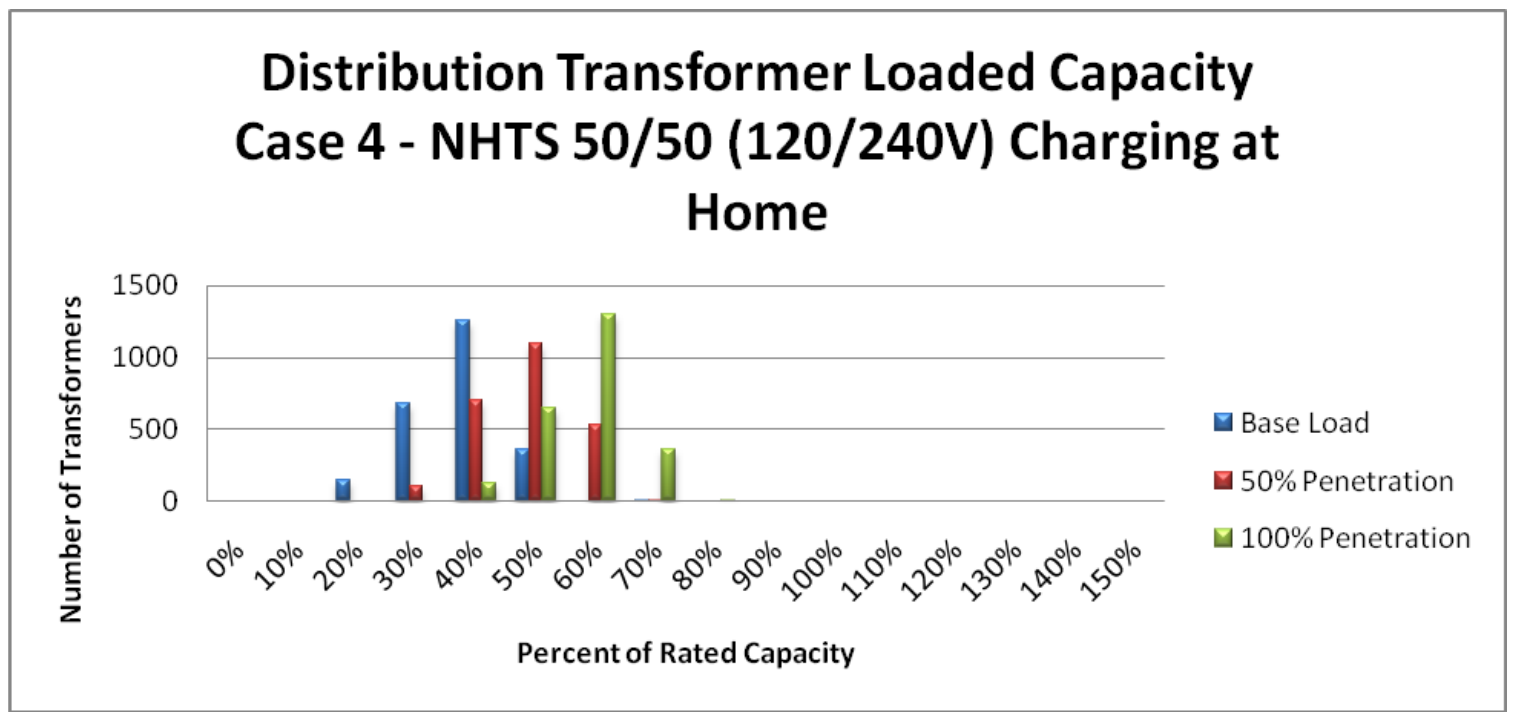

Figure 4-40: Snohomish PUD Transformer Loading for Case 4 


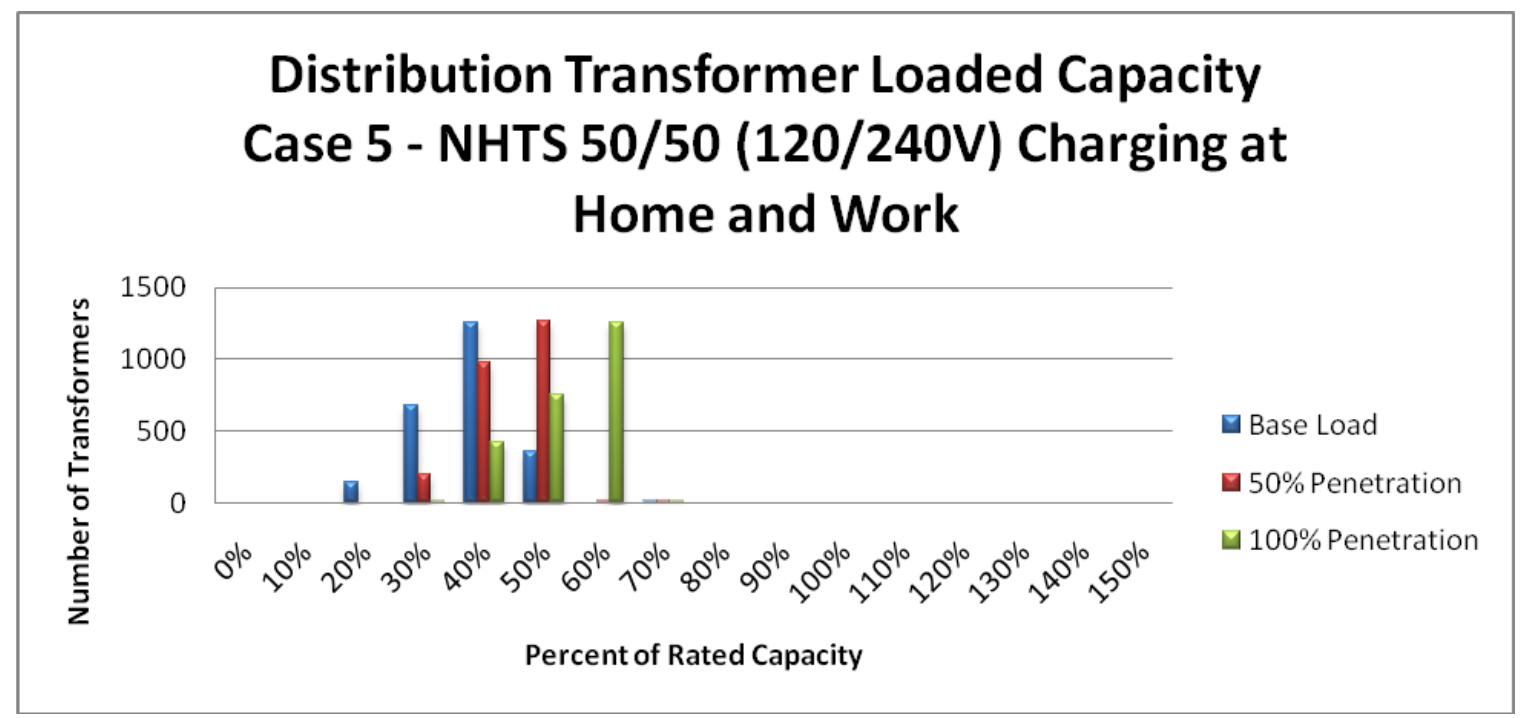

Figure 4-41: Snohomish PUD Transformer Loading for Case 5

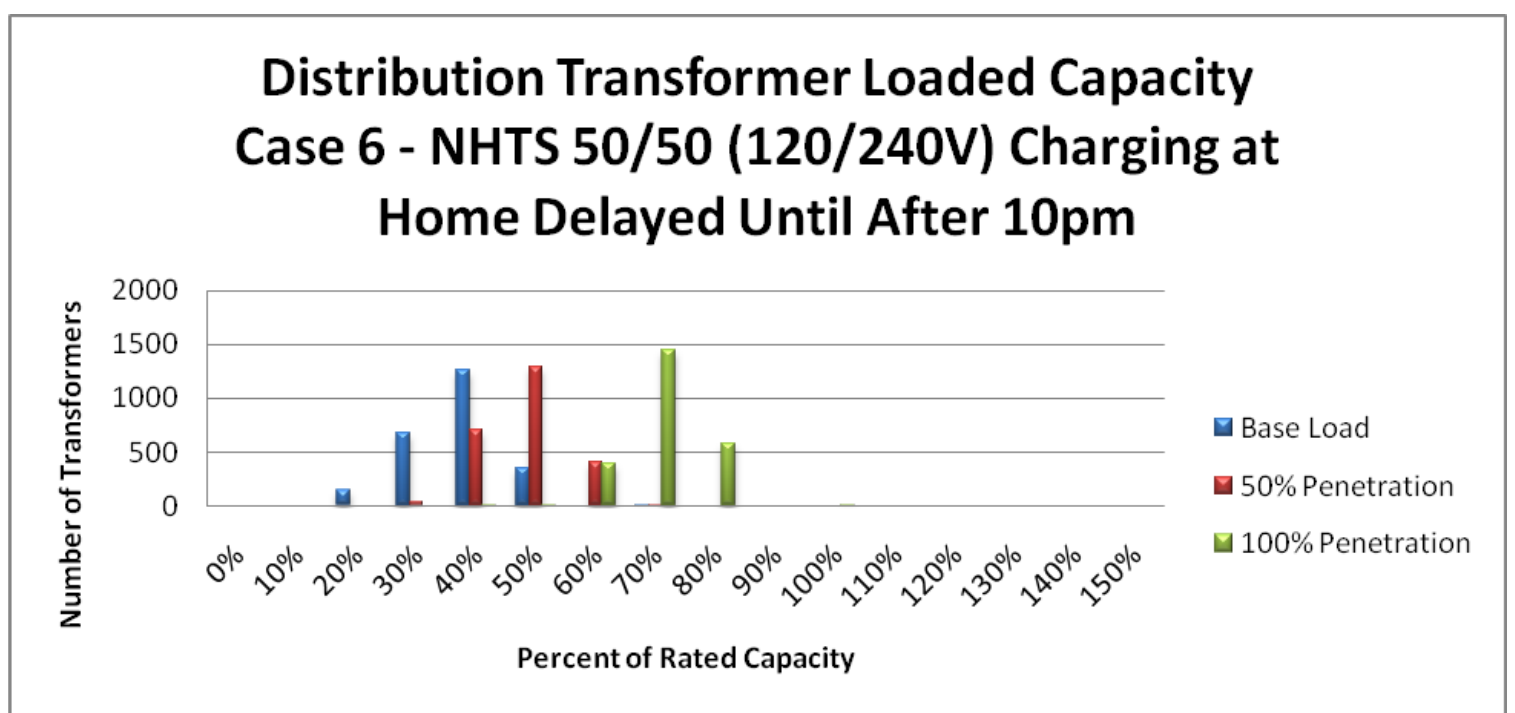

Figure 4-42: Snohomish PUD Transformer Loading for Case 6 


\section{Key Findings and Conclusions}

Analysis of PHEV charging impacts on the representative feeders of three utilities in the Pacific Northwest showed that for the most part the rated capacity of individual distribution system components was not exceeded. This was true over a range of six scenarios with different charging strategies. The most common component found prone to failure from overloading was the protective fuse. Fuse failures are generally easy to repair and their vulnerability can be mitigated by simply replacing them with a higher rated device.

Overall, the charging strategy defined as Case 1 (120-V Charging at Home Profile) provides the most reasonable approach with the least impact. In contrast, a quick charge scenario, in which the PHEV battery is completely recharged in the 3-hour period after people arrive home from work, has a broader range of system impacts. On one of the systems evaluated, this scenario caused some fuses, lines, switches and reclosers to be failure prone.

The PHEV charging curves considered in this study add feeder load diversity that generally helps to lessen their overall impact on the electrical distribution system. The quick charging curve removes this diversity and could significantly impact the system with a spike in demand and usage at a time when the system peak demand from other loads is already occurring.

In some cases, the additional load introduced by PHEV charging was found to increase the time secondary distribution transformers operate in excess of rated capacity. Supported by the findings of Lee et al. (2009), this will tend to have a direct impact on transformer life. Depending on whether utilities load their transformers lightly or heavily, these results could be significant. Those utilities that have heavily loaded transformers should be able to use these results and the results of related studies (e.g., the UM study by Lee et al.) to determine how the life of the transformer will be impacted. In contrast, utilities with lightly loaded transformers may be able to verify that the additional PHEV load will not affect the life of their transformers.

Addition of PHEV load to an individual residence may or may not have a noticeable effect on the existing distribution system depending on the overall penetration and charging strategy used. A utility's initial philosophy used to size distribution transformers and the backbone feeder system will also play a large part in determining whether, in practice, the additional load will overload the system.

The load curves developed in this analysis can be used by electric utilities to modify their own load curves to prepare for the emergence and increased deployment of PHEVs and other electric vehicles. Utilities can use the results and further extrapolate them to create new formulas for calculating the diversity factor that is used to size transformers for new and existing services. 


\subsection{Caveats}

Naturally occurring load growth was not considered in this study because of the uncertainties how energy efficiency and demand response strategies may influence future load behavior and load profiles. If they would have been considered to assess the impacts of PHEVs for a future point in time, say 2020, congestion in the distribution system and capacity problems may occur at PHEV penetration levels perhaps lower than those analyzed in this report.

The diversity of distribution system component vintages, sizing and design practices varies greatly across the nation. With older infrastructure, which had been initially designed for much less load per residential customer than its current use, it is very likely that the PHEV impacts are more severe and impactful than to a relatively new infrastructure. Comparing the infrastructure analyzed in this report to those in older and established neighborhoods of coastal or mid-western metropolitan areas, where some of the system components are 100 years or older, we would consider the distribution feeder infrastructure - by and large - newer and by no means at the end or beyond the end of its expected life time. As a consequence, the results obtained are more representative for newer systems that were originally designed with significant capacity margins to accommodate load growth, than for those established early $20^{\text {th }}$ century neighborhoods.

\subsection{Conclusions}

For the near-term, the emergence of PHEVs using $120-\mathrm{V}$ charging strategies is not likely to have a significant impact on distribution systems with relatively new infrastructures. This result is not too surprising when considering that the additional demand of a PHEV would be comparable to or only slightly more than that of a 1000-W electric hair dryer. When, however, quick charging strategies are explored, the analysis indicates that they would likely impose a significant burden on common residential feeders operating at higher levels of load concentration. These impacts are exacerbated when the load is nondiversified, i.e., the charging occurs concurrently or almost concurrently at peak load times, as assumed in our quick charging scenario. Concurrency for the charging may not be too far fetched, particularly, when one considers neighborhoods of professionals who have similar work hours and are likely to arrive home at similar times. In such an event, the high demand during quick charging would impact the secondary transformer first, with additional impacts on the upstream components of distribution system. Fuses inadequate for the higher demand could be replaced with high rated ones at low cost; however, in most cases, it would require additional up-sizing of other line components at generally more significant cost.

The discussion on quick charging strategies has recently attracted more attention because of numerous announcements by many credible manufacturers to make electric vehicles (EVs) commercially available. With the larger battery sizes of EVs (30 kWh and more), compared to those of PHEVs ( $10 \mathrm{kWh}$ and more), it is likely to become desirable to charge at higher charging rates than a 120-V/15-A circuit will allow. Should 240-V charging become the commonly adopted charging mode, the adoption of the quick charging scenario could become reality sooner rather than later. However, it is not 
expected that utility planners will be surprised overnight by this new load growth. Because of the high public awareness of PHEVs and EVs, it is expected that utility planners will monitor the growth of this emerging technology and prepare for its implementation accordingly. Furthermore, with the growing deployment of smart grid technologies into the distribution system and the efforts by the Society of Automotive Engineers (SAE) to develop communication standards between a vehicle and a smart electric infrastructure, it is likely that sophisticated load management and smart charging technologies would be deployed that can diversify or even coordinate the charging of PHEVs and EVs in a manner to mitigate their impacts on the distribution system and the grid as a whole. 


\section{References}

Balducci, P. 2008. Plug-In Hybrid Electric Vehicles Market Penetration Scenarios. PNNL-17441. Pacific Northwest National Laboratory, Richland, WA. September.

Curtin, R., Y. Shrago and J. Mikkelsen. 2009. Plug-in Hybrid Electric Vehicles University. Task 2a Final Report. University of Michigan. Ann Arbor, Michigan, June.

DOT. 2001. U.S. Household Travel Survey. Department of Transportation, Washington, DC

Duvall, M. 2002. Comparing the Benefits and Impacts of Hybrid Electric Vehicle Options for Compact Sedan and Sport Utility Vehicles. (Final report 1006892). Electric Power Research Institute. Palo Alto, CA.

EIA. 2008a. "Annual Energy Outlook 2008.” Revised to include the impact of H.R.6, "Energy Independence and Security Act of 2007" enacted in December 2007. Energy Information Administration, Washington, DC.

Filipi, Z., R. Patil, B. Adornato, Y. Kim, T. Gordon, and Z. Bareket. 2009. Technological Barriers for Acceptable PHEV Performance and Cost. Task 1. Final Report. Department of Mechanical Engineering and Transportation Research Institute, University of Michigan, Ann Arbor, June 2009

“IEEE Guide for Loading Mineral-Oil-Immersed Transformers,” IEEE Std. C57.91, Institute of Electrical and Electronics Engineers (1995).

Lee, J., A. Varuttamaseni, F. Rahman, and T. Briley. 2009. Impact of PHEVs on the Reliability of the Electric Grid. Task 3 Final Report. Department of Nuclear Engineering and Radiological Sciences, University of Michigan, Ann Arbor, Michigan, June.

McManus, W. and R. Senter. 2009. Market Models for Predicting PHEV Adoption and Diffusion. Task 2c Final Report. University of Michigan Transportation Research Institute, Ann Arbor, Michigan, June.

Schneider, K., C. Gerkensmeyer, M. Kinter-Meyer and R. Fletcher 2008. “Impact Assessment of Plug-In Hybrid Vehicles on Pacific Northwest Distribution Systems.” IEEE PESE General Conference, IEEE, Piscataway, NJ, 2008.

Sentech. 2009. PHEV Market Introduction Study, Final Report. ORNL/TM-2009/019. Oak Ridge, Tennessee, June.

Sullivan. J.L., I. Salmeen, and C. Simon. 2009. PHEV Marketplace Penetration. An Agent-Based Simulation. Task 2b Final Report. University of Michigan, Ann Arbor, Michigan, June.

SynerGEE. 2009. Power Distribution Analysis and Optimization Software. Advantica. Houston, TX. http://www.advantica.biz. 